\title{
Click Chemistry in Natural Product Modification
}

\author{
Xiang Zhang ${ }^{1 \dagger}$, Shuning Zhang ${ }^{2 \dagger}$, Songfeng Zhao ${ }^{1 *}$, Xuan Wang $^{3}$, Bo Liu ${ }^{3 *}$ and Hongtao Xu ${ }^{2 *}$ \\ ${ }^{1}$ Department of Pharmacy, The First Affiliated Hospital of Zhengzhou University, Zhengzhou University, Zhengzhou, China, \\ ${ }^{2}$ Shanghai Institute for Advanced Immunochemical Studies, ShanghaiTech University, Shanghai, China, ${ }^{3}$ The Second Clinical \\ Medical College, Guangdong Provincial Key Laboratory of Clinical Research on Traditional Chinese Medicine Syndrome, \\ Guangzhou University of Chinese Medicine, Guangzhou, China
}

Click chemistry is perhaps the most powerful synthetic toolbox that can efficiently access the molecular diversity and unique functions of complex natural products up to now. It enables the ready synthesis of diverse sets of natural product derivatives either for the optimization of their drawbacks or for the construction of natural product-like drug screening libraries. This paper showcases the state-of-the-art development of click chemistry in natural product modification and summarizes the pharmacological activities of the active derivatives as well as the mechanism of action. The aim of this paper is to gain a deep understanding of the fruitful achievements and to provide perspectives, trends, and directions regarding further research in natural product medicinal chemistry.

Keywords: natural product, click chemistry, drug discovery, modular synthesis, triazole, sulfur(VI) fluoride exchange, pharmacological activity

\section{INTRODUCTION}

Natural products (NPs) are secondary metabolites that are produced by the evolutionary optimization of nature. They usually possess diverse and complex architectures and are endowed with versatile pharmacological activities, offering an abundant source for therapeutic drug discovery (Hunter, 2008; Jiménez, 2018) Newman and Cragg, 2020; Rodrigues et al., 2016; Li and Vederas, 2011). Natural product-based drug discovery can date back to the isolation of morphine, the first pharmacologically active pure natural product which was purified by Friedrich Sertürner more than 200 years ago. From then on, considerable works have been devoted to the synthesis of natural derivatives (Wang M. et al., 2018; Foley et al., 2020), and/or natural product-like screening libraries with the aim of therapeutic drug discovery (Huigens et al., 2013; Crane and Gademann, 2016; Ma et al., 2019; Wilson et al., 2020; Xie et al., 2020). These efforts have led to the discovery of various important clinical drugs, such as anticancer agents (e.g., taxol and doxorubicin), immunosuppressants (e.g., cyclosporine and doxorubicin), antimalarial agents (e.g., quinine and artemisinin) and lipid regulate drugs (e.g., lovastatin and relatives). Even today, natural products still serve as a fundamental source of diverse biological functions, facilitating the development of chemical biology and drug discovery.

As natural products are usually complex molecules with various stereo centers, sp3 carbon, and labile functionalities, the de novo synthesis of natural products or their derivatives always need complicated synthetic strategies, and accomplished in time-consuming multistep syntheses with low quantity and a limited number of derivatives. Therefore, chemistries that can be used for the late-stage functionalization and diversification of natural products are highly desirable, and should meet the following criteria: 1) reliable, selective, orthogonality to other 
i) Representative click chemistries

$$
\begin{aligned}
& \text { CUAAC Cu }
\end{aligned}
$$

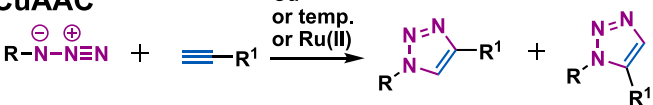

\section{SPAAC}

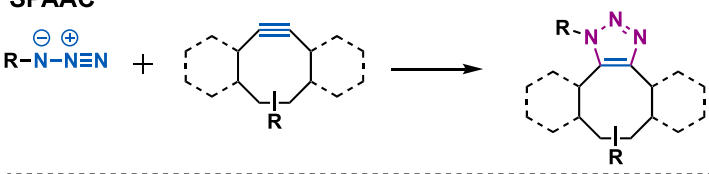

$$
\begin{aligned}
& \text { SuFEx }
\end{aligned}
$$

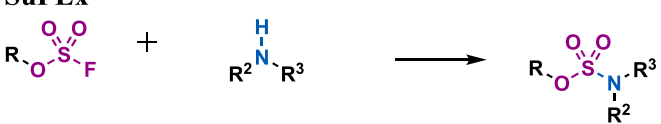

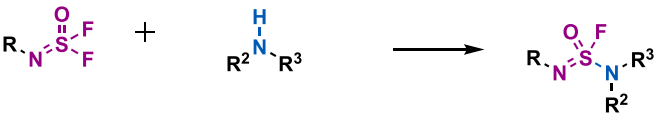

\section{ii) Representative FDA approved drugs}

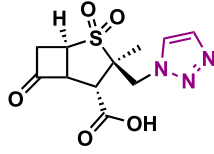

Tazibactum (Antibacterial)

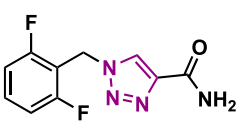

Rufinamide (Lennox-Gastuat syndrome)

\section{iii) Publicatoins from 2001 to 2020}

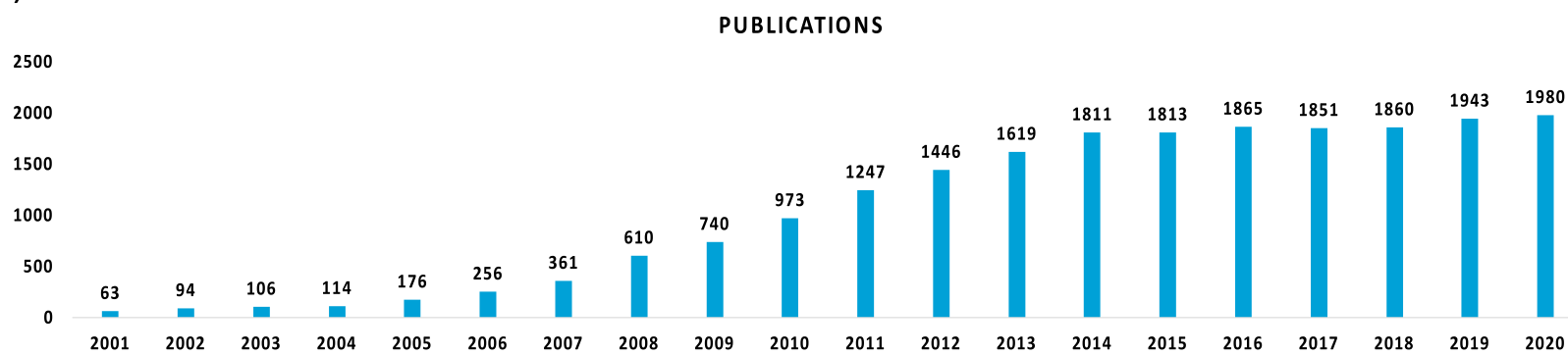

iv) Derivatives/baper. disease areas and screenina methods
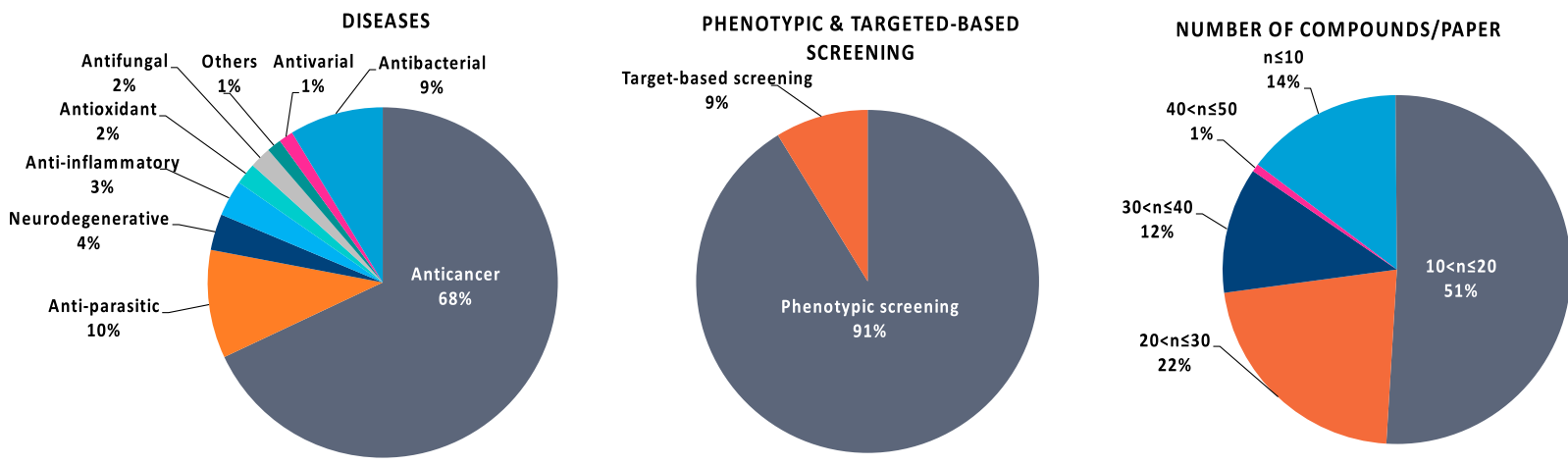

FIGURE 1 (i) Representative click chemistries; ii) representative drugs synthesized by CuAAC; iii) number of papers published between 2001 and 2020 that contain the keywords click chemistry, SPAAC, IED-DA, sulfur fluoride exchange or 1,2,3-triazole according to Scopus; iv) number of compounds per paper, screening methods, disease areas of 137 papers that analyzed in this review.

functionalities; 2) modular, broad substrate scope; 3) high yield; 4) operational simplicity. In 2001, these criteria were codified by Professor K. Barry Sharpless, who termed such ideal chemistries as "click chemistry" (Kolb et al., 2001). From then on, click chemistry reactions, especially the $\mathrm{Cu}(\mathrm{I})$ catalyzed Huisgen 1,3-dipolar cycloaddition between alkynes and azides (CuAAC) was quickly recognized as versatile players in the modification of various molecules, especially complex natural products, providing enhanced properties or new functions for chemical biology and drug discovery (Figure 1).

Despite the success of CuAAC, the search for other click chemistries has never stopped. Today several elegant click chemistries have been well developed, such as strain-promoted azide-alkyne cycloaddition (SPAAC), inverse electron-demanded Diels-Alder (IEED-DA), and Sulfur (VI) Fluoride Exchange (SuFEx) chemistry. These chemistries have played a key in chemical biology and drug discovery, particularly the emerging 
TABLE 1 | Typical reaction conditions of click chemistry in this paper.

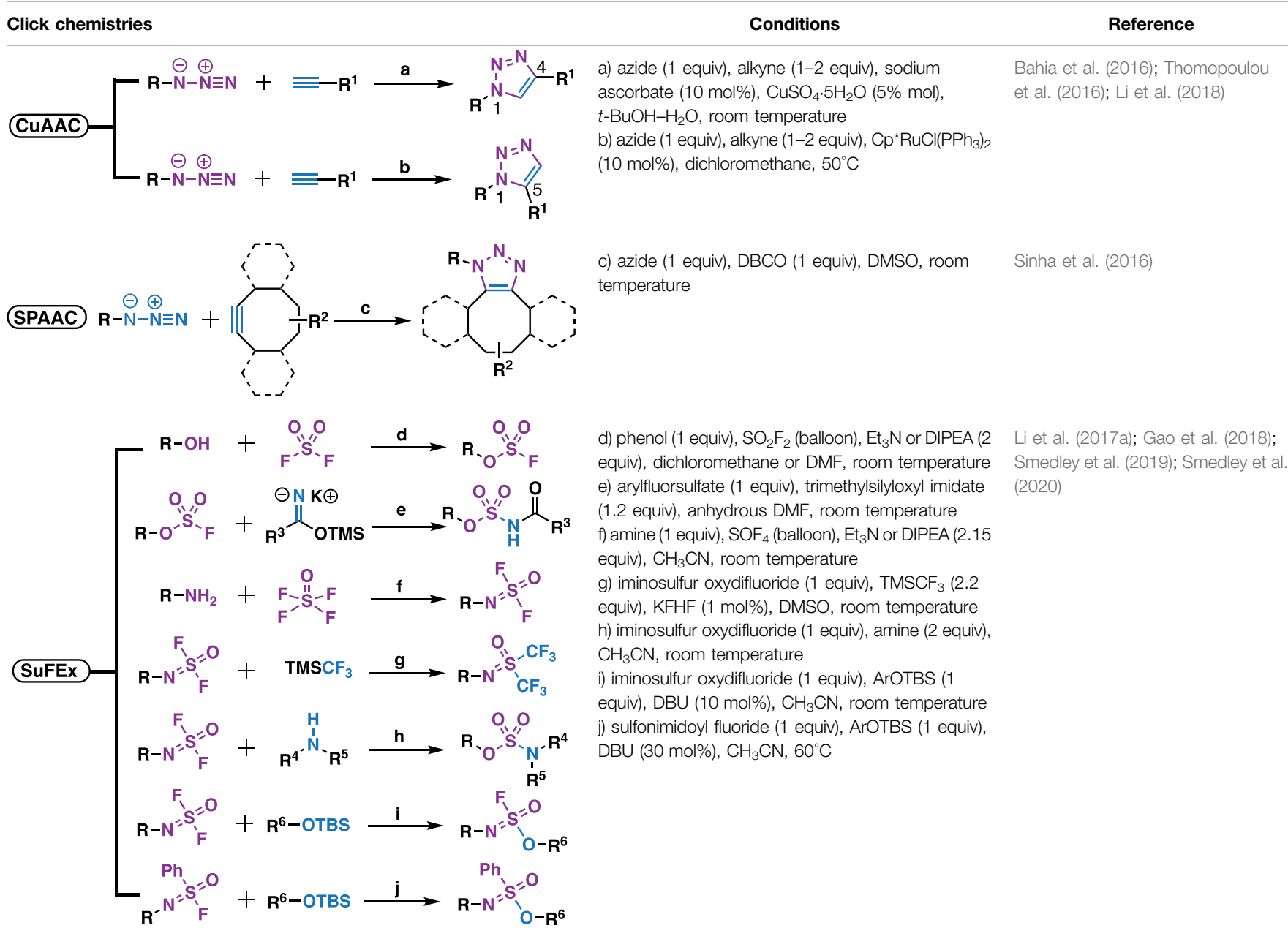

SuFEx chemistry, another ideal click reaction proposed by Professor Sharpless in 2014 (Dong et al., 2014; Barrow et al., 2019), have already gained wide application in the synthesis of drug screening libraries (Kitamura et al., 2020; Smedley et al., 2020), late-stage modification of drugs and natural products (Li S. et al., 2017; Liu et al., 2018), DNA-encoded library synthesis (Liu et al., 2019; Xu H. et al., 2019; Zhang et al., 2021), and the synthesis of ${ }^{18} \mathrm{~F}$ radio tracers (Zheng et al., 2021).

Indeed, now that natural products have met with click chemistry, a new era of natural product-based drug discovery has come. Previously, several elegant review papers have summarized the CuAAC reaction in medicinal chemistry, mainly focused on the synthesis of 1,2,3-trizaoles for various properties such as anti-cancer (Xu Z. et al., 2019; Liang et al., 2021), anti-bacterial, etc., (Kacprzak et al., 2016; Rani et al., 2020; Guo et al., 2021; Kumar et al., 2021; Serafini et al., 2021). Especially, this review focuses on the late-stage modification of natural products by using not only the CuAAC reaction but also other click chemistries such as SPAAC and especially the emerging SuFEx chemistry (Table 1) (Dong et al., 2014), and thus encompasses a much wider variety of natural product derivatives and the corresponding pharmacological activities. These natural product derivatives are classified according to their structural features, covering a time span mainly of the last decade.

The aim of this paper is to showcase the state-of-the-art development of click chemistry in natural product modification, thereby gain a deep understanding of the fruitful achievements, and provide perspectives, trends, and directions regarding further research in natural product medicinal chemistry.

\section{CLICK CHEMISTRY-BASED MODIFICATION OF TERPENOIDS}

Terpenoids, also known as isoprenoids, are the largest class of plant secondary metabolites, representing $60 \%$ of the known natural products. Terpenoids derive from 5-carbon isoprene and usually have oxygen-containing functionalities. Many diterpenoids, especially cyclic sesqui-, di- and triterpenoids are endowed with bewildering structural features such as multiple 

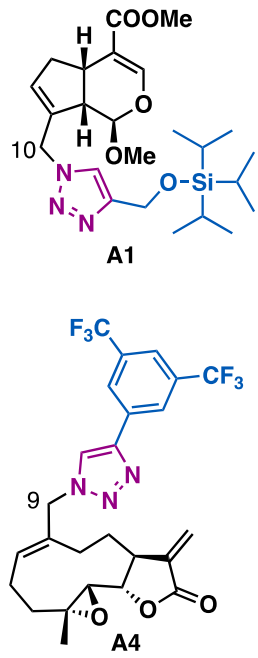

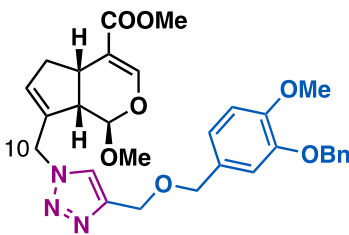

A2<smiles>CN(C)C[C@H]1C(=O)O[C@H]2[C@H]1CC/C(Cn1cc(-c3cc(C(F)(F)F)cc(C(F)(F)F)c3)nn1)=C\CC[C@@]1(C)O[C@@H]21</smiles>

A5<smiles>C=C1C(=O)O[C@@H]2C/C(=C/CC[C@]3(C)OC3(C)C)CC[C@@H]12</smiles>

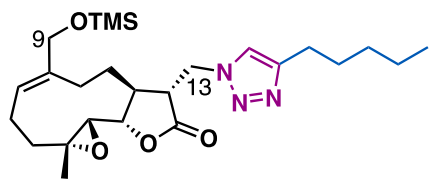<smiles>CCCC(C)=CC[C@H]1OC(=O)[C@H](Cn2cc(Cn3ccc4cc(Br)ccc43)nn2)[C@H]1CC=C(C)CC</smiles>

A7

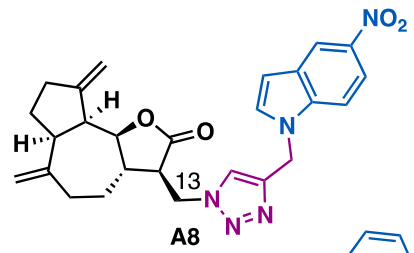

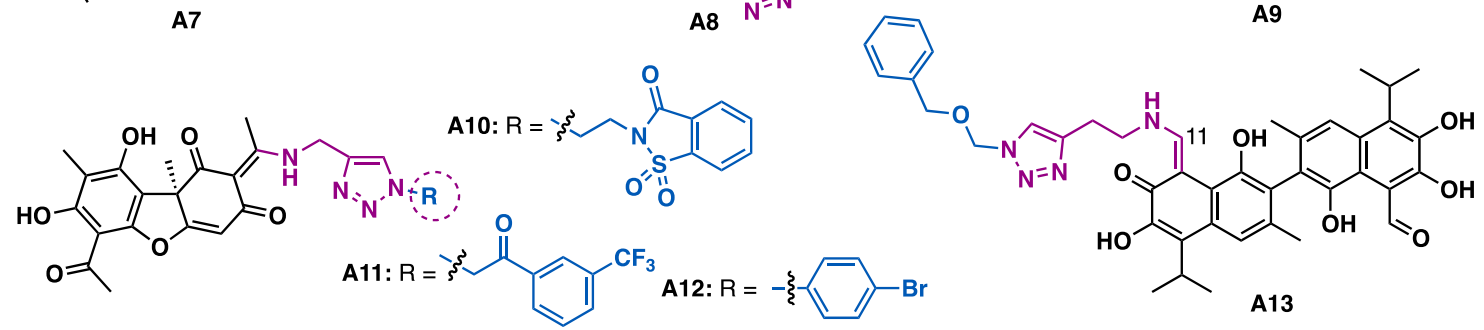

FIGURE 2 | Representative iridoid-, sesquiterpenoid-, and bisesquiterpenoid-triazole derivatives.

chiral centers, rigid skeleton, diverse functionalities, and the consequent various promising biological activities. Moreover, some of the terpenoids are readily available from nature, thereby can serve as inexhaustible starting materials for the synthesis of bioactive natural products or natural product-like drug screening libraries (Xu et al., 2014b). By arching azide or alkyne at the suitable position of terpenoids, followed by reactions with various alkyne or azide containing building blocks, a lot of terpenoid derivatives have been synthesized and evaluated for various biological activities.

Genipin (Figure 2), an iridoid derived from Gardenia jasminoides Ellis, has been reported to possess various biological activities such as anticancer and antioxidant. The introduction of triazole moiety into genipin has been demonstrated to generate derivatives with improved cytotoxicity. For example, $\mathrm{C} 10$ genipin-triazole al (P-388: $\mathrm{IC}_{50}$ $\left.=2.54 \mu \mathrm{M} ; \mathrm{A} 549: \mathrm{IC}_{50}=4.53 \mu \mathrm{M}\right)$ and $\mathbf{a} 2\left(\mathrm{P}-388: \mathrm{IC}_{50}=5.49 \mu \mathrm{M}\right.$; $\left.\mathrm{A} 549, \mathrm{IC}_{50}=4.81 \mu \mathrm{M}\right)$ could exert more potent inhibitory activity than the parental genipin against tumor cells $\left(\mathrm{P}-388: \mathrm{IC}_{50}=\right.$ $11.12 \mu \mathrm{M}$; A549 > $20 \mu \mathrm{M}$ ) (Silalai et al., 2020). Molecular docking studies have indicated that a 2 engaged four hydrogen bonds in the colchicine binding site of tubulin (Asn- $\beta-258$ and the carbonyl group of genipin (Silalai et al., 2020), Asn- $\beta$-249 and oxygen atom of ether moiety of triazole, Ala- $\beta-250$ and the triazole, and Glu- $\alpha-183$ and methoxy group of benzylether).

Melampomagnolide $\mathrm{B}$, a sesquiterpene lactone identified from Magnolia grandiflora, could exert moderate inhibitory activity against Bel7402, HCT-116, PANC1, A549, and U87 cancer cell lines $\left(\mathrm{IC}_{50}=4.93-10.86 \mu \mathrm{M}\right)$. Whereas, $\mathrm{C} 13$ triazole containing derivative a3 could exert improved inhibitory activity $\left(\mathrm{IC}_{50}=\right.$ 0.43-1.54 $\mu \mathrm{M}$ ), (Ding et al., 2018), and especially it could exert submicromolar inhibitory activity against HCT116 cells with $\mathrm{IC}_{50}$ value of $0.43 \mu \mathrm{M}$, which is 11.5 times more potent than melampomagnolide $\mathrm{B} \quad\left(\mathrm{IC}_{50}=4.93 \mu \mathrm{M}\right)$. Preliminary mechanistic studies indicated that a3 could induce apoptosis and inhibit the proliferation and migration of the tested HCT116 cells. Crooks et al. reported that melampomagnolide B-triazole a4 could exert low micromolar to submicromolar $\left(\mathrm{GI}_{50}=0.02-1.86 \mu \mathrm{M}\right)$ inhibitory activity against the growth of a panel of 60 cancer cell lines derived from different organs including lung, CNS, leukemia, colon, renal, melanoma, ovary, prostate and breast cancer cells (Janganati et al., 2018), and especially it could exert nanomolar $\left(\mathrm{EC}_{50}=0.4-0.7 \mu \mathrm{m}\right)$ inhibitory activity against two clinical AML specimens. In 

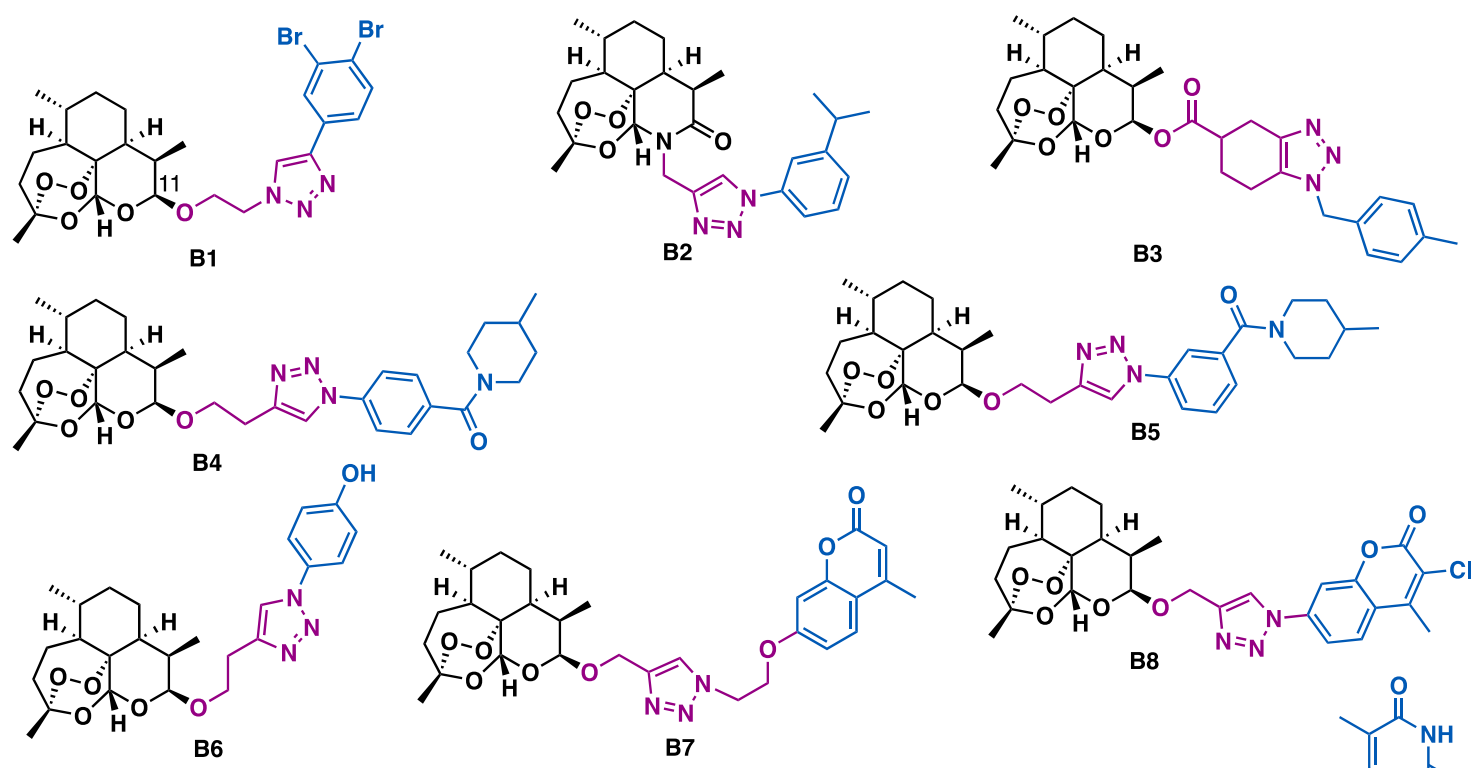

B8
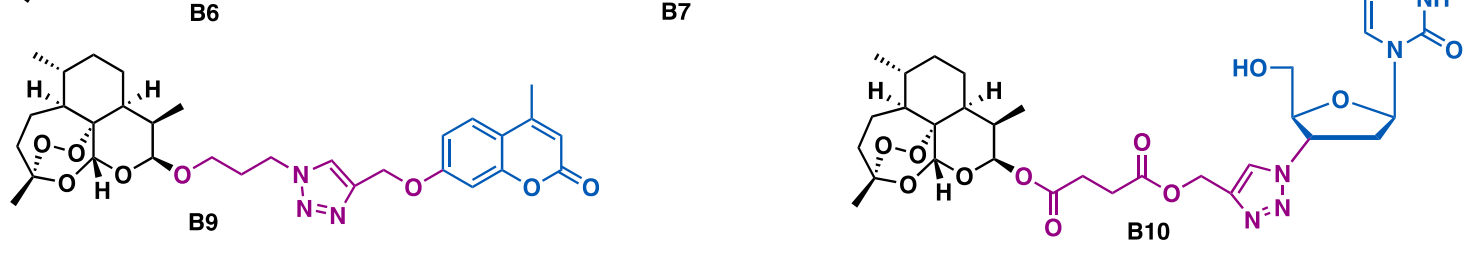

FIGURE 3 | Representative artemisinin derivatives.

addition, salt a5, a water-soluble prodrug of a4, could also exert comparable inhibitory activity as a4 in primary AML cells. Whereas, the C13 melampomagnolide B-triazole derivatives generally showed reduced inhibitory activity, with only a6 $\left(\mathrm{GI}_{50}: 46-76 \mu \mathrm{M}\right)$ showed marginal inhibitory activity against the tested cancer cell lines (A549, MCF-7, SKMEL-28, and Hs683), implying the $a$-methylene-c-lactone motif may play a key role in retaining the potent cytotoxicity (Zaki et al., 2016).

Babu et al. synthesized 20 triazole containing derivatives by Michael addition of the $\alpha$-methylene-c-lactone motif of costunolide and dehydrocostus by sodium azide, followed by reaction with various terminal alkynes under $\mathrm{CuAAC}$. In vitro data indicate that costunolide-triazole-coumarin a7 $\left(\mathrm{IC}_{50}=\right.$ $0.12 \mu \mathrm{M})$ could exert more potent cytotoxic activity than the precursor costunolide $\left(\mathrm{IC}_{50}=0.56 \mu \mathrm{M}\right)$ in MDA-MB-231 cells (Pavan Kumar et al., 2016). Similarly, indole-triazoledehydrocostus-lactone a $8\left(\mathrm{IC}_{50}=0.16 \mu \mathrm{M}\right)$ could exert more potent cytotoxic activity than dehydrocostus-lactone $\left(\mathrm{IC}_{50}=\right.$ $0.56 \mu \mathrm{M})$ in MDA-MB-231 cells, while derivative a9 $\left(\mathrm{IC}_{50}=\right.$ $0.68 \mu \mathrm{M})$ showed more potent cytotoxic activity than dehydrocostus-lactone $\left(\mathrm{IC}_{50}=4.1 \mu \mathrm{M}\right)$ in IMR-32 cells (Pavan Kumar et al., 2016).

Usnic acid is a dibenzofuran secondary metabolite that is isolated from lichen genera. Usnic acid-triazole-saccharin hybrid a10 $(\mathrm{MIC}=2.5 \mu \mathrm{M})$ could exert slightly better inhibitory activity than clinical drug isoniazid ( $\mathrm{MIC}=2.9 \mu \mathrm{M})$ against Mycobacterium tuberculosis (Mtb) (Bangalore et al., 2020), but failed to show any antibacterial activity against Bacillus subtilis, while hybrid a11 (MIC $=40.9 \mu \mathrm{M})$ could exert good antibacterial activity against Bacillus subtilis. Molecular docking studies indicated that the usnic acid moiety of a10 could occupy the active site of Mtb enzyme enoyl reductase (InhA), while the oxygen of sulfamide in saccharin could engage a hydrogen bond with GLN100, and the triazole moiety could have $\pi-\pi$ stacking interaction with PHE97. Guo et al. reported that usnic acidtriazole hybrid a12 could exert selective anti-Toxoplasma gondii activity with a good selectivity index $\left(\mathrm{IC}_{50}=261 \mu \mathrm{M}, \mathrm{SI}=1.34\right)$, which is slightly better than the reference drugs sulfadiazine (SI = $1.15)$, pyrimethamine $(S I=0.89)$, and spiramycin $(S I=0.72)$ and also the parental $(+)$-usnic acid $(S I=0.96)$ (Guo et al., 2019).

Gossypol is a natural yellow pigment bi-sesquiterpene that acts as a plant defense system against insects and fungi. Pyta et al. reported that gossypol-triazole a13 $(\mathrm{MIC}=16 \mu \mathrm{g} / \mathrm{ml})$ could exert comparable inhibitory as miconazole against Fusarium oxysporum (MIC $=16 \mu \mathrm{g} / \mathrm{ml}$ ). Mechanistic studies indicated that a13 might inhibit biosynthesis of ergosterol, thereby exerting its anti-fungal activity (Pyta et al., 2016).

Artemisinin derivatives with peroxide-containing sesquiterpenoid lactone structures such as artesunate, arteether, and dihydroartemisinin are the main chemotherapeutic drugs for malaria. Beyond their intrinsic antimalarial potential, artemisinin derivatives, particularly derivatives that are conjugated with another pharmacophore by triazole could exert promising anticancer activity. For example, Dehaen et al. reported that $\mathrm{C} 11$ artemisinin-triazole b1 $\left(\mathrm{CEM}: \mathrm{IC}_{50}=0.92 \mu \mathrm{M}\right.$; Hela: $\left.\mathrm{IC}_{50}=1.2 \mu \mathrm{M}\right)$ could exert more potent inhibitory activity than b2 (CEM: $\mathrm{IC}_{50}=2.7 \mu \mathrm{M}$; Hela: $\left.\mathrm{IC}_{50}=11 \mu \mathrm{M}\right)$ 

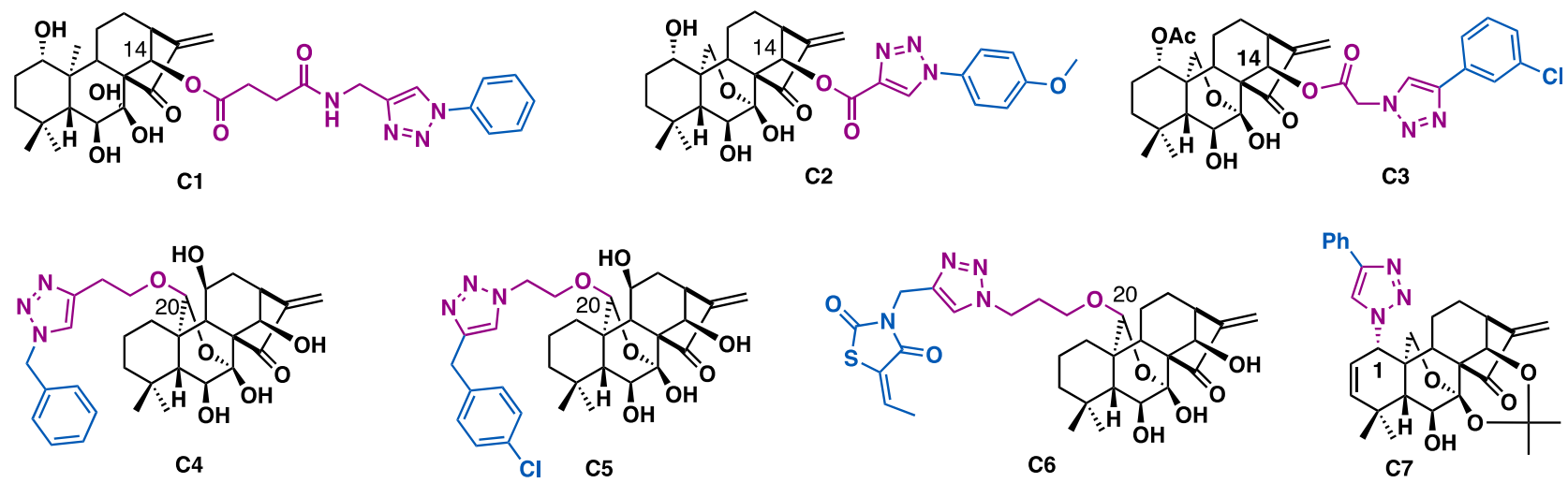

FIGURE 4 | Representatives oridonin derivatives.

and b3 (CEM: $\mathrm{IC}_{50}=10 \mu \mathrm{M}$; Hela: $\left.\mathrm{IC}_{50}=16 \mu \mathrm{M}\right)$ (Figure 3), indicating the linker between triazole and artemisinin could influence their potential (Jana et al., 2017).

Binh et al. reported that artemisinin-triazole b4 ( $\mathrm{IC}_{50}$ : 2.5-4.7 $\mu \mathrm{M}$ ) could exert more potent inhibitory activity than its regio-isomer b5 $\left(\mathrm{IC}_{50}: 13.5-19.9 \mu \mathrm{M}\right)$ and dihydro artemisinin (DHA, $\mathrm{IC}_{50}: 39.9-84.3 \mu \mathrm{M}$ ) against a panel of cancer cell lines including P388, MCF-7, HL-60, and LU-1 cells, indicating the position of the amide substituent on the benzene was critical to the potent inhibitory activity (Binh et al., 2016). Bhakuni et al. reported that b6 could inhibit the growth of a panel of cancer cell lines $\left(\mathrm{IC}_{50}=4.06-36.65 \mu \mathrm{M}\right)$ by arresting cell cycle (G2/M phase) and inducing apoptosis in lung and skin cancer cells (Kapkoti et al., 2018).

Hybridization of dihydroartemisinin with other natural products or drug molecules is another good strategy to obtain potential anticancer compounds. Artemisinin-coumarin hybrid b7, b8, and b9 could only exert moderate cytotoxic activity against MDA-MB-231, HCT-116, and HT-29 cancer cells under normoxic conditions (Tian et al., 2016; Yu et al., 2018). Whereas, under anoxic conditions, hybrid b7 (anoxic, $\mathrm{IC}_{50}=$ $0.05 \mu \mathrm{M}$; normoxic, $\mathrm{IC}_{50}=17.7 \mu \mathrm{M}$ ) and b8 (anoxic, $\mathrm{IC}_{50}=$ $0.01 \mu \mathrm{M}$; normoxic, $\mathrm{IC}_{50}=1.5 \mu \mathrm{M}$ ) showed 334-fold and 150-fold more potent than that under normoxic conditions in HT-29 cells, which is probably associated with the high expression of CA IX on the membrane of HT-29 cells. While, hybrid b9 showed a 41.38-fold and 20.03-fold higher activity than that under normoxic conditions in HCT-166 (anoxic, $\mathrm{IC}_{50}=0.43 \mu \mathrm{M}$; normoxic, $\mathrm{IC}_{50}=17.96 \mu \mathrm{M}$ ) and MDA-MB-231 cells (anoxic, $\mathrm{IC}_{50}=3.62 \mu \mathrm{M}$; normoxic, $\left.\mathrm{IC}_{50}=72.5 \mu \mathrm{M}\right)$, respectively. Structure activity relationship (SAR) studies indicated that the spacer between triazole-artiartemisinin and triazole-coumarin as well as the substituents on the coumarin were critical to the selective inhibitory activity. Artemisinin-azidothymidine hybrid b10 $\left(\mathrm{IC}_{50}=16.5 \mu \mathrm{M}\right)$ could exert more potent antiproliferative activity than artesunate $\left(\mathrm{IC}_{50}=78.5 \mu \mathrm{M}\right)$ against $\mathrm{KB}$ cancer cells (Tien et al., 2016), indicating the azidothymidine moiety plays a key role in the increased activity. In addition, SAR studies showed that hybrids with ester triazole-linker could exert more potent antiproliferative activity than hybrids with amide triazole-linker.
Oridonin is an ent-kaurene diterpenoid that was initially isolated from various Isodon species, which was widely used as home remedy herb medicine in China and Japan. Oridonintriazoles generally showed broad-spectrum anticancer activity. For example, C14 oridonin-triazole C1 (HTC116: $\mathrm{IC}_{50}=6.89 \mu \mathrm{M}$; MCF7: $\left.\mathrm{IC}_{50}=6.81 \mu \mathrm{M}\right), \mathrm{C} 2\left(\mathrm{HTC} 116: \mathrm{IC}_{50}=\right.$ $1.94 \mu \mathrm{M}$; MCF7: $\left.\mathrm{IC}_{50}=3.83 \mu \mathrm{M}\right)$ (Figure 4) (Shen et al., 2019), C3 (PC-3: $\mathrm{IC}_{50}=3.1 \mu \mathrm{M}$; LNCaP: $\mathrm{IC}_{50}=4.1 \mu \mathrm{M}$ ) could exert more potent anti-proliferative activities than that of oridonin $\left(\mathrm{IC}_{50}=16.28-24.80 \mu \mathrm{M}\right)$ (Hou et al., 2019a). In addition, they could effectively overcome drug resistance and showed weak cytotoxicity on non-cancer cells. SAR studies indicated that the phenyl 1,2,3-triazole moiety and the linker between oridonin and triazole play a key role in improving antiproliferative activity. Preliminary mechanistic studies indicated that $\mathrm{C} 3$ could arrest cell cycle (G2/M phase) and induce apoptosis of PC-3 cells. Through the introduction of azide or alkyne linkers at the C20 hydroxyl group, Liu et al. synthesized a focused library of Jiyuan oridonin A-triazoles, in vitro data indicated that all the triazole derivatives could exert good anti-proliferative activities. Among them, C4 ( $\mathrm{IC}_{50}$ $=4.26-8.95 \mu \mathrm{M})$ and $\mathbf{C 5}\left(\mathrm{IC}_{50}=2.70-5.04 \mu \mathrm{M}\right)$ could exert broad-spectrum inhibitory activity against a panel of cancer cell lines including Eca109, EC9706, SMMC7721, and MCF7. Mechanistic studies indicated that C5 could promote intracellular ROS level, arrest cell cycle (G2/M phase) and significantly induce cell apoptosis in the tested MGC-803 cells (Ke et al., 2018b). Later, the same group reported that C6 $\left(\mathrm{IC}_{50}\right.$ $=0.6-5.0 \mu \mathrm{M})$ could exert potent anti-proliferative activities on several cancer cell lines (Eca109, EC9706, SMMC7721, and MCF7) with good selectivity towards normal cells. Mechanistic studies indicated that C6 could inhibit cell migration with the Wnt signaling pathway involved, arrest cell cycle (G1 phase), and induce cell apoptosis in the tested SMMC-7721 cells (Ke et al., 2018a). Due to the challenge of the introduction of azide at $\mathrm{C} 1$ of oridonin, there are only limited C1 triazole derivatives have been reported, and according to the reported data, derivative C7 could exert submicromolar inhibitory activity on the tested cancer cells $\left(\mathrm{MCF}-7: \mathrm{IC}_{50}=0.38 \mu \mathrm{M} ; \mathrm{MDA}-\mathrm{MB}-231: \mathrm{IC}_{50}=0.48 \mu \mathrm{M}\right)$ 

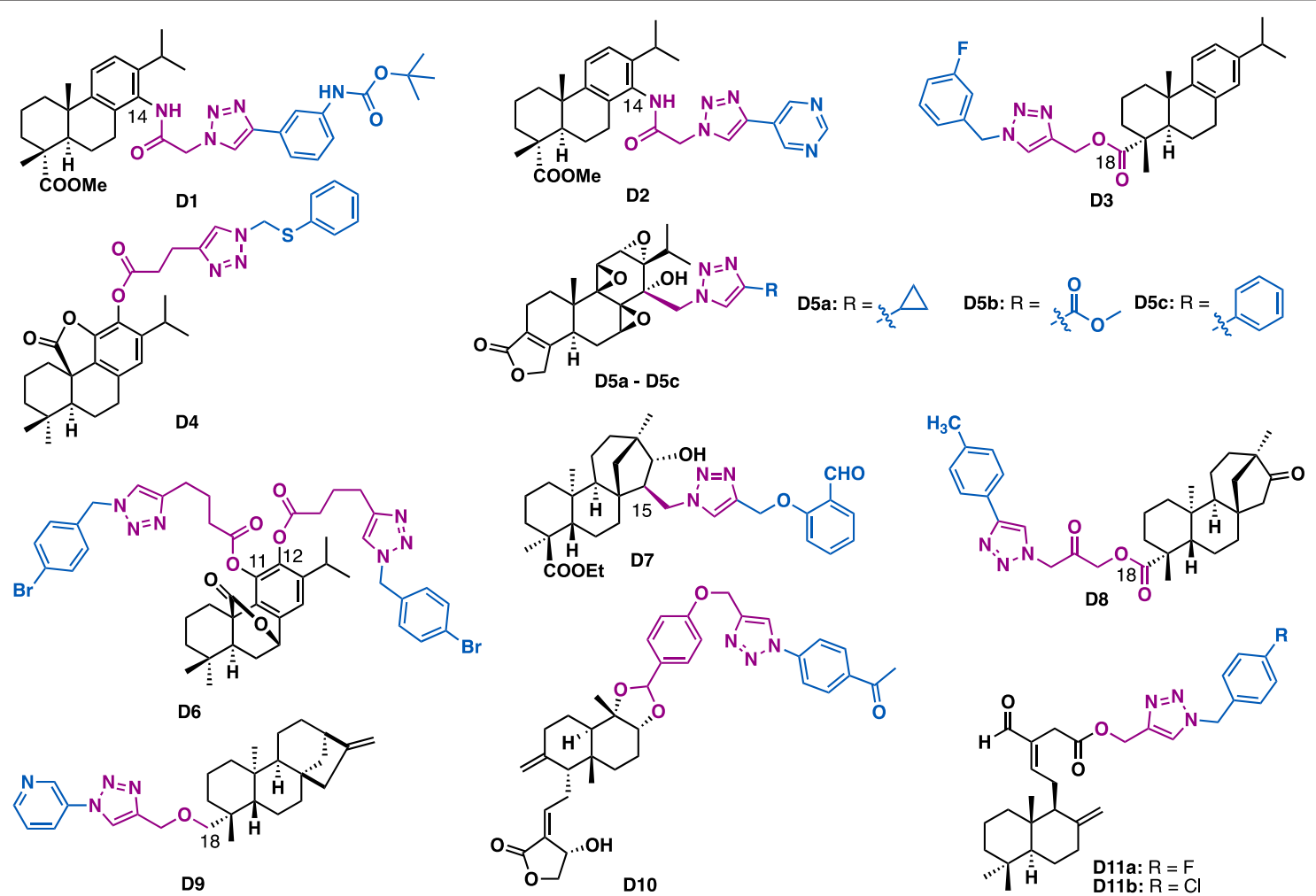

FIGURE 5 | Representative abietane, ent-beyerane, kaurene and labdane diterpene derivatives.

(Ding et al., 2013), implying the introduction of triazole at C1 of oridonin was tolerated.

Abietane-type diterpenes are a series of tricyclic terpenoids that possess various biological activities. For example, dehydroabietic acid and abietic acid are readily available diterpenoids that can be isolated from disproportionated rosin. They have been widely used as starting materials for the synthesis of natural products or natural product-like drug screening libraries (Xu et al., 2014b; Xu et al., 2017). With the installation of azide or alkyne functionalities at C14 or C18, several series of dehydroabietic acid-triazole derivatives were synthesized. The screening of antiproliferative and antibacterial activities indicated that D1 could inhibit the growth of several cancer cell lines $\left(\mathrm{IC}_{50}=0.7-1.2 \mu \mathrm{M}\right.$ ) (Figure 5) (Hou et al., 2017a). Mechanistic studies indicated that D1 could induce apoptosis of MDA-MB-231 cells. In addition, the C18 triazole derivative $\mathrm{D} 3\left(\mathrm{IC}_{50}=5.90 \mu \mathrm{M}\right)$ could exert comparable inhibitory activity to the reference drug cisplatin against HepG2 cells $\left(\mathrm{IC}_{50}=\right.$ $6.42 \mu \mathrm{M}$ ) (Li et al., 2019), and derivative D2 could exert antibacterial activities against both Gram-positive bacteria (Bacillus subtilis and Staphylococcus aureus) and Gramnegative bacteria (Escherichia coli and Pseudomonas fluorescens) strains (MIC $=1.6-3.1 \mathrm{mg} / \mathrm{ml}$ ) with good druglike properties and low cytotoxicity in noncancerous mammalian cells (Hou et al., 2017b).

Carnosic acid and carnosol are phenolic diterpenes that were identified from rosemary and mountain desert sage. Carnosic acid $\gamma$-lactone-triazole D4 could exert moderate inhibitory activity on MRC-5 $\left(\mathrm{IC}_{50}=45.1 \mu \mathrm{M}\right)$ and $\mathrm{AGS}\left(\mathrm{IC}_{50}=\right.$ $39.2 \mu \mathrm{M}$ ) cancer cells (Pertino et al., 2015), while C11, C12 carnosol-bistriazole D6 $(\mathrm{MIC}=125 \mu \mathrm{g} / \mathrm{ml})$ could inhibit the growth of $C$. neoformans at the concentration of $250 \mu \mathrm{g} / \mathrm{ml}$ (Pertino et al., 2015).

Triptolide is an abietane-type diterpene that was identified from Tripterygium wilfordii Hook.f (TWHF). It has the unique structural features of three successive epoxides and an unsaturated $\alpha, \beta$-lactone. Due to its various promising biological activities, considerable work has been devoted to its total synthesis, structural modification, and targeted delivery with the aim to reduce its toxicity (Hou et al., 2019b; Xu and Liu, 2019; Zhang X. et al., 2019). With the introduction of azidomethyl at C14 of triptolide, $\mathrm{Li}$ et al. synthesized a series of C14 triazole substituted epi-triptolide derivatives D5a, D5b, and D5c (Xu et al., 2014a). In vitro data indicated that these derivatives only showed weak cytotoxic activity as compared to triptolide. However, considering various promising biological activities of triptolide (Hou et al., 2019b), further evaluation of their biological activates such as neuroprotective and anti-inflammatory activities are highly expected.

Isosteviol is a tetracyclic ent-beyerane diterpene that is endowed with multifarious bioactivities and can be readily isolated from stevia plant. Diversification of isosteviol by click chemistry at $\mathrm{C} 19$ or $\mathrm{C} 15$ could generate derivatives with potential anticancer activity. Tao et al. reported that 


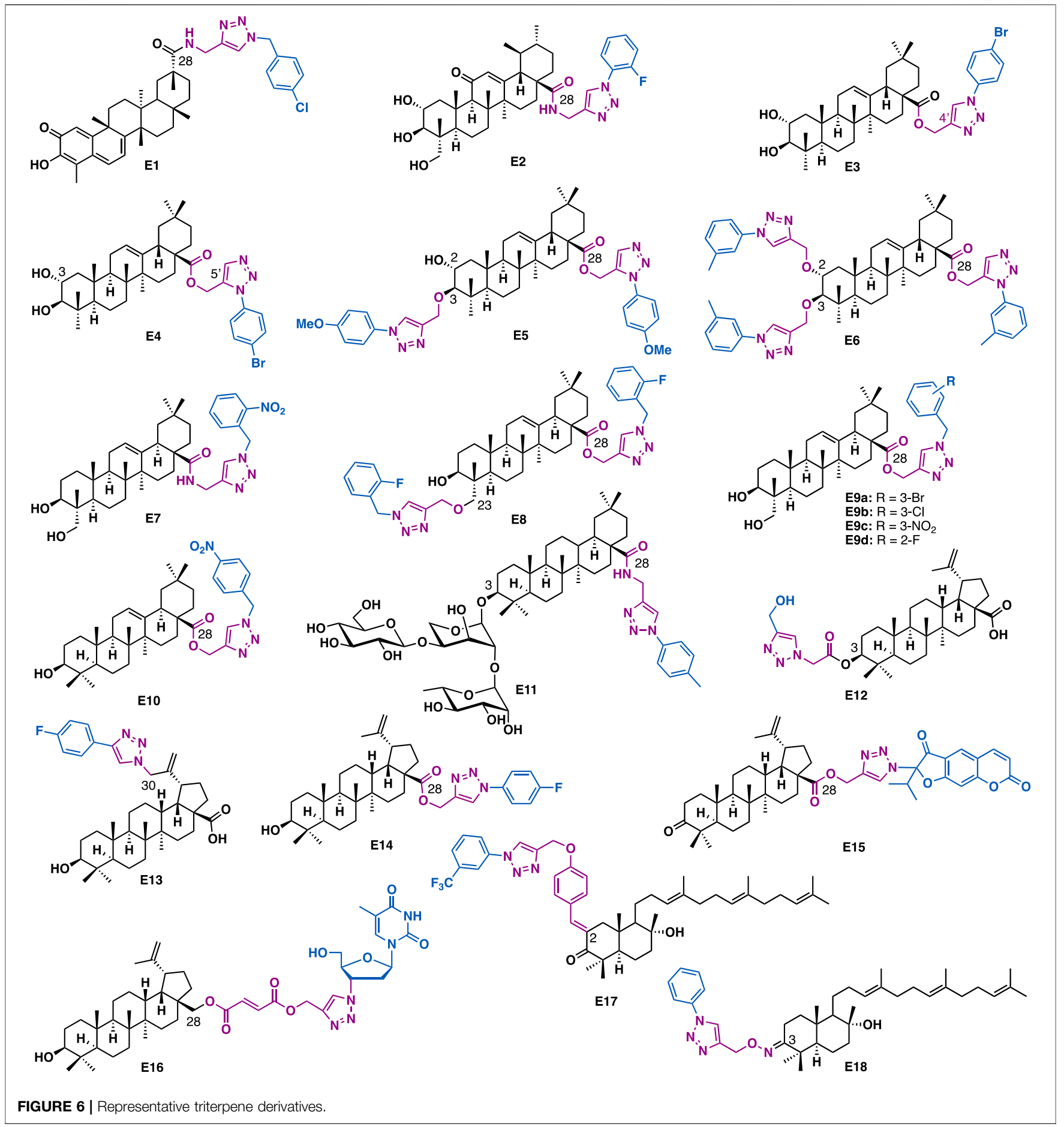

C15 isosteviol-triazole D7 $\left(\mathrm{IC}_{50}=2.987 \mu \mathrm{M}\right)$ could exert slightly better inhibitory activity than cisplatin $\left(\mathrm{IC}_{50}=3.906 \mu \mathrm{M}\right)$ against HCT-116 cells (Liu et al., 2016). Quan et al. reported that C19 isosteviol-triazole D8 could inhibit the growth of several cancer cell lines (HCT-116, BEL-7402, and HepG2) with $\mathrm{IC}_{50}$ values in the range of $5.38-15.91 \mu \mathrm{M}$, and that was 1.3 - to 4.6-fold more potent than the reference drug 5fluorouracil, and 6.3 - to 16.8 -fold more potent than the parental isosteviol (Luan et al., 2019). Mechanism studies indicated that D8 could inhibit colony formation and arrest cell cycle (S phase) in HCT-116 cells.

Kaurenoic acid (KA) is a kaurene diterpene that can be isolated from the fruits of $X$. aethiopica. Oliveira et al. reported that C19 kaurenoic acid-triazole D9 could exert moderate antimalarial activity $\left(\mathrm{IC}_{50}=53 \mu \mathrm{M}\right)$ (De Santos et al., 2016), together with good selectivity (selective index $(\mathrm{SI})=774)$. 
Both andrographolide and (E)-labda are labdane diterpenes. Andrographolide is one of the principal biological active compounds of andrographis paniculate, a traditional herb medicine widely used in China and India for the treatment of multiple diseases such as inflammation and cancer. Chinthala et al. reported that andrographolide triazole derivative D10 could exert selective inhibitory activity against K562 cancer cells with $\mathrm{IC}_{50}$ values of $8 \mu \mathrm{M}$.(Chinthala et al., 2016). In silico docking studies indicated that D10 could bind with transient receptor potential vanilloid 1 (RPV1). (E)-labda is isolated from fresh rhizomes of Curcuma amada. Somappa et al. reported that labdane triazole derivatives $\mathrm{D} 11 \mathrm{a}\left(\mathrm{IC}_{50}=0.75 \mu \mathrm{M}\right)$ and $\mathrm{D} 11 \mathrm{~b}$ $\left(\mathrm{IC}_{50}=0.77 \mu \mathrm{M}\right)$ could exert excellent pancreatic lipase (PL) inhibitory activity, slightly better than the reference drug orlistat $\left(\mathrm{IC}_{50}=0.8 \mu \mathrm{M}\right)$ (Jalaja et al., 2018).

Triterpenes represent an important class of natural terpenoids that are composed of three terpene units. They are endowed with the abilities to balance hormones, blood pressure, circulation, and digestion, and they also have been documented with anti-viral and anti-inflammatory activities.

Celastrol is a pentacyclic nortriterpene that is isolated from the root of Tripterygium wilfordii and/or Triptergium regelii. SAR studies indicated that its quinone methide moiety plays a key role in exerting various promising biological activities, thereby its structural modification was mainly conducted at C28 carboxyl group (Hou et al., 2020). For example, Zhang et al. reported that the C28 celastrol-triazole E1 could exert submicromolar antiproliferative effect against AGS $\left(\mathrm{IC}_{50}=0.97 \mu \mathrm{M}\right), \mathrm{HCT}-116\left(\mathrm{IC}_{50}\right.$ $=0.78 \mu \mathrm{M})$ and BEL-7402 $\left(\mathrm{IC}_{50}=0.63 \mu \mathrm{M}\right)$ cancer cell lines (Figure 6) (Zhang H.-J. et al., 2018).

Asiatic acid (AA) is a pentacyclic triterpenoid that was identified from the tropical herb medicine Centella asiatica. It has been reported to possess various biological activities such as antiinflammation, antidiabetics, and antitumor. Huang et al. reported that AA-triazole E2 could bind to NF- $\kappa \mathrm{B}(\mathrm{KD}=$ $0.36 \mu \mathrm{M})$ and exert low micromolar inhibitory activity against TNF- $\alpha$-induced NF- $\kappa$ B activation $\left(\mathrm{IC}_{50}=0.14 \mu \mathrm{M}\right.$ ) (Huang et al., 2019). Molecular docking studies indicated that E2 could fit well in the active site of NF- $\kappa$ B. The fluorine of benzene could form one hydrogen-bonding interaction with DNA chain (DA6), while the benzene could engage $\pi-\pi$ interactions with PHE307 (Huang et al., 2019). Notably, 1,2,3-triazole as a hydrogen acceptor could establish four hydrogen bonds with amino hydrogen of LYS272 and DA5, indicating that the triazole moiety was crucial for the improved potency of E2. C-2 and C-3 hydroxy groups of AA could form two hydrogen bonds with the DNA backbone $\mathrm{P}=\mathrm{O}$ of DG2. Also, C-23 hydroxy of AA formed two hydrogen bonds with LYS249. Moreover, the pentacyclic skeleton of AA moiety was surrounded by LYS241, PRO243, SER246, ASN247, LYS249, ASP271, and LYS272 via the hydrophobic interaction. Further, mechanistic studies indicated that E2 could inhibit NF- $\kappa$ B DNA binding, nuclear translocation, and $\mathrm{I} \kappa \mathrm{B} \alpha$ phosphorylation. In vitro data showed that E2 could inhibit the growth of A549 cells $\left(\mathrm{IC}_{50}=2.67 \mu \mathrm{M}\right)$ by at least partial inhibition of the activity of NF- $\kappa \mathrm{B}$, as well as cell apoptosis and migration.

Maslinic acid is a pentacyclic triterpenoid that is isolated from pomace olive (Olea europea L.). It is reported that the introduction of triazole into maslinic acid could promote its anti-inflammatory activity (Chouaib et al., 2016). For the mono triazole derivatives, the triazole 1',4'-regioisomers have more potent anti-inflammatory activity than the 1',5'-regioisomers, for example, E3 (IL-1 $\beta$ production $=21 \% ; 100 \mu \mathrm{M}$ ) is more potent than $\mathrm{E} 4$ (IL- $1 \beta$ production $=61 \% ; 100 \mu \mathrm{M})$. Regarding the bistriazole derivatives, bis-3,28-disubstituted triazoles were more potent than the bis-2,28-disubstituted triazoles, with derivative E5 showed the highest inhibitory activity (IL- $1 \beta$ production $=34 \% ; 100 \mu \mathrm{M})$. While 2,3,28-trisubstituted hybrids were the most potent series of all the triazole derivatives. Among them, E6 showed the highest potency (IL$1 \beta$ production $=23 \% ; 30 \mu \mathrm{M})$. These data indicated that both the number and the position of the triazole were critical to the promising anti-inflammatory activity.

Hederagenin is an oleane-type pentacyclic triterpenoid that can be isolated in large quantities from Sapindus saponaria L. Hederagenin-triazole derivatives could not only exert anti-cancer activity but also have anti-leishmanial activity. For example, Barbosa et al. reported that E7 $\left(\mathrm{IC}_{50}=2 \mu \mathrm{M}\right.$, SI $\left.=22.5\right)$ could inhibit the growth of Leishmania infantum with a higher selectivity index as compared to the commercial drug potassium antimonyl tartrate trihydrate $\left(\mathrm{IC}_{50}=80 \mu \mathrm{M}\right.$, SI $=$ 0.1) (Rodríguez-Hernández et al., 2016a), highlighting its potential in anti-leishmanial drug development. Later, the same group reported $\mathrm{E} 8$, in which two triazoles were installed at C3 and C28, respectively, could also inhibit the growth of intracellular amastigote forms of Leishmania infantum with a good selectivity index $\left(\mathrm{IC}_{50}=5.6 \mu \mathrm{M}, \mathrm{SI}=178\right)$ (RodríguezHernández et al., 2017). C28 Hederagenin-triazole derivatives containing ester linkers are generally showed more potent cytotoxic activities than those that containing amide linkers (Rodríguez-Hernández et al., 2016b). In vitro antiproliferative activity data indicated that $\mathrm{E} 9 \mathrm{a}\left(\mathrm{IC}_{50}=3.2-4.0 \mu \mathrm{M}\right), \mathrm{E} 9 \mathrm{~b}\left(\mathrm{IC}_{50}=\right.$ 3.1-4.0 $\mu \mathrm{M})$, and $\mathrm{E} 9 \mathrm{c}\left(\mathrm{IC}_{50}=3.2-4.1 \mu \mathrm{M}\right)$ could exert potent inhibitory activity against a panel of human cancer cell lines including 518A2, A2780, A549, HT-29, MCF-7, and 8505C, and are at least eight times more potent than the parental hederagenin, while E9d could exert selective inhibitory activity against HT-29 cells $\left(\mathrm{IC}_{50}=1.6 \mu \mathrm{M}\right)$ with low toxicity in normal NIH 3 T3 cells.

Oleanolic acid is a natural pentacyclic triterpenoid related to betulinic acid. It is widely distributed in many medicinal herbs in the form of free acid or saponin glycosides. Derivative E10, a C28 triazole derivative (Wei et al., 2015), in which the triazole moiety was installed by an ester linker, could exert potent antiproliferative activities against A375-S2 $\left(\mathrm{IC}_{50}=4.97 \mu \mathrm{M}\right)$ and HT1080 $\left(\mathrm{IC}_{50}=3.51 \mu \mathrm{M}\right)$ cancer cells. Meanwhile, its C3 saponin triazole relative, $\mathrm{C} 28$ hederacolchiside-triazole E11 ( $\mathrm{IC}_{50}$ $=0.54-2.66 \mu \mathrm{M})$ could exert more potent inhibitory activity than 5-fluorouracil $\left(\mathrm{IC}_{50}=8.45-69.07 \mu \mathrm{M}\right)$ against a panel of cancer cell lines including PC3, HT29, HepG2, A549, HL60, and U937 (Li et al., 2018). Mechanistic studies indicated that E11 could arrest cell cycle (G1/S) and induce apoptosis of HepG2 cells.

Betulinic acid is a pentacyclic lupane-type triterpenoid that is isolated from the stem bark of Platanus orientalis and many other plants such as the birch trees Ziziphus spp., Syzygium spp., 
<smiles></smiles>

F1<smiles>O=C1CCN(Cc2cn(-c3ccccc3F)nn2)C2(CCCCC2)c2ccccc21</smiles>

F2<smiles>O=C1CN(Cc2cn(-c3ccccc3F)nn2)C2(CCCCC2)c2ccccc21</smiles><smiles>[R]c1ccc(-n2cc(-c3cc([C@H](O)[C@@H]4CC5CCN4CC5)c4cc(OC)ccc4n3)nn2)cc1</smiles>

F4b: $\mathrm{R}=\mathrm{OH}$<smiles>OC(C1=CC=NC2CC=C(n3cc(-c4ccccc4)nn3)C=C12)C1CN2CCCC1C2</smiles>

F5<smiles>COc1ccc2nccc([C@@H](C3CC4CCN3CC4)n3cc(-c4ccc5ccccc5n4)nn3)c2c1</smiles>

F6<smiles>COc1ccc2nccc([C@@H](OCCc3cn(-c4ccc(C)cc4)nn3)C3CC4C=CC3CC4)c2c1</smiles>

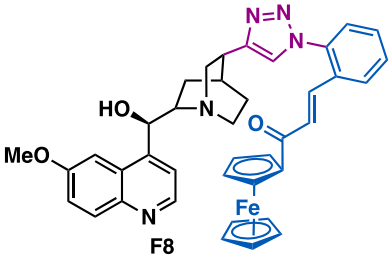

F7<smiles>COc1cc2c(c(OC)c1OC)-c1ccc(OC)c(=O)cc1[C@@H](n1cc(CCC(=O)OCc3ccc(F)cc3)nn1)CC2</smiles>

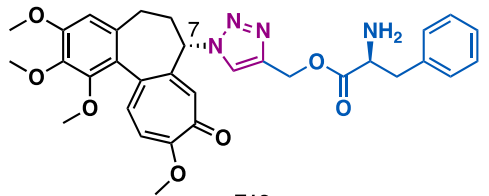

F12<smiles>[O-][N+]1=Cc2cc3cccc(OCc4cn(Cc5ccc(-c6ccccc6)cc5)nn4)c3cc2CC1</smiles>

F10<smiles></smiles><smiles>CC12CCC(CC1=NCCOCc1cn(CCCCCCN3CC4CC(C3)c3cccc(=O)n3C4)nn1)C2(C)C</smiles>

F15<smiles>CC(C(=O)OCc1cn(CCC(=O)NC2CCCC2)nn1)n1cnc2c1c(=O)n(C)c(=O)n2C</smiles><smiles>CCn1c(=O)ccn(C2OC3OC(Cn4cc(COC(=O)C(C)NC(=O)C(C)N5C=NC6C5C(=O)N(C)C(=O)N6C)nn4)C(O)C3O2)c1=O</smiles><smiles>CN1C(=O)C2C(N=CN2CC(=O)NCC(=O)OCc2cn(CC3OC4(n5ccc(=O)[nH]c5=O)OC3C(O)C4O)nn2)N(C)C1=O</smiles>

FIGURE 7 | Representative alkaloid derivatives.

Paeonia spp., etc. So far, several series of C3, C28, and C30 betulinic acid-triazole derivatives have been synthesized and evaluated for various biological activities. Chakraborty et al. reported that $\mathrm{C} 3$ betulinic acid-triazolide $\mathrm{E} 12\left(\mathrm{IC}_{50}=14.9 \mu \mathrm{M}\right)$ could exert more potent inhibitory activity than betulinic acid and 5-fluorouracil in HT-29 cells (Chakraborty et al., 2015). Mechanistic studies indicated that E12 could induce apoptosis of cancer cells. Biophysical data showed that E12 could act as a DNA minor groove binder. Sangwan et al. reported that C28 betulinic acid triazole derivative E14 could exert promising inhibitory activity in a panel of cancer cell lines (HL-60: $\mathrm{IC}_{50}$ $=7 \mu \mathrm{M} ; \mathrm{MiaPaCa}: \mathrm{IC}_{50}=5 \mu \mathrm{M}$; PC-3: $\mathrm{IC}_{50}=7 \mu \mathrm{M}$; and A549: $\left.\mathrm{IC}_{50}=7 \mu \mathrm{M}\right)$ (Khan et al., 2016). Mechanistic studies indicated that E14 could block cell cycle at the G1 phase, induce mild cell apoptosis via both intrinsic and extrinsic pathways in HL-60 cells. Lipeeva et al. reported that C28 betulonic acid-furocoumarin oreoselone hybrid E15 could significantly reduce histamineinduced paw edema (edema index: $24.5 \%$ ) to a level that was comparable to the nonsteroidal anti-inflammatory drug indomethacin (edema index: 22.4\%) (Lipeeva et al., 2020). Shi et al. reported that $\mathrm{C} 30$ betulinic acid-triazole derivative $\mathrm{E} 13$ ( $\mathrm{IC}_{50}$ $=1.3 \mu \mathrm{M})$ could exert more potent antiproliferative than betulinic acid $\left(\mathrm{IC}_{50}=11.5 \mu \mathrm{M}\right)$ in HL-60 cells (leukaemia) (Shi et al., 2015). Kiem et al. reported that C28 botulin-triazole-AZT hybrid E16 could exert promising antiproliferative activity against both $\mathrm{KB}$ $\left(\mathrm{IC}_{50}=0.38 \mu \mathrm{M}\right)$ and HepG2 $\left(\mathrm{IC}_{50}=1.32 \mu \mathrm{M}\right)$ cancer cells (Anh et al., 2017). Clearly, hybrid E16 showed much more potent inhibitory activity than AZT ( $\mathrm{IC}_{50}>400 \mu \mathrm{M}$ for both cell lines), implying the added value of merging betulin and AZT into a single hybrid.

Myrrhanone $\mathrm{C}$ is a natural bicyclic triterpene that is isolated from the gum resin of Commiphora mukul. By modification of $\mathrm{C} 2$ methene and C3 keto, Uppuluri et al. synthesized 27 myrrhanone C-triazoles (Poornima et al., 2015). In vitro data indicated that E17 could selectively inhibit the growth of DU-145 $\left(\mathrm{IC}_{50}=\right.$ $13.8 \mu \mathrm{M})$ and HepG2 $\left(\mathrm{IC}_{50}=9.332 \mu \mathrm{M}\right)$ cancer cells, while E18 $\left(\mathrm{IC}_{50}=6.16-9.59 \mu \mathrm{M}\right)$ could exert pan inhibitory activity against a panel of cancer cell lines (A549, Hela, MCF-7, DU-145, and HepG2). Both of them were more potent than the precursor myrrhanone $\mathrm{C}\left(\mathrm{IC}_{50}=12.02-26.61 \mu \mathrm{M}\right)$. Mechanistic studies 
indicated that E18 could arrest cell cycle (G2/M phase) and induce cell apoptosis.

\section{CLICK CHEMISTRY-BASED MODIFICATION OF ALKALOIDS}

Alkaloids are a series of nitrogen-containing compounds of plant origin, they usually possess various pronounced physiological effects on humans and other animals, such as morphine, quinine, strychnine, nicotine, and ephedrine.

Matrine is a quinolizidine alkaloid that is isolated from the root of Sophora flavescens Ait (also known as Kushen), which is a traditional Chinese herb medicine that has been used for the treatment of liver diseases for thousands of years. Zhao et al. reported that matrine-triazol-chalcone hybrids could inhibit the growth of a panel of cancer cells (Figure 7) (Zhao et al., 2015). Among them, F1 $\left(\mathrm{IC}_{50}=5.01-7.31 \mu \mathrm{M}\right)$ could exert broadspectrum anticancer activities against a panel of cancer cell lines (A549, Bel-7402, Hela and MCF-7). Notably, F1 is more potent than the combination of matrine and chalcone $\left(\mathrm{IC}_{50}>\right.$ $50 \mu \mathrm{M})$, and also 5-fluotouracil $\left(\mathrm{IC}_{50}=8.93-40.38 \mu \mathrm{M}\right)$. SAR studies indicated that the $\alpha, \beta$-unsaturated ketone moiety and the triazole together might play a key in determining the promoted inhibitory activity. Further studies indicated that F1 could induce apoptosis in A549 cells, and suppress tumor growth in A549xenografted nude mouse model $(10 \mathrm{mg} / \mathrm{kg})$ with no apparent cytotoxicity.

Homoharringtonine and homoerythrina are naturally occurring alkaloids that are isolated from genus Cephalotaxus. Their derivatives have been reported to exert various biological activities, and especially anticancer activity. Li et al. reported that homoerythrina-triazole F2 $\left(\mathrm{IC}_{50}=1.89-4.19 \mu \mathrm{M}\right)$ could exert more potent inhibitory activity than rucaparib $\left(\mathrm{IC}_{50}=\right.$ $4.91-13.51 \mu \mathrm{M})$ and harringtonine $\left(\mathrm{IC}_{50}: 10.55-11.71 \mu \mathrm{M}\right)$ in A549, HCT-116, and MCF-7 cancer cells (Li et al., 2020a). Mechanistic studies indicated that F2 could arrest cell cycle at the $S$ phase, prevent the biosynthesis of PAR, and induce apoptosis in A549 cells. The same group also reported thaterythrian-triazole $\mathrm{F} 3\left(\mathrm{IC}_{50}=0.23-1.13 \mu \mathrm{M}\right)$ could exert more potent inhibitory activity than rucaparib $\left(\mathrm{IC}_{50}=\right.$ 2.58-13.82 $\mu \mathrm{M}$ ) in a panel of cancer cell lines (A549, OVCAR3, HepG2, A375, and SW-620) (Li et al., 2020b). Mechanistic studies indicated that $\mathrm{F} 3$ could also prevent the biosynthesis of PAR, and induce apoptosis in A549 cells.

Quinine is one of the most abundant natural cinchona alkaloids, and also is the mainstay of antimalarial drugs. With the introduction of azide at $\mathrm{C} 9, \mathrm{C} 2$ ' and $\mathrm{C}^{\prime}$ of quinine, Boratyński et al. synthesized a focused library of triazole containing chinchona alkaloids (F4a, F4b, F5, and F6) (Boratyński et al., 2018). In vitro data indicated that nearly all the derivatives could exert moderated antiproliferative activities. Among them, $\mathrm{F} 4 \mathrm{a}\left(\mathrm{IC}_{50}=0.53 \mu \mathrm{M}\right)$ showed the highest potential in MC-4-11 cells, while, $\mathrm{F} 4 \mathrm{~b}\left(\mathrm{IC}_{50}=1.2 \mu \mathrm{M}\right)$ showed the highest potential in HT-29 cells.

The conjugation of small molecules with ferrocene, a unit that showed tunable redox characteristics, can usually generate new molecules with unexpected properties. Pešić et al. reported that ferrocene-quinine conjugate F8 $\left(\mathrm{IC}_{50}=2.34-2.13 \mu \mathrm{m}\right)$ could not only inhibit the growth of drug-sensitive NCI-H460 cancer cells, but also multi-drug resistant (MDR) NCI-H460/R cancer cells (Podolski-Renić et al., 2017). Mechanistic studies indicated that F8 could increase ROS production and induce mitochondrial damage in MDR cancer cells, highlighting the importance of the ferrocene moiety. Panda et al. reported that $\mathrm{F} 7\left(\mathrm{IC}_{50}=27 \mathrm{nM}\right)$ could exert more potent in vitro antimalarial activity than quinine $\left(\mathrm{IC}_{50}=58 \mathrm{nM}\right)$ against $P$. falciparum strain 3D7 (Faidallah et al., 2016), and the reason is probably due to the introduction of the hydrophobic alkyl chain at $\mathrm{C}$, thereby increasing the penetration ability of the parental scaffold. Sahu et al. reported that C19 quinine-triazole derivative F9 could exert potent antimalarial $\left(P\right.$. falciparum, $\left.\mathrm{IC}_{50}=0.25 \mu \mathrm{M}\right)$ and antileishmanial activities $\left(L\right.$. donavani, $\left.\mathrm{IC}_{50}=1.78 \mu \mathrm{M}\right)$ with no apparent adverse effects (Sahu et al., 2019). The structural toxicological activity relationship studies indicated that the introduction of the triazole moiety to quinine would result in decreased toxicity.

20(S)-Camptothecin is a potent DNA topoisomerase I inhibitor that isolated from Camptotheca acuminata in 1966. With the installation of alkyne at C10 of homocamptothecin, followed by reactions with various azides under $\mathrm{CuAAC}$, Xu et al. synthesized a series of $\mathrm{C} 10$ homocamptothecin-triazole derivatives. Among them, derivative $\mathrm{F} 10\left(\mathrm{IC}_{50}=30 \mathrm{nM}\right)$ could exert more potent inhibitory than $20(S)$-camptothecin $\left(\mathrm{IC}_{50}=\right.$ $170 \mathrm{nM}$ ) against A549 cancer cells in a Topo I-dependent manner (Xu et al., 2016). Mechanistic studies indicated that F10 could arrest cell cycle at the G2 and S phases.

Colchicine is a well-known antimitotic agent that is isolated from Colchicum autumnale. By utilization of the fast and efficient CuAAC derivatization strategy, Schmalz et al. synthesized C7 colchicine-triazole F11, which $\left(\mathrm{IC}_{50}=3.5-5.52 \mathrm{nM}\right.$ ) could exert more potent inhibitory activity than colchicine $\left(\mathrm{IC}_{50}=\right.$ 13.2-20.4 nM) in a panel of cancer cell lines (THP-1, Jurkat, Hela, A549 and MES1) (Thomopoulou et al., 2016). In addition, one of the derivative F12 could not only distort the microtubule morphology but also exert a significant centrosomedeclustering effect on MDA-MB-231 cells and H1975 cells.

Berberine is an isoquinoline alkaloid that is isolated from various Berberis plants. Berberine-triazoles could not only exert anticancer activity but also exhibit antimalarial activity. Sun et al. reported that F13 could inhibit the growth of SW-1990 $\left(\mathrm{IC}_{50}=\right.$ $22.2 \mu \mathrm{M})$ and SMMC-7721 $\left(\mathrm{IC}_{50}=14.9 \mu \mathrm{M}\right)$ cancer cells (Jin et al., 2014). Nath et al. reported that berberine-triazole F14 (IC $\mathrm{IC}_{50}$ $=0.142 \mu \mathrm{M})$ could exert antimalarial activity against $P$. falciparum (3D7) strain with no apparent cytotoxicity in human PC-3 cells $\left(\mathrm{IC}_{50}>200 \mu \mathrm{g} / \mathrm{ml}\right)$ (Batra et al., 2018).

Hybridization of two different natural products by $\mathrm{CuAAC}$ is an efficient strategy to generate novel functional compounds. For example, cytisine-triazole-camphor F15 could exert antiviral activity against influenza virus A/Puerto Rico/8/34 (H1N1) with low toxicity and good selectivity index $\left(\mathrm{IC}_{50}=8 \mu \mathrm{M}\right.$, $\mathrm{CC}_{50}=168 \mu \mathrm{M}, \mathrm{SI}=20$ ) (Artyushin et al., 2019). Notably, its selectivity index is higher than that of the reference drug rimantadine $\left(\mathrm{IC}_{50}=67 \mu \mathrm{M}, \mathrm{CC}_{50}=335 \mu \mathrm{M}, \mathrm{SI}=5\right)$. 


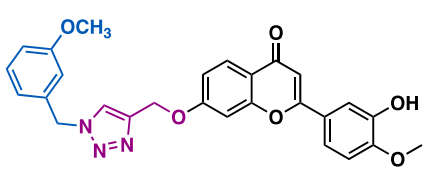

G1

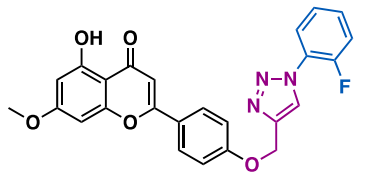

G5

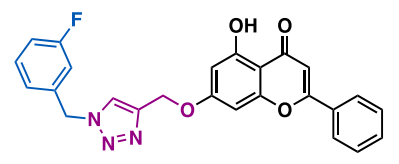

G2
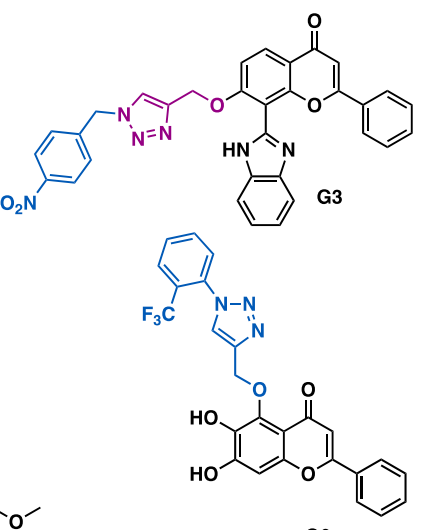

G6

FIGURE 8 | Representative flavone derivatives.

Theophylline, a naturally occurring purine base, is a bronchodilator drug that is used for the treatment of various respiratory diseases such as chronic pulmonary obstructive disease and asthma. Murugulla et al. reported that theophylline-triazole F16 could exert potent cytotoxicity on a panel of cancer cells with $\mathrm{IC}_{50}$ values in the range of $1.2-2.3 \mu \mathrm{M}$ (Ruddarraju et al., 2017). In silico docking results indicated that F16 might bind to human epidermal growth factor receptor 2 (EGFR II). Triazole-tethered theophylline-nucleoside hybrid F17 could inhibit the growth of A549, HT-29, MCF-7 and A375 cancer cells $\left(\mathrm{IC}_{50}=1.89-4.89 \mu \mathrm{m}\right.$ ) (Ruddarraju et al., 2016), while hybrid F18 could exert potent antibacterial activities against both Gram-positive (Staphylococcus aureus, Bacillus cereus) and Gram-negative (Escherichia coli and Pseudomonas aeruginosa) bacterial strains with MIC values $(\mathrm{MIC}=0.03125-0.125 \mu \mathrm{g} / \mathrm{ml})$, which are comparable to or more potent than that of the clinical drug ciprofloxacin $(\mathrm{MIC}=0.0156-0.0625 \mu \mathrm{g} / \mathrm{ml})$.

\section{CLICK CHEMISTRY-BASED MODIFICATION OF PHENYLPROPANOIDS}

Phenylpropanoids, also known as cinnamic acids, are a series of secondary metabolites that are synthesized by plants from phenylalanine and tyrosine. It mainly includes flavonoids, chalcones, isoflavonoids, lignols, coumarins, stilbenes, aurones, catechin, and phenolic acids.

Flavones are a series of privileged polyphenolic natural products that possess broad-spectrum pharmacological activities. Their synthetic derivatives have been reported to have antitumor, antioxidant, anti-inflammatory, and antiviral activities, etc. Some flavones such as luteolin are under clinical trials for the treatment of cancer (Maggioni et al., 2015), implying the potential of flavones or their derivatives in innovative drug discovery.

Through the introduction of alkyne functionality at various positions of flavonoids, and the concurrent click chemistry, several series of flavonoid derivatives have been synthesized, though they usually showed moderate biological activities. Patel et al. reported that hesperetin-triazole hybrids $\mathrm{G} 1{\left(\mathrm{IC}_{50}\right.}$ $=14.9-56.8 \mu \mathrm{M}$ ) could exert potent antioxidant activity in $\mathrm{DPPH}$ $\left(\mathrm{IC}_{50}=30.6 \mu \mathrm{M}\right)$ and $\mathrm{ABTS}^{+}\left(\mathrm{IC}_{50}=9.1 \mu \mathrm{M}\right)$ assays (Figure 8) (Mistry et al., 2017), and moderate inhibitory activity against a panel of cancer cell lines (CaSki, HeLa and SKOV-3) with low toxicity (Madin-Darby canine kidney (MDCK), $\mathrm{IC}_{50}=$ $290.9 \mu \mathrm{M})$. Yang et al. reported that chrysin-triazole hybrids G2 $\left(\mathrm{IC}_{50}=1.02-7.30 \mu \mathrm{M}\right)$ could exert more potent inhibitory activity than the parental chrysin $\left(\mathrm{IC}_{50}=16.30-73.02 \mu \mathrm{M}\right)$ in several cancer cell lines (BEL-7402, HepG-2, SGC-9701) (Luan et al., 2020). Rao et al. reported that the flavone/imidazole-triazole derivative G3 could exert moderate antiproliferative activity against MCF-7 cancer cells $\left(\mathrm{IC}_{50}=17.9 \mu \mathrm{M}\right.$ ) (Rao et al., 2018). Chen et al. reported that apigenin-triazole G4 could exert inhibitory activity against SKOV-3 cells $\left(\mathrm{IC}_{50}=10 \mu \mathrm{M}\right)$ (Qi et al., 2018). Mechanistic studies indicated that G4 could promote the level of cellular reactive oxygen species (ROS) and reduce the mitochondrial membrane potential, thereby inducing the apoptosis of SKOV-3 cells. It could also modulate the expression of B-cell lymphoma 2 (Bcl-2) and Bcl-2 associated $\mathrm{X}$ protein (Bax). Sangwan et al. reported that bavachinin-triazole G5 $\left(\mathrm{IC}_{50}=30.5-36.3 \mu \mathrm{M}\right)$ could exert comparable antiproliferative activity to bavachinin against a panel of cancer cell lines including A549, HCT-116, PC-3, and MCF-7 (Gupta et al., 2018). Mechanistic studies indicated that G5 could induce apoptotic cell death via PARP cleavage and loss of MMP, and it could also inhibit cell migration and colony formation in A549 cells. Baicalein is isolated from Scutellaria baicalensis. Niue et al. reported that baicalein-triazole G6 could prevent respiratory tract infection by respiratory syncytial viruses (RSV) via the suppression of oxidative damage (Zhang C. et al., 2019).

Chalcones, also known as chalconoids, are a series of natural polyphenols. Structurally, they are $\alpha, \beta$-unsaturated ketones, consisting of two aromatic rings conjugated by an $\alpha$, $\beta$-unsaturated carbonyl system. Chalcones and their derivatives possess various biological functions such as anticancer, antiinflammatory and antiviral activities, etc. Thus, hybridization of chalcone scaffold with another pharmacophore by click 


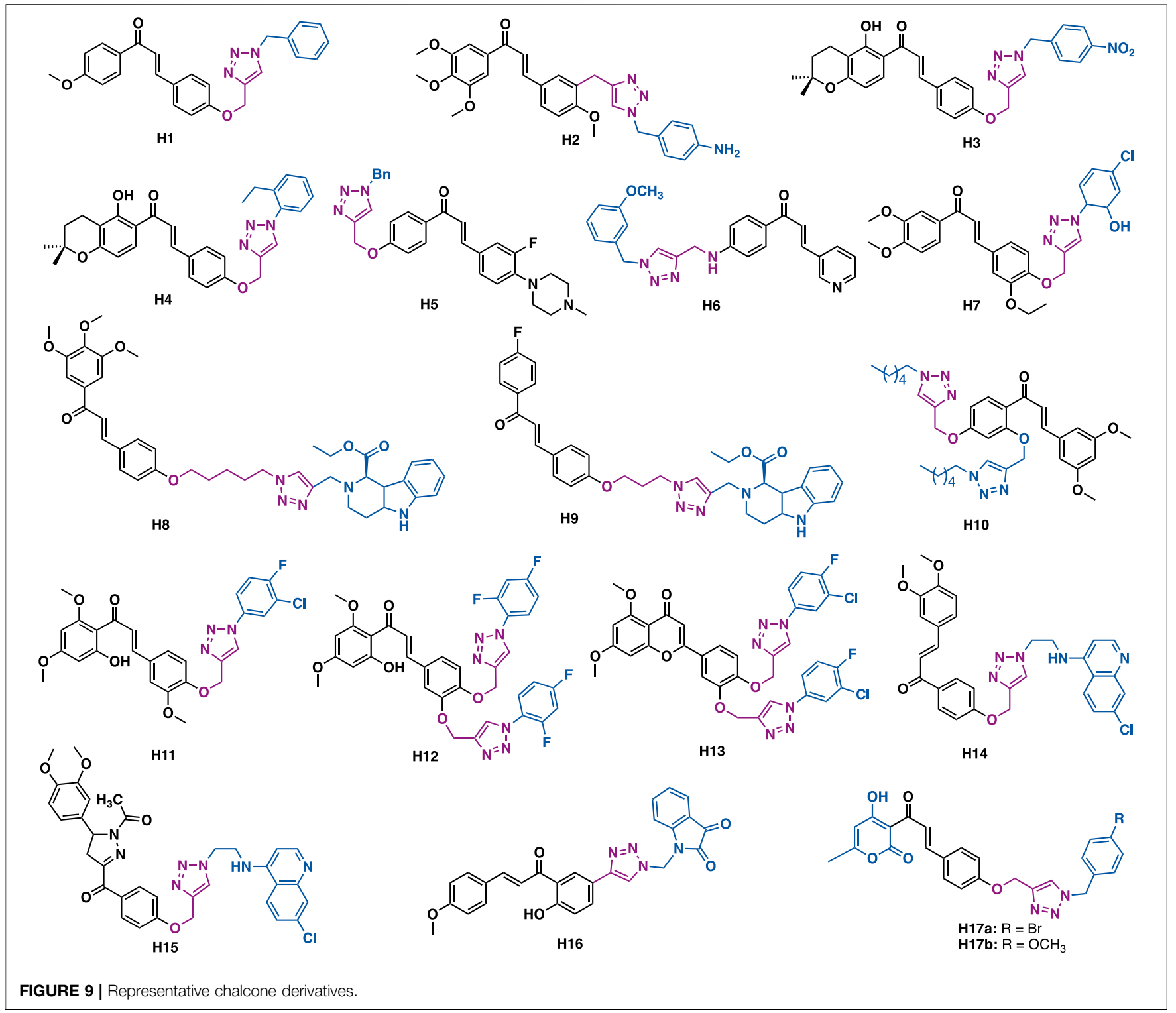

chemistry may generate derivatives with valuable therapeutic functions.

Lal et al. reported that chalcone-triazole hybrid $\mathrm{H} 1$ could exert inhibitory activity against MIA-Pa-Ca-2, MCF-7, HepG2, and A549 cancer cell lines with $\mathrm{IC}_{50}$ values in the range of 4-11 $\mu \mathrm{M}$ (Figure 9) (Yadav et al., 2017). Mechanistic studies indicated that $\mathrm{H} 1$ could arrest cell cycle (G2/S phase) and induce apoptosis of MIA-Pa-Ca-2 cells by reducing mitochondrial potential and activating PARP-1 and caspase-3.

Kamal et al. reported that triazole-chalcone hybrids $\mathrm{H} 2$ could exert low micromolar inhibitory activity against Hela, DU145, HepG2, and A549 cancer cells with $\mathrm{IC}_{50}$ values in the range of 1.5-7.7 $\mu \mathrm{M}$ (Hussaini et al., 2016). SAR studies indicated that the $\alpha, \beta$-unsaturated ketone of the chalcone skeleton was critical to the potent cytotoxicity, as the replacement of the $\alpha$, $\beta$-unsaturated ketone moiety would result in significant loss of cytotoxicity.
Kumar et al. reported that chalcone-triazole hybrid $\mathrm{H} 3$ could inhibit the growth of MCF-7, DU-145, and 1MR-32 cancer cells with $\mathrm{IC}_{50}$ values in the range of 17.1-29.9 $\mu \mathrm{M}$ (Chinthala et al., 2015), in silico docking studies indicated that $\mathrm{H} 3$ might bind to DNA topoisomerase II $\alpha$. While hybrid $\mathrm{H} 4$ could exert $\alpha$-glucosidase inhibitory activity $\left(\mathrm{IC}_{50}=67.77 \mu \mathrm{M}\right)$, in silico docking studies indicated that $\mathrm{H} 4$ has a similar binding pattern to the known antidiabetic drug acarbose with $\alpha$-glucosidase (Chinthala et al., 2015). Notably, the 1,2,3triazole ring might serve as a hydrogen bond acceptor to form two hydrogen bonds with Arg526, and it might also have $\pi-\pi$ stacking interaction with Trp406.

Liu et al. reported that hybrid $\mathrm{H} 5\left(\mathrm{IC}_{50}=5.47-11.56 \mu \mathrm{M}\right)$ and H6 $\quad\left(\mathrm{IC}_{50}=1.53-2.73 \mu \mathrm{M}\right)$ could exert low micromolar antiproliferative activity against SK-N-SH, HepG-2, and MGC803 cancer cells (Fu et al., 2016). Notably, H6 could exert more potent inhibitory activity than 5-fluorouracil $\left(\mathrm{IC}_{50}=\right.$ 


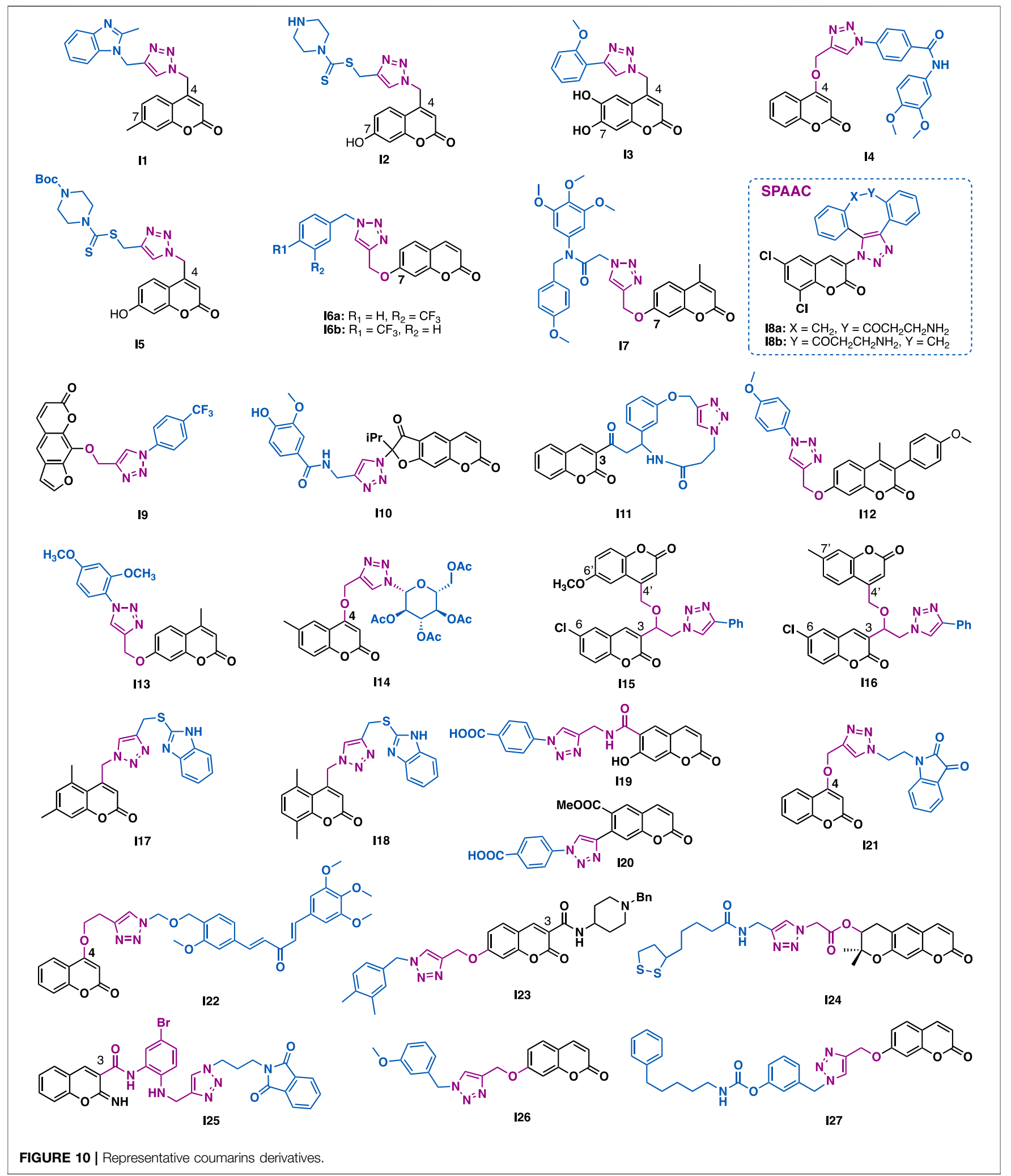

7.22-10.32 $\mu \mathrm{M})$. Mechanistic studies indicated that H6 could arrest cell cycle (G1 phase) and induce apoptosis of SK-N-SH cancer cells.
Subhashini et al. reported that triazole chalcone hybrids H7 could exert submicromolar inhibitory activity against the growth of MCF-7 $\left(\mathrm{IC}_{50}=0.02 \mu \mathrm{M}\right)$ and MDA-MB-231 $\left(\mathrm{IC}_{50}=0.31 \mu \mathrm{M}\right)$ 
with low toxicity in non-tumorigenic MCF-10a epithelial cells $\left(\mathrm{IC}_{50}=139.29 \mu \mathrm{M}\right)$ (Gurrapu et al., 2020).

Kumar et al. reported that tetrahydro- $\beta$-carboline-chalcone derivative $\mathrm{H} 8\left(\mathrm{IC}_{50}=21.99 \mu \mathrm{M}\right)$ could inhibit the growth of MDA-MB-231 cells (Sharma et al., 2020), being three times more potent than the reference drug tamocifen $\left(\mathrm{IC}_{50}=75 \mu \mathrm{M}\right)$, while $\mathrm{H} 9\left(\mathrm{IC}_{50}=10.33 \mu \mathrm{M}\right)$ could inhibit the growth of MCF-3 cells and was five times more potent than tamoxifen. Molecular docking results indicated that they could fit well into the $\mathrm{ER} \alpha$ ligand binding domain. The analysis of the H9- ER $\alpha$ complex indicated that both direct and water-mediated hydrogen bond interactions of triazole and tetrahydro- $\beta$-carboline with residues (e.g., Leu346, Thr347, and Asp351) crucial to estrogenic inhibitory activity might play a key role in exerting the potent activity (Sharma et al., 2020).

Jalapathi et al. reported that bis-triazole-chalcone hybrid $\mathrm{H} 10$ could exert comparable antibacterial activity to the reference drug gentamicin sulphate against several Gram-positive (Micrococcus luteus, methicillin-resistant Staphylococcus aureus, Bacillus subtilis, and Bacillus cereus) and Gram-negative (Pseudomonas aeruginosa, Klebsiella pneumoniae, Escherichia coli, and Proteus vulgaris) bacterial strains at concentrations of 75 and $100 \mu / \mathrm{ml}$ (Sunitha et al., 2020).

Agarwal et al. reported that derivative $\mathrm{H} 11\left(\mathrm{IC}_{50}=2.74 \mu \mathrm{g} / \mathrm{ml}\right)$ could exert potent antiplasmodial activity against the erythrocytic stages of $P$. falciparum (3D7 strain) with no apparent cytotoxicity (Huh-7 cells, $\mathrm{CC}_{50}>100 \mathrm{mg} / \mathrm{ml}$ ) (Kant et al., 2016), while bitriazole hybrid H12 (MIC $=6.25-12.5 \mu \mathrm{g} / \mathrm{ml})$ could exert comparable antibacterial activity to ciprofloxacin $(\mathrm{MIC}=$ $6.25 \mu \mathrm{g} / \mathrm{ml}$ for all the tested strains) against a panel of bacterial strains (S. aureus, E. faecalis, E. coli, P. aeruginosa, S. boydii, and $K$. pneumoniae) with low cytotoxicity (Huh-7 cells, $\mathrm{CC}_{50}>100 \mathrm{mg}$ / ml) (Kant et al., 2016), and H13 (MIC $=6.25-12.5 \mu \mathrm{g} / \mathrm{ml}$ ) could exert potent antifungal activity with low cytotoxicity (Huh-7 cells, $\mathrm{CC}_{50}>100 \mathrm{mg} / \mathrm{ml}$ ) (Kant et al., 2016).

By merging chloroquine (CQ) pharmacophore and chalcone by a triazole linker, Kumar et al. synthesized a potent hybrid derivative $\mathrm{H} 14$, which showed potent in vitro antiplasmodial activity against Plasmodium falciparum (CQR W2 strain, $\left.\mathrm{IC}_{50}=114.1 \mathrm{nM}\right)$ with low cytotoxicity (Hela cells, $\mathrm{IC}_{50}=$ $36.5 \mu \mathrm{M}$; SI = 311) (Kumar et al., 2017). Further, with the trapping of the $\alpha, \beta$-unsaturated ketone functionality of the hybrid by hydrazine hydrate, followed by acetylation with acetic acid, they have synthesized $\mathrm{N}$-acetylpyrazoline derivative H15, which showed increased activity against Plasmodium falciparum (CQR W2 strain, $\mathrm{IC}_{50}=53.7 \mathrm{nM}$ ) and an excellent selectivity index (Hela cells, $\mathrm{IC}_{50}=42.7 \mu \mathrm{M}$; SI = $795)$, indicating the $\alpha, \beta$-unsaturated ketone functionality was not critical for antiplasmodial activity.

Hayallah et al. reported that chalcone-triazole-isatin hybrid H16 could exert potent and selective COX-2 inhibitory activity $\left(\mathrm{COX}-1, \mathrm{IC}_{50}=13.3 \mu \mathrm{M}\right.$; COX-2, $\mathrm{IC}_{50}=0.037 \mu \mathrm{M}$; $\left.\mathrm{SI}=359.46\right)$ as well as good 15-LOX inhibitory activity $\left(\mathrm{IC}_{50}=1.95 \mu \mathrm{M}\right)$ (Boshra et al., 2020). SAR studies indicated that the isatin moiety would play a key in exerting the potent COX-2 inhibitory activity. In vitro anti-inflammatory activity studies indicated that $\mathrm{H} 16$ has comparable efficiency as celecoxib at a $3 \mathrm{~h}$ interval test.
Lal et al. synthesized a series of dehydroacetic acid chalconetriazole hybrids, in which the A ring was replaced by dehydroacetic acid (DHA) (Lal et al., 2018). In vitro antibacterial and antifungal data indicated that $\mathrm{H} 17 \mathrm{a}$ could exert more potent antibacterial activity in both Gram-positive (Staphylococcus epidermidis, MIC $=0.006 \mu \mathrm{M} / \mathrm{ml} ;$ Bacillus subtilis, MIC $=0.0030 \mu \mathrm{M} / \mathrm{ml}$ ) and Gram-negative (Escherichia coli, $\mathrm{MIC}=0.003 \mu \mathrm{M} / \mathrm{ml}$; Pseudomonas aeruginosa, $\mathrm{MIC}=0.006 \mu \mathrm{M} / \mathrm{ml})$ bacterial strains than the reference drug ciprofloxacin $(\mathrm{MIC}=0.0047 \mu \mathrm{M} / \mathrm{ml}$ for all the tested strains), while derivative $\mathrm{H} 17 \mathrm{~b}$ (Aspergillus niger, $\mathrm{MIC}=0.0068 \mu \mathrm{M} / \mathrm{ml}$; Candida albicans, $\mathrm{MIC}=0.0034 \mu \mathrm{M} / \mathrm{ml})$ could exert more potent antifungal activity than the reference drug fluconazole (Aspergillus niger, $\mathrm{MIC}=0.0102 \mu \mathrm{M} / \mathrm{ml}$; Candida albicans, $\mathrm{MIC}=0.0051 \mu \mathrm{M} / \mathrm{ml}$ ).

Coumarins are privileged natural products that possess a fascinating array of biological activities. Their synthetic derivatives have also been reported to exert various pharmacological activities such as anticancer, antiinflammatory, antibacterial, and antifungal activities, etc.

Raić-Malić et al. reported that C4 coumarin-triazole I1 could exert submicromolar inhibitory activity against HepG2 cells $\left(\mathrm{IC}_{50}\right.$ $=0.9 \mu \mathrm{M}$ ) with low toxicity (normal fibroblasts WI38, $\mathrm{IC}_{50}=$ $45.33 \mu \mathrm{M}$, SI $=50)$ (Figure 10) (Kraljević et al., 2016). Mechanistic studies indicated that I1 could inhibit 5lipoxygenase (5-LO), disturb intracellular acid ceramidase (ASAH) activity, thereby perturbing sphingolipid signaling, while I2 could exert high selectivity antibacterial activity against Enterococcus species $(\mathrm{MIC}=16 \mu \mathrm{g} / \mathrm{ml})$. Moreover, it could also inhibit the growth of clinically derived vancomycinresistant Enterococcus faecium $(\mathrm{MIC}=64 \mu \mathrm{g} / \mathrm{ml})$, whereas the reference antibiotics ceftazidime (CAZ) and ciprofloxacin (CIP) were inactive (MIC > $256 \mu \mathrm{g} / \mathrm{ml}$ ) (Kraljević et al., 2016). The same group further reported $\mathrm{C} 4$ modified derivative I3 could exert potent antioxidant activity (DPPH assay), and moderate cytotoxic activity against Hela, CaCo-2, and K562 cancer cells $\left(\mathrm{IC}_{50}=9.7-41.6 \mu \mathrm{M}\right)$ (Bistrović et al., 2017).

Guo et al. reported that the ether tethered triazole-coumarin I4 could potently inhibit the growth of MDA-MB-231 cells under hypoxia conditions $\left(\mathrm{IC}_{50, \text { hypoxia }}=0.03 \mu \mathrm{M} ; \mathrm{IC}_{50, \text { normoxia }}=1.34\right.$; $\mathrm{SI}_{\text {hypoxia/normoxia }}=46.31$ ) (An et al., 2018), and it was 20 times and 156 times more potent than that of doxorubicin $\left(\mathrm{IC}_{50}=0.6 \mu \mathrm{M}\right)$ and cisplatin $\left(\mathrm{IC}_{50}=4.68 \mu \mathrm{M}\right)$, respectively, whereas the parental 4-hydroxycoumarin was inactive at the concentration of $100 \mu \mathrm{M}$.

Liu et al. reported that $\mathrm{C} 4$ coumarin derivative $\mathrm{I} 5$ could inhibit the growth of PC-3, MGC-803, and MCF-7 cancer cells $\left(\mathrm{IC}_{50}=\right.$ 4.96-36.84 $\mu \mathrm{M}$ ), and that was comparable to or more potent than that of 5-fluorouracil ( $\left.\mathrm{IC}_{50}=7.01-27.07 \mu \mathrm{M}\right)$ (Duan et al., 2013).

Magolan et al. reported that C7 coumarin derivative I6a could inhibit the growth of pancreatic cancer cell lines including MIA PaCa-1, Capan-1, and PANC-1 ( $\left.\mathrm{IC}_{50}=8.5-29 \mu \mathrm{M}\right)$. A subtle change of the position of the trifluoromethyl from meta-to paraposition (I6b) led to the inactivity of the compound against Capan-1 and PANC-1 cells $\left(\mathrm{IC}_{50}>100 \mu \mathrm{M}\right)$, but slightly increased cytotoxic activity against MIA PaCa-1 cells $\left(\mathrm{IC}_{50}=\right.$ $9.6 \mu \mathrm{M}$ ), implying the trifluoromethyl may play a key role in exerting the selective inhibitory activity against MIA PaCa- 1 cells (Farley et al., 2016). 
Zhang et al. reported that $\mathrm{C} 7$ modified hybrid $\mathrm{I} 7 \mathrm{PC}-3, \mathrm{IC}_{50}=$ $\left.0.34 \mu \mathrm{M} ; \mathrm{MGC} 803, \mathrm{IC}_{50}=0.13 \mu \mathrm{M}\right)$ could exert more potent inhibitory activity than colchicine $\left(\mathrm{PC}-3, \mathrm{IC}_{50}=0.59 \mu \mathrm{M}\right.$; MGC803, $\left.\mathrm{IC}_{50}=0.27 \mu \mathrm{M}\right)$ against PC3 and MGC803 cancer cells (Fu et al., 2019). Mechanistic studies indicated that I7 could arrest cell cycle (G2/M phase), inhibit colony formation, and promote apoptosis of the tested MGC803 cells by regulating Bcl-2 and DR5. In addition, I7 $(1 \mu \mathrm{M})$ could inhibit tubulin polymerization by interacting with the colchicine binding site.

By using the SPAAC click chemistry of cyclooctyne (DBCO) and azide-coumarin, Paira et al. synthesized I8a and its regioisomer I8b with the aim of theranostic application (Sinha et al., 2016). In vitro data indicated that both I8a and I8b could exhibit maximum quantum yields and good uptake by MCF-7 cells, implying their potential for cancer diagnosis. Moreover, they could inhibit the growth of Hela $\left(\mathrm{IC}_{50}=17.5 \mu \mathrm{M}\right)$ and MCF-7 $\left(\mathrm{IC}_{50}=9.83 \mu \mathrm{M}\right)$ cancer cells with good selectivity.

Xanthotoxin is a furanocoumarin identified from the traditional Egyptian medicinal plant Ammi majus L. Quan et al. reported that xanthotoxin-triazole I9 could exert potent antiproliferative activity against AGS cells $\left(\mathrm{IC}_{50}=7.5 \mu \mathrm{M}\right)$ with low toxicity (normal L02 cell, $\mathrm{IC}_{50}>100 \mu \mathrm{M}$ ) (Shen et al., 2017), and that it was more potent than the parental xanthotoxin $\left(\mathrm{IC}_{50}>\right.$ $100 \mu \mathrm{M})$ and the reference drug 5-fluorouracil $\left(\mathrm{IC}_{50}=29.6 \mu \mathrm{M}\right)$.

Shults et al. reported that reoselone-triazole I10 could inhibit the growth of CEM-13, U-937, and MT-4 cancer cells with $\mathrm{IC}_{50}$ values in the range of $8-10 \mu \mathrm{M}$ (Lipeeva et al., 2015). Molecular docking studies indicated that I10 might bind to the active site of phosphodiesterase (PDE-4B) and showed good interactions with amino acid residues of PDE4B. Both the aryl-substituted triazole and the dihydrofurocoumarin were involved in the $\pi-\pi$ stacking interaction with Phe446 (Lipeeva et al., 2015). Notably, the triazole ring of 110 might involve in the binding with sulfurs of Met347 and Met431 by forming $\pi$-sulfur interactions. Bahulayan et al. reported that some coumarin-containing macrocyclic derivatives, like I11, could also exert inhibitory activity against cancer cells (Raj and Bahulayan, 2017).

Dharavath et al. reported that $\mathrm{I} 12\left(\mathrm{IC}_{50}=1.29 \mu \mathrm{M}\right)$ could exert comparable antioxidant activity to ascorbic acid $\left(\mathrm{IC}_{50}=1.46 \mu \mathrm{M}\right)$ in DPPH assays (Dharavath et al., 2020). In vitro antiinflammatory data indicated that $\mathrm{I} 12\left(\mathrm{IC}_{50}=15.90 \mu \mathrm{M} / \mathrm{ml}\right)$ could exert more potent activity than the reference drug diclofenac $\left(\mathrm{IC}_{50}=17.52 \mu \mathrm{M}\right)$ in heat-induced hemolytic assays. The antibacterial activity evaluation results indicated that I12 could inhibit the growth of the tested Gram-positive (Staphylococcus aureus and Bacillus subtilis) and Gramnegative (Escherichia coli and Klebsiella pneumonia) bacterial strains at the concentrations of 10 or $20 \mu \mathrm{g} / \mathrm{ml}$. Moreover, I12 could also exert antifungal activity against three fungal strains (Aspergillus niger, Aspergillus favus, and Fusariumoxy sporum) at the concentration of $50 \mu \mathrm{g} / \mathrm{ml}$, and it was comparable to the reference drug clotrimazole.

Awasthi et al. reported that coumarin-triazole I13 could exert potent antimalarial activity against $P$. falciparum $3 \mathrm{D} 7$ strain $\left(\mathrm{IC}_{50}\right.$ $=0.763 \mu \mathrm{g} / \mathrm{ml}$ ) with low cytotoxicity (human hepatoma cell (huh7), $\mathrm{CC}_{50}>100 \mu \mathrm{g} / \mathrm{ml}$ ) (Yadav et al., 2018). Mechanistic studies using Escherichia coli DNA gyrase, indicated that I13 might disrupt the catalytic activity of DNA enzyme gyrase, thereby switching off its supercoiling activity.

Sagar et al. reported that triazole- $N$-glycoside-coumarin I14 could exert low micromolar $\left(\mathrm{IC}_{50}=10.97 \mu \mathrm{M}\right)$ selective inhibitory activity against breast MCF-7 cancer cells (Kumari et al., 2019). Mechanistic studies indicated that I14 could promote the level of cellular reactive oxygen species (ROS), thereby inducing the generation of toxic products in MCF-7 cancer cells.

Kalkhambkar et al. reported that derivative I15 $(\mathrm{MIC}=1 \mu \mathrm{g} /$ $\mathrm{ml}$ ) could exert comparable antibacterial activity to the reference drug ciprofloxacin (MIC $=1 \mu \mathrm{g} / \mathrm{ml}$ ) in the tested Gram-positive (Staphylococcus aureus) and the Gram-negative (Pseudomonas aeruginosa) bacterial strains (Savanur et al., 2018), while I16 could exert comparable antifungal activity to itraconazole against Candida albicans and Aspirgillus niger strains with MIC values of $1 \mu \mathrm{g} / \mathrm{ml}$.

Kulkarni et al. reported that coumarin-2mercaptobenzimidazole hybrid I17 $(\mathrm{MIC}=3.8 \mu \mathrm{M})$ and $\mathrm{I} 18$ $(\mathrm{MIC}=3.8 \mu \mathrm{M})$ could exert more potent antibacterial activity than the reference drugs pyrazinamide $(\mathrm{MIC}=25.2 \mu \mathrm{M})$, streptomycin $(\mathrm{MIC}=10.7 \mu \mathrm{M})$, and ciprofloxacin $(\mathrm{MIC}=$ $9.4 \mu \mathrm{M})$ against $M$. tuberculosis $\left(\mathrm{H}_{37} \mathrm{Rv}\right)$ (Anand et al., 2016).

Shults et al. reported that $\mathrm{I} 19$ (S. aureus $209 \mathrm{p}, \mathrm{MIC}=0.16 \mu \mathrm{M}$; $S$. aureus $\mathrm{C}-18, \mathrm{MIC}=0.65 \mu \mathrm{M}$ ) could exert 6 - and 10 -fold more potent antibacterial activity than the reference drug ceftriaxone (S. aureus 209p, $\mathrm{MIC}=0.97 \mu \mathrm{M} ;$ S. aureus $\mathrm{C}-18, \mathrm{MIC}=6.5 \mu \mathrm{M}$ ) against Staphylococcus aureus 209p and C-18 bacterial strains (Lipeeva et al., 2019), while I20 ( $\mathrm{MIC}=0.21 \mu \mathrm{M})$ could exert a 5fold more potent antibacterial activity than ceftriaxone $(\mathrm{MIC}=$ $1.03 \mu \mathrm{M}$ ) against Staphylococcus aureus "Viotko" bacterial strain.

Bedi et al. reported that coumarin-isatin I21 could exert promising antiproliferative activity against THP-1, COLO-205, and HCT-116 cancer cells $\left(\mathrm{IC}_{50}=0.73-3.45 \mu \mathrm{M}\right)$ by inhibiting the polymerization of the tubulin $\left(\mathrm{IC}_{50}=1.06 \mu \mathrm{M}\right.$ ) (Singh et al., 2017). The same group also reported that coumarin-curcuminoid hybrid 22 could exert promising antiproliferative activity against THP-1, COLO-205, and HCT-116 cancer cells $\left(\mathrm{IC}_{50}=\right.$ $0.82-4.68 \mu \mathrm{M})$ by inhibiting the polymerization of the tubulin $\left(\mathrm{IC}_{50}=1.55 \mu \mathrm{M}\right)$ (Singh et al., 2016).

For a long time, the great potential of coumarin-triazole hybrids in anti-Alzheimer's disease drug discovery has been well demonstrated by the target-based screening of acetylcholinesterase (AChE) (Saeedi et al., 2017; Rastegari et al., 2019), butyrylcholinesterase (BuChE) (Park et al., 2016), and $\beta$-secretase (BACE1) inhibitors (Iraji et al., 2017). For example, Saeedi et al. reported that I23 could exert selective AChE inhibitory activity (AChE, $\mathrm{IC}_{50}=1.8 \mu \mathrm{M}$; BuChE, $\mathrm{IC}_{50}>$ $100 \mu \mathrm{M})$ (Rastegari et al., 2019). And also, it could exert a neuroprotective effect against $\mathrm{H}_{2} \mathrm{O}_{2}$-induced cell death of PC12 neurons. Park et al. reported that decursinol-lipoic acidtriazole hybrid $\mathrm{I} 24\left(\mathrm{AChE}, \mathrm{IC}_{50}>350 \mu \mathrm{M} ; \mathrm{BuChE}, \mathrm{IC}_{50}=\right.$ $5.89 \mu \mathrm{M}$ ) could exert selective BuChE inhibitory activity (Park et al., 2016), and that it is more potent than that of galantamine $\left(\mathrm{BuChE}, \mathrm{IC}_{50}=9.4 \mu \mathrm{M}\right)$. SAR studies indicated that its selectivity (AchE/BuChE) might result from neither decursinol nor triazole, but the hybrid derivative I24. $\beta$-Secretase (BACE1), a transmembrane aspartic protease, is an attractive target for the 
<smiles>COC(=O)c1ccc(-c2cn(CC(=O)OC3COC(=O)C3Cc3cc4c5cc3[C@@H](COCO4)OCO5)nn2)cc1OC</smiles>

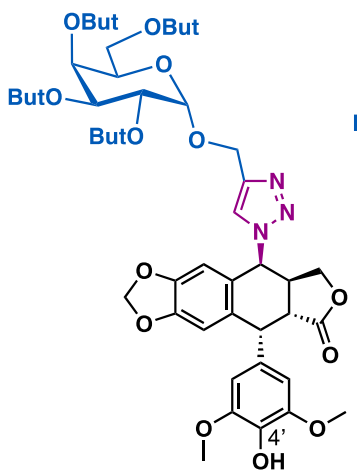

J4<smiles></smiles><smiles>COc1ccc2oc(=O)cc(OCc3cn(C4c5cc6c(cc5[C@H](c5cc(OC)c(OC)c(OC)c5)[C@H]5C(=O)OC[C@@H]45)OCO6)nn3)c2c1</smiles>
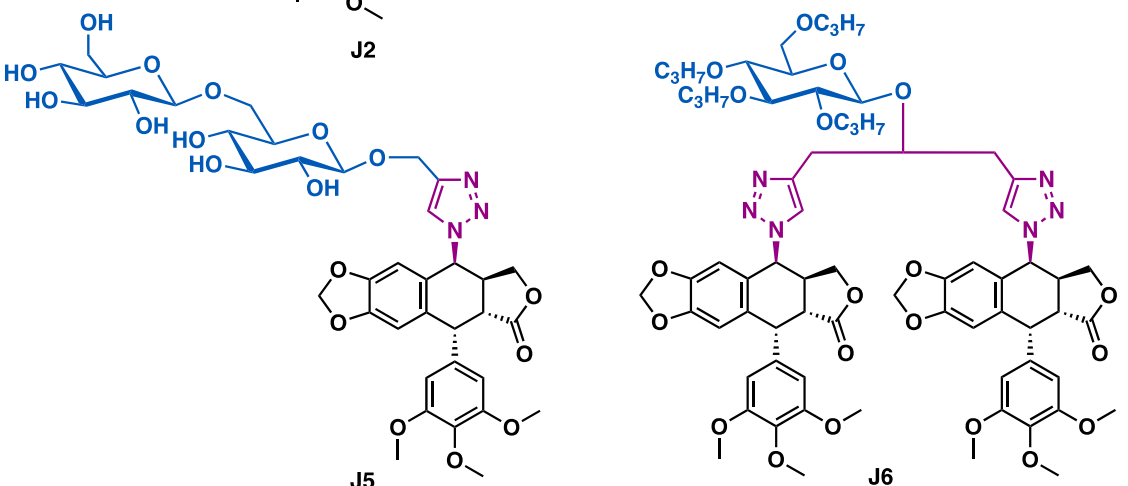

FIGURE 11 | Representative podophyllotoxin derivatives.

development of $\mathrm{AD}$ therapeutic drugs as it is critical in trigging the amyloidogenic pathway. Miri et al. reported that iminochromene-triazole I25 (Iraji et al., 2017), a non-peptidic $\beta$-secretase (BACE1) inhibitor, could exert promising BACE1 inhibitory activity $\left(\mathrm{IC}_{50}=2.2 \mu \mathrm{M}\right)$ with no apparent cytotoxicity. Notably, it could exert a 10 -fold more potent neuro protective effect $\left(\mathrm{IC}_{50}=7.9 \mu \mathrm{M}\right)$ than the reference caffeic acid $\left(\mathrm{IC}_{50}=\right.$ $75.8 \mu \mathrm{M})$ in $\mathrm{A} \beta$ induced toxicity in $\mathrm{pC} 12$ neurons. Foroumadi et al. synthesized a dual $\mathrm{AChE}\left(\mathrm{IC}_{50}=3.4 \mu \mathrm{M}\right)$ and $\mathrm{BuChE}\left(\mathrm{IC}_{50}\right.$ $=1.1 \mu \mathrm{M}$ ) inhibitor I26 (Moradi et al., 2018), which could also exert promising protective effective in $\mathrm{H}_{2} \mathrm{O}_{2}$-induced cell death of $\mathrm{PC}_{12}$ neurons. With the aim of discovering a multi-targetdirected ligand for neurodegenerative disease, Rampa et al. synthesized I27 (Montanari et al., 2016), a dual FAAH/BuChE inhibitor, which could exert well-balanced nanomolar inhibitory activities $\left(r \mathrm{FAAH}, \mathrm{IC}_{50}=27.9 \mathrm{nM} ; h \mathrm{BuChE}, \mathrm{IC}_{50}=42.7 \mathrm{nM}\right.$; $\left.\mathrm{hAChE}, \mathrm{IC}_{50}=922 \mathrm{nM}\right)$. Considering that indirectly enhancing endocannabinoid signaling by FAAH inhibitors might be preventing or slowing the progression of neurodegenerative disorders such as Alzheimer's disease, I27 may be a valuable candidate for $\mathrm{AD}$ treatment.

Podophyllotoxin is a natural lignin that is isolated from the roots of Podophyllum hexandrum. Podophyllotoxin and its derivatives could exert antiproliferative activity by inhibiting tubulin polymerization, while epipodophyllotoxins and its derivatives could inhibit topoisomerase II. So far, some podophyllotoxin-/epipodophyllotoxin-derived therapeutic agents such as teniposide and etoposide have already entered into clinical use for the treatment of cancer. Diversification of podophyllotoxin by click chemistry has been reported to generate derivatives with increasing inhibitory activity whereas reducing toxicity. For example, $4 \alpha$-podophyllotoxin-triazole J1 could exert broad-spectrum inhibitory activity against a panel of cancer cell lines (A549, PC-3, MCF-7, U251, SKBR-3, and LNCaP) with $\mathrm{IC}_{50}$ values in the range of $19.6-42.9 \mathrm{nM}$ (Figure 11). Moreover, it could effectively overcome drug resistance, and showed weak cytotoxicity in non-cancer cells. Preliminary mechanistic studies implied that J1 could interact with microtubule, arrest cell cycle (G2/M phase) and induce cell apoptosis in PC-3 cells (Hou et al., 2019c). Kamal et al. reported that epipodophyllotoxin-triazole J2 $\left(\mathrm{IC}_{50}=0.70-4.11 \mu \mathrm{M}\right)$ could exert potent inhibitory activity against a panel of cancer cell lines (A549, MCF-7, DU-145, Hela, HepG2, and HT-29) with weak cytotoxic activity in normal NIH/3T3 cells $\left(\mathrm{IC}_{50}=89.04 \mu \mathrm{M}\right)$ (Reddy et al., 2018). Mechanistic studies indicated that J2 could inhibit topoisomerase II, arrest cell cycle (G2/M phase), and effectively induce apoptosis of the tested DU-145 cells. Hui et al. reported that podophyllotoxin-triazole-coumarin hybrid J3 $\quad\left(\mathrm{IC}_{50}=\right.$ 4.9-17.5 $\mu \mathrm{M})$ could exert more potent inhibitory activity than the etoposide $\left(\mathrm{IC}_{50}=10.5-25.6 \mu \mathrm{M}\right)$ in a panel of cancer cell lines including A549, HepG2, HeLa, and LoVo (Hao et al., 2019). Mechanistic studies indicated that $\mathbf{J 3}$ could bind to CT DNA, disrupt microtubules, arrest cell cycle (G1 phase) and inhibit Topo-II $\beta$.

Podophyllotoxin-triazole-sugar hybrids also possess promising inhibitory activity against various cancer cells. For example, Jiang et al. reported that hybrid J4, which bearing a perbutylated $\alpha$-D-(+)-galactosyl residue could exert promising 


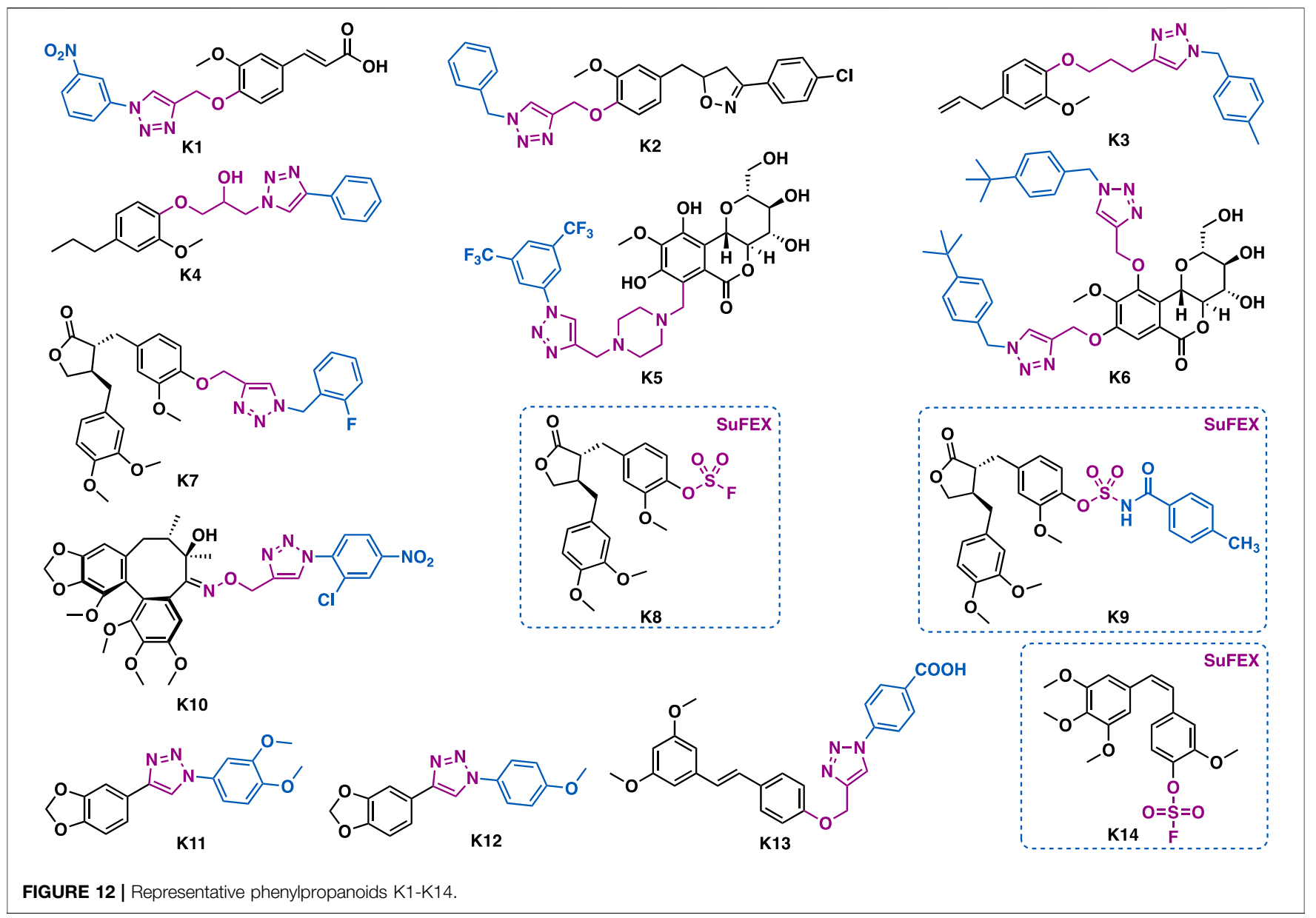

inhibitory activity against a panel of cancer cell lines (A-549, HL-60, MCF-7, SMMC-7721, and SW480) with $\mathrm{IC}_{50}$ values in the range of $0.49-6.70 \mu \mathrm{M}$, ( $\mathrm{Zi}$ et al., 2015), which is more potent than or comparable to the reference drugs etoposide and cisplatin. SAR studies indicated that the spacer between triazole and sugar residue, as well as a 4'- hydroxyl group of podophyllotoxin scaffold that might play a key role in exerting the potent activity. Derivative $\mathrm{J} 5$, which bearing a 1,6- $\beta$-D-di-glucose residue could exert potent inhibitory activity against the tested HL-60, SMMC-7721, A549, MCF7 , and SW480 cancer cells with $\mathrm{IC}_{50}$ values in the range of $0.67-7.41 \mu \mathrm{M}$ (Zi et al., 2017). Hu et al. reported that bistriazole-tethered bis-epipodophyllotoxin-glucose $\mathrm{J} 6\left(\mathrm{IC}_{50}=\right.$ $0.43-3.50 \mu \mathrm{M})$ could exert more potent inhibitory activity than cisplatin $\left(\mathrm{IC}_{50}=1.67-10.85 \mu \mathrm{M}\right)$ in several cancer cell lines including HL-60, SMMC-7721, A549, MCF-7 and SW480 with low toxicity (normal BEAS-2B cells, $\mathrm{IC}_{50}=15.38 \mu \mathrm{M}$; SI = 4.4-35.8) (Zi et al., 2018).

Ferulic acid is an abundant phenolic phytochemical found in plant cell walls. Abid et al. reported that ferulic acid-triazole K1 could exert selective inhibitory activity against carbonic anhydrase IX (CA IX) $\left(\mathrm{IC}_{50}=24 \mathrm{nM}\right.$ ) (Figure 12) (Aneja et al., 2020). Further studies indicated that K1 could inhibit colony formation and cell migration, downregulate CA IX expression, decrease epithelial to mesenchymal transition (EMT), and induce apoptosis in HepG2 cancer cells.

Eugenol is the principal active component of clove oil. Eugenoltriazoles possess several biological activities such as anticancer and anti-parasitic activities. Morjani et al. reported that eugenoltriazole K2 could exert broad-spectrum antiproliferative activity against a panel of cancer cell lines including HT1080, A549, MCF7 , and MDA-MB-231 with $\mathrm{IC}_{50}$ values in the range of 15.31-23.51 $\mu \mathrm{M}$ (Taia et al., 2020). Teixeira et al. reported that eugenol-triazole $\mathrm{K} 3$ could not only exert extracellular leishmanicidal activities $\left(\mathrm{IC}_{50}=7.4 \mu \mathrm{M}\right)$ (Teixeira et al., 2018), but also intracellular leishmanicidal activities against leishmania parasites inside peritoneal macrophages $\left(\mathrm{IC}_{50}=1.6 \mu \mathrm{M}\right)$ without interfering with the viability of macrophages $\left(\mathrm{IC}_{50}=211.9 \mu \mathrm{M} ; \mathrm{SI}=\right.$ 132.5). Notably, it was more potent than clinical drugs glucantime and pentamidine. De Souza et al. reported that dihydroeugenoltriazole $\mathrm{K} 4\left(\mathrm{IC}_{50}=42.8 \mu \mathrm{M}\right)$ could exert comparable trypanocidal activity to the reference drug benznidazole against the epimastigote forms of Trypanosoma cruzi (T. cruzi., Y strain) with low toxicity (Souza et al., 2020). In vivo data showed that $\mathrm{K} 4(100 \mathrm{mg} / \mathrm{kg}$, p. o.) could reduce more than $50 \%$ of the parasitemia in T. cruzi infected mice.

Bergenin, a dihydroisocoumarin, has been reported to have various biological activities such as anti-HIV, neuroprotective, 
<smiles>CC12CCC3C(CC=C4CC(OC(=O)Cn5cc(CN6C(=O)C(=O)c7c(Cl)ccc(Cl)c76)nn5)CCC43C)C1CCC2=O</smiles>

L1<smiles>CC12CCC3C(CC=C4C[C@@H](O)CC[C@]43C)C1CC(=Cc1cn(-c3ccc(I)cc3)nn1)C2=O</smiles>

L2<smiles>CCc1ccc(-c2cn([C@@H]3C[C@H]4CCc5cc(OCc6ccccc6)ccc5C4CC[C@@]3(C)O)nn2)cc1</smiles>

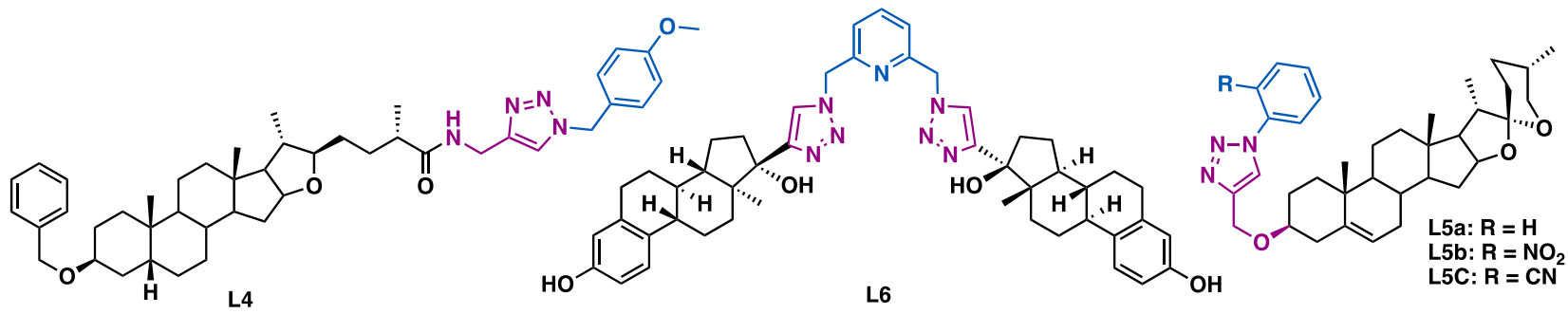

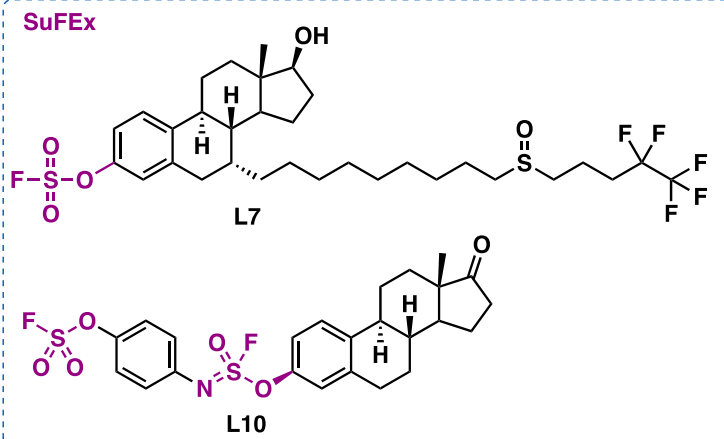<smiles>CC12CCC3c4ccc(NS(=O)(F)(F)F)cc4CCC3C1CCC2=O</smiles>

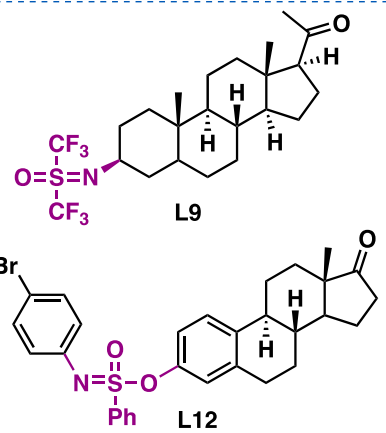

FIGURE 13 | Representative steroids derivatives.

and anticancer activities (Bajracharya, 2015). Babu et al. reported that derivative $\mathrm{K} 5$ could inhibit the growth of $\mathrm{A} 549\left(\mathrm{IC}_{50}=\right.$ $1.86 \mu \mathrm{M})$ and HeLa $\left(\mathrm{IC}_{50}=1.33 \mu \mathrm{M}\right)$ cells (Pavan Kumar et al., 2019), and that was comparable to doxorubicin. Mechanistic studies indicated K5 could arrest cell cycle (G2/M phase) and induce apoptosis in Hela cells. Moreover, it could inhibit the polymerization of tubulin and disrupt the balance of intracellular tubulin-microtubule. Yang et al. reported that $\mathrm{K} 6\left(\mathrm{IC}_{50}=\right.$ 6.2-17.6 $\mu \mathrm{M}$ ) could exert more potent inhibitory activity than the parental bergenin against EC9706, B16 and MGC803 cancer cells (Yang et al., 2015). In addition, it $\left(\mathrm{IC}_{50}=6.2 \mu \mathrm{M}\right)$ could exert comparable inhibitory activity to 5-fluorouridine $\left(\mathrm{IC}_{50}=6.3 \mu \mathrm{M}\right)$ in EC9706 cancer cells.

Arctigenin is a lignan that is isolated from the dry ripe fruit of Arctium lappa. Quan et al. reported that arctigenin-triazole K7 could exert more potent and selective anti-Toxoplasma gondii activity (Toxoplasma gondii, $\mathrm{IC}_{50}=17.1 \mu \mathrm{M} ;$ Hela, $\mathrm{IC}_{50}=$ $600 \mu \mathrm{M} ;$ SI $=35.09)$ than both of the lead arctigenin (Toxoplasma gondii, $\mathrm{IC}_{50}=586.4 \mu \mathrm{M} ;$ Hela, $\mathrm{IC}_{50}=572.7 \mu \mathrm{M}$; $\mathrm{SI}=0.98$ ) than the reference drug spiramycin (Toxoplasma gondii, $\mathrm{IC}_{50}=262.2 \mu \mathrm{M} ;$ Hela, $\mathrm{IC}_{50}=189.0 \mu \mathrm{M} ;$ SI = 0.72).(Zhang H.-b. et al., 2018). By using sulfur (VI) exchange chemistry, Zhang et al. synthesized derivatives K8 and K9 (Zhang S. et al., 2019), and preliminary in vitro data indicated that these compounds could exert good anti-inflammatory activity.

Babu et al. reported that dibenzoclooctene type natural product gomisin B-triazole K10 could exert broad-spectrum antiproliferative activity against a panel of cancer cell lines including A549, DU-145, MDA-MB-231, PANC1, IMR32, and SIHA cells $\left(\mathrm{IC}_{50}=0.24-12.8 \mu \mathrm{M}\right)$. Particularly, it could exert submicromolar inhibitory activity against SIAH cells $\left(\mathrm{IC}_{50}=\right.$ $0.24 \mu \mathrm{M}$ ), (Poornima et al., 2017), and it was more potent than that of the parental Gomisin $\mathrm{B}\left(\mathrm{IC}_{50}=51.2-66.8 \mu \mathrm{M}\right)$. Mechanistic studies indicated that it could stall cell cycle (G2/ $\mathrm{M}$ phase) and promote tubulin polymerization in the tested HeLa cells.

Machilin G is a natural lignan that is isolated from Magnolia denudate. Replacement of the tetrahydrofuran ring of machilin with 1,2,3-triazole, the resulting mimic $\mathrm{K} 11\left(\mathrm{IC}_{50}=1.1 \mu \mathrm{M}\right)$ could exert 8-fold more potent inhibitory activity than the recommended drug pentamidine $\left(\mathrm{IC}_{50}=8.9 \mu \mathrm{M}\right)$ against promastigote form of L. amazonensis (Cassamale et al., 2016). Moreover, it $\left(\mathrm{NIH} / 3 \mathrm{~T} 3, \mathrm{IC}_{50}=768.5 \mu \mathrm{M}\right.$; SI $\left.=698.6\right)$ showed a higher selectivity index than that of pentamidine $\left(\mathrm{NIH} / 3 \mathrm{~T} 3, \mathrm{IC}_{50}\right.$ $=78.7 \mu \mathrm{M}$; SI $=8.8$ ), while derivative $\mathrm{K} 12$ could exert selective inhibitory activity against Trypanosoma cruzi trypomastigotes with an $\mathrm{IC}_{50}$ value of $28.6 \mu \mathrm{M}$ and SI value of 29.6.

Pterostilbene is a bioactive natural stilbenoid that is isolated from blueberries and Pterocarpus marsupium heartwood. Structurally, it is very similar to resveratrol, a healthy benefiting compound that is rich in red wine. Diversification of pterostilbene by $\mathrm{CuAAC}$ could generate derivatives with improved antibacterial activity. For example, derivative K13 could exert potent antibacterial activity against methicillin- 
resistant Staphylococcus aureus (MRSA) with an MIC value of $1.2-2.4 \mu \mathrm{g} / \mathrm{ml}$ and a minimum bactericidal concentration (MBC) of $19.5-39 \mu \mathrm{g} / \mathrm{ml}$, (Tang et al., 2019), while the MIC value of pterostilbene is $41-161.5 \mu \mathrm{g} / \mathrm{ml}$. Mechanistic studies indicated that it could inhibit DNA polymerase, but not the bacterial cell membrane and cell wall.

Combretastatin A-4 (CA-4) is a stilbenoid phenolic natural product that is isolated from the African willow tree, Combretum caffrum (Shan et al., 2011). It can exert potent reversible inhibitory activity in the polymerization of tubulin. Structural modifications of CA-4 have yielded several novel CA-4 derivatives with potent tubulin inhibitory activity. Taking advantage of the powerful sulfur (IV) fluoride exchange (SuFEX) click chemistry, Wu et al. synthesized the fluorine sulfonate CA-4 K14 $\left(\mathrm{IC}_{50}=8.9 \mu \mathrm{M}\right)$, which could exert 70fold more potent inhibitory activity than the parental CA-4 against drug in HT-29 cells $\left(\mathrm{IC}_{50}=8.9 \mu \mathrm{M}\right)$ (Liu et al., 2018).

\section{CLICK CHEMISTRY-BASED MODIFICATION OF STEROIDS}

Steroids are series of naturally occurring compounds that are ubiquitously distributed in animals, plants and fungi, etc. They can act as signaling molecules or as key components of cell membranes. Derivatization of steroids by click chemistry can quickly generate novel molecules with new functions for drug discovery.

Dehydroepiandrosterone is a unique active substance found in sweet potato and yam. Dehydroepiandrosterone derivatives containing triazole at the $\mathrm{C} 3$ and/or $\mathrm{C} 16$ could exert antiproliferative effects. By molecular hybridization of dehydroepiandrosterone and isatin, Liu et al. synthesized hybrid L1 (Figure 13) (Yu et al., 2016), which could exert comparable inhibitory activity $\left(\mathrm{IC}_{50}=4.06 \mu \mathrm{M}\right)$ to the reference drug 5-fluorouracil $\left(\mathrm{IC}_{50}=3.26 \mu \mathrm{M}\right)$ in SH-SY5Y cancer cells. Mechanistic studies indicated that L1 could potently inhibit LSD1 $\left(\mathrm{C}_{50}=3.18 \mu \mathrm{M}\right)$, decrease mitochondrial membrane potential, arrest cell cycle (G2/M phase), and induce cell apoptosis. Notably, L1 is the first steroid-based lysine-specific demethylase (LSD1) inactivator. Quan et al. reported that C16 dehydroepiandrosterone-triazole L2 could inhibit the growth of HepG-2 $\left(\mathrm{IC}_{50}=9.18 \mu \mathrm{M}\right)$ and MCF-7 $\left(\mathrm{IC}_{50}=\right.$ $9.18 \mu \mathrm{M})$ cancer cells by arresting cell cycle (G2 phase) and inducing cell apoptosis (Huang X. et al., 2018). Mernyák et al. reported that $\mathrm{C} 16 \alpha$-estrone-triazole $\mathrm{L} 3\left(\mathrm{IC}_{50}=2.6-6.5 \mu \mathrm{M}\right)$ could exert broad-spectrum antiproliferative activities against a panel of cancer cell lines including HeLa, MCF-7, A431, A2780, T47D (expressing androgen, progesterone and estrogen receptors), MDA-MB-231 (expressing HER2 and estrogen receptor) and triple-negative MDA-MB-361 (Mernyák et al., 2015), and it was comparable to or better than the reference drug cisplatin $\left(\mathrm{IC}_{50}=1.3-19.1 \mu \mathrm{M}\right)$. Mechanistic studies indicated that $\mathrm{L} 3$ could induce apoptosis by the intrinsic pathway.

Sarsasapogenin is one of the active ingredients that is isolated from Rhizoma anemarrhenae. Song et al. reported that sarsasapogenin-triazole L4 could inhibit the aggregation of
$\mathrm{A} \beta_{1-42}\left(\mathrm{IC}_{50}=5.84 \mu \mathrm{M}\right)$ (Wang W. et al., 2018). Moreover, in vitro data indicated that $\mathrm{L} 4$ could exert moderate neuroprotective effects against $\mathrm{H}_{2} \mathrm{O}_{2}$-induced neurotoxicity in SH-SY5Y cells. Further in vivo studies showed that L4 $(17.5 \mathrm{mg} / \mathrm{kg}$, p. o.) could significantly ameliorate cognitive impairments in behavioral tests, and it was comparable to or better than the reference drug cisplatin.

Diosgenin, is a steroidal sapogenin that isolated from Dioscorea deltoidei. Structurally, it is similar to cholesterol and other steroids. Ara et al. reported that diosgenin-triazole hybrids L5a $\left(\mathrm{IC}_{50}=5.54-10.33 \mu \mathrm{M}\right), \mathrm{L} 5 \mathrm{~b}\left(\mathrm{IC}_{50}=5.77-8.67 \mu \mathrm{M}\right)$ and $\mathrm{L} 5 \mathrm{c}$ $\left(\mathrm{IC}_{50}=6.33-9.44 \mu \mathrm{M}\right)$, bearing simple phenyl moiety at the C4' of the triazole moiety, could inhibit the growth of A549, HCT-116, HT-29, and HBL-100 cancer cell lines (Masood-ur-Rahman et al., 2017).

Sedlák et al. reported the triazole tethered estradiol dimers L6 $\left(\mathrm{IC}_{50}=0.49-3.65 \mu \mathrm{M}\right)$ could exert potent inhibitory activity in a panel of cancer cell lines including A549, HeLa, HCT116, K562, K562-Tax (Paclitaxel resistant), CCRF-CEM (childhood T acute lymphoblastic leukemia), U2OS, and HCT116p53/(null p53 gene) by inhibiting tubulin polymerization (Jurášek et al., 2018).

Taking advantage of the emerging SuFEx click chemistry, several steroid derivatives such as fluorosulfate L7 (Liu et al., 2018), iminosulfur oxydifluoride L8 (Li S. et al., 2017), bis(trifluoromethyl)sulfur oxyimine L9 (Smedley et al., 2019), sulfurofluoridoimidate L10 (Li S. et al., 2017), sulfonimidoyl fluoride L11 and sulfonimidate L12 have been synthesized by using $\mathrm{SO}_{2} \mathrm{~F}_{2}$ or its sister gas $\mathrm{SOF}_{4}$ as key reagents in the presence of tertiary amine additives (e.g., TEA, DIPEA, DBU) (Li S. et al., 2017; Gao et al., 2018; Smedley et al., 2019). Among them, the fluorosulfate version of fulvestrant $\mathrm{L} 7\left(\mathrm{IC}_{50}=4.8-5.5 \mathrm{nM}\right)$ could exert more potent inhibitory activity than fulvestrant $\left(\mathrm{IC}_{50}=\right.$ 7.7-14.8 nM). Notably, its inhibitory activity was $\mathrm{ER}^{-}$dependent $\left(\mathrm{MCF} 7, \mathrm{IC}_{50}=5.5 \mathrm{nM} ; \mathrm{ER}^{-} \mathrm{MCF} 7, \mathrm{IC}_{50}>10,000 \mathrm{nM}\right)$. The biological activities of the other SuFEx click chemistry steroid derivatives are yet to report.

\section{CLICK CHEMISTRY-BASED MODIFICATION OF XANTHONES AND QUINONES}

Xanthones is a series of bioactive substance that can be readily obtained from plants and/or microorganisms. The key structural feature of these compounds is a biphenyl pyranone containing a planar three-ring system. Yu et al. reported that M1 could exert inhibitory activity against $\mathrm{A} 549$ cells $\left(\mathrm{IC}_{50}=32.4 \mu \mathrm{M}\right)(\mathrm{Wu}$ et al., 2019). Western blotting data indicated that M1 could significantly upregulate protein levels of caspase 3, Bax, c-Jun N-terminal kinase, and also p53 in A549 cells (Figure 14). Zhang et al. reported that gambogic acid-triazole $\mathrm{M} 2\left(\mathrm{IC}_{50}=0.31-3.79 \mu \mathrm{M}\right)$ could exert sustained cytotoxicity against a panel of cancer cell lines (U2OS, HepG2, A549, and HCT116) and two drug resistant cancer cell lines (Taxol-resistant or cisplatin-resistant A549 cells) with improved aqueous solubility and permeability ( $\mathrm{Li} \mathrm{X}$. et al., 2017). Notably, it could exert in vivo antitumor activity in A549-transplanted mice models. 
<smiles>O=c1c2ccccc2oc2cc(OCc3cn(Cc4ccc(Br)cc4)nn3)cc(O)c12</smiles><smiles>CCc1ccc(-c2cn(CCNC3=C(C)C(=O)c4ccccc4C3=O)nn2)cc1</smiles>

M4<smiles>COc1ccc(-n2cc(-c3cc4c(o3)C(=O)c3ccccc3C4=O)nn2)cc1</smiles><smiles>O=C1C(=O)c2ccccc2C2=C1CC(Cn1cc(C[Se]c3ccccc3)nn1)O2</smiles>

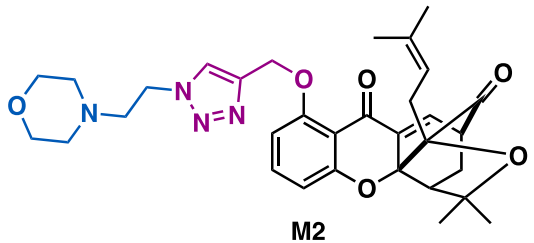<smiles>O=C1C=C(NCc2cn(-c3ccc(C(F)(F)F)cc3)nn2)C(=O)c2ccccc21</smiles>

M5<smiles>COc1ccc(-n2cc(C3CC4=C(O3)c3ccccc3C(=O)C4=O)nn2)cc1</smiles>

M8

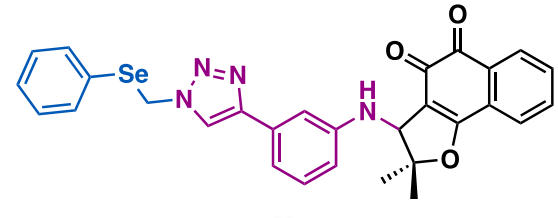<smiles>CC(=O)OCC1OC(n2cc(COC3=CC(=O)c4ccccc4C3=O)nn2)[C@H](OC(C)=O)[C@@H](OC(C)=O)[C@@H]1O</smiles>

M3<smiles>O=Cc1ccccc1OCc1cn(Cc2ccc3c(c2)C(=O)c2ccccc2C3=O)nn1</smiles>

M6<smiles>Cc1ccc(-c2cn(CC3CC4=C(O3)c3ccccc3C(=O)C4=O)nn2)cc1</smiles><smiles>CC1(C)OC2=C(C(=O)c3ccccc3C2=O)[C@@H](n2nncc2-c2ccccc2)[C@@H]1Br</smiles>

FIGURE 14 | Representative xanthone and quinone derivatives.

Quinone is a privileged pharmacophore that presents in many bioactive natural products, such as mitomycin, saintopin, and doxorubicin. Its various promising biological activities might attribute to i) its ability to generate ROS, which usually leads to the damage of DNA, and ii) its ability to electrophilic arylation of critical cellular nucleophiles. Thus, the derivatization of quinone by using click chemistry would quickly generate molecules with desirable functions.

Lawsone is a natural bioactive quinone that is isolated from genus Lawsonia. Alves et al. reported that Lawsone-glycosyl triazole M3 could exert promising inhibitory against SKBR-3 cells $\left(\mathrm{IC}_{50}=0.78 \mu \mathrm{M}\right)$ with good selectivity index (normal HGF cell, $\mathrm{IC}_{50}=17.65 \mu \mathrm{M}, \mathrm{SI}=22.6$ ) (Ottoni et al., 2020). It is more potent than lawsone $\left(\mathrm{IC}_{50}>50 \mu \mathrm{M}\right)$, which could be ascribed to the introduction of the peracetylated D-glucose to the hybrid M3, thereby generating a more favorable lipophilic-hydrophilic balance and being absorbed by tumor cells more easily.

Naphthoquinone-triazole hybrid M4 could exert inhibitory activity against DU-145, Hela, A549, and MCF-7 cancer cell lines $\left(\mathrm{IC}_{50}=8.02-26.12 \mu \mathrm{M}\right)$, (Prasad et al., 2018), and that was comparable to the reference drug tamoxifen $\left(\mathrm{IC}_{50}=\right.$ 10.87-18.63 $\mu \mathrm{M})$. Mechanistic studies implied that M4 could arrest cell cycle (G0/G1 phase) and induce apoptosis in MCF7 cancer cells. While, naphthoquinone-triazole $\mathrm{M} 5\left(\mathrm{IC}_{50}=\right.$ 6.8-10.4 $\mu \mathrm{M}$ ) could exert broad-spectrum inhibitory activity against HT-29, MOLT-4, and MCF-7 cancer cell lines
(Gholampour et al., 2019), and could arrest cell cycle (G0/G1 phase) in the tested MCF-7 cells.

Anthraquinone has the structural core of anthracycline. Meng et al. reported that anthraquinone-triazole derivative $\mathrm{M} 6\left(\mathrm{IC}_{50}=\right.$ $0.6 \mu \mathrm{M})$ could exert more potent inhibitory against xanthine oxidase_ a well-known target for the treatment of hyperuricemia and gout, than the reference allopurinol $\left(\mathrm{IC}_{50}=\right.$ $9.8 \mu \mathrm{M}$ ) (Zhang et al., 2017). SAR studies revealed that the benzaldehyde moiety might play a more important role than the anthraquinone moiety in its inhibitory potency.

The 1,4-furanaphthoquinone-triazole hybrid M7 ( $\mathrm{IC}_{50}$ : 81.81-99.56 $\mu \mathrm{M})$ and its regioisomer 1,2-furanaphthoquinonetriazole hybrid $\mathrm{M} 8\left(\mathrm{IC}_{50}: 23.04-41.10 \mu \mathrm{M}\right)$ could only exhibit moderate inhibitory activity against MDA-MB-231 and CaCo-2 cancer cells (Costa et al., 2018), whereas 1,2-furanaphthoquinonetriazole M9 ( $\left.\mathrm{IC}_{50}: 0.74-1.77 \mu \mathrm{M}\right)$ could exert superior cytotoxic activity against HCT-116 and MCF-7 cancer cells (Chipoline et al., 2018), and the selenium version hybrid M10 ( $\mathrm{IC}_{50}: 0.07-0.29 \mu \mathrm{M}$ ) and M11 ( $\mathrm{IC}_{50}: 0.07-0.38 \mu \mathrm{M}$ ) showed high activity against HL-60, PC3, HCT-116, SF295, OVCAR-8, and MDA-MB-435 cancer cell lines (da Cruz et al., 2016). Mechanistic studies revealed that their apoptosis effect was associated with ROS production. The 1,2-naphthoquinonetriazole $\mathrm{M} 12\left(\mathrm{IC}_{50}=0.41-1.59 \mathrm{mM}\right)$ bearing an pyran fragment also showed good inhibitory potency against PC3, HL-60, SF-295, HCT116 and MDA-MB-435 cancer cells (Bahia et al., 2016). 


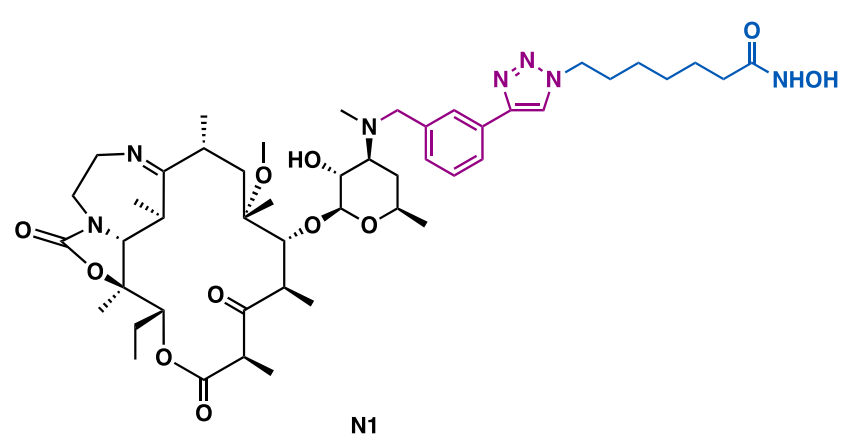

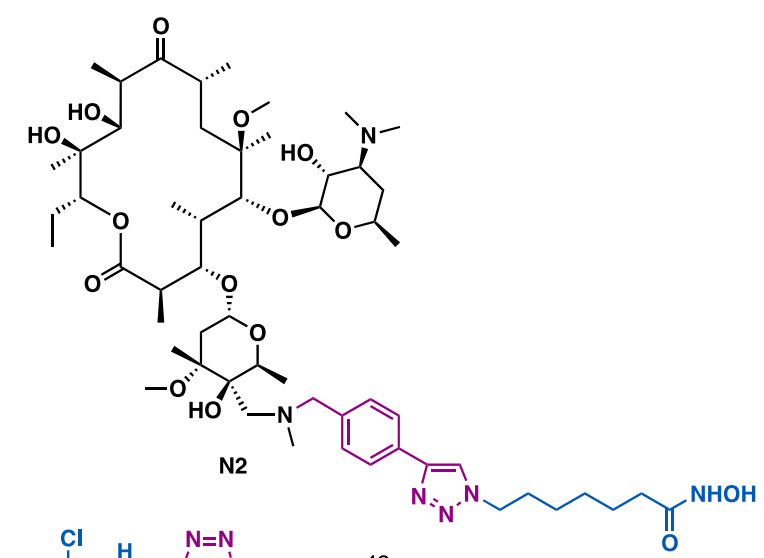

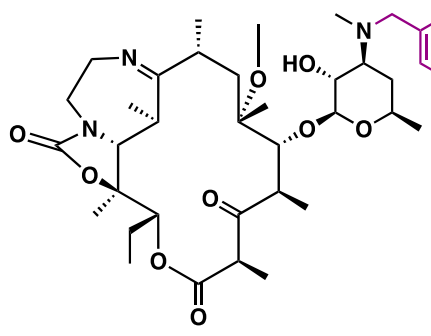

N3

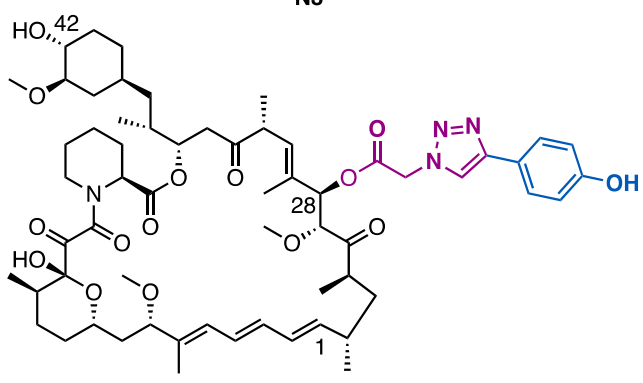

N5

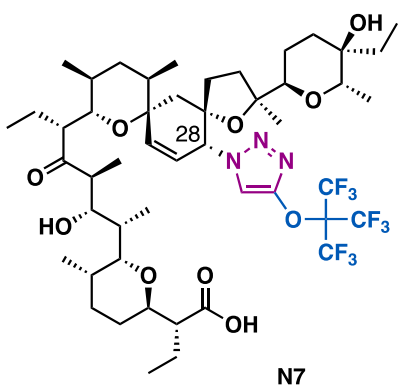<smiles>Cc1cn(CCCCCCC(=O)O)nn1</smiles>

\section{$\mathrm{Cl}$}

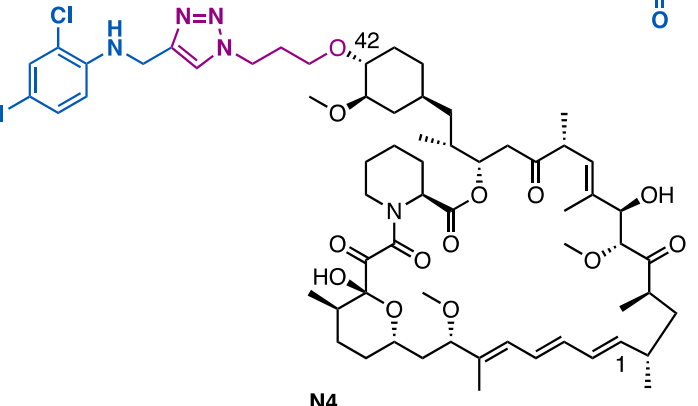

N4

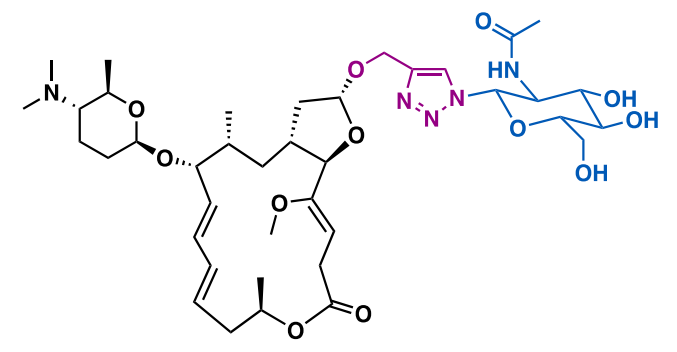

N6

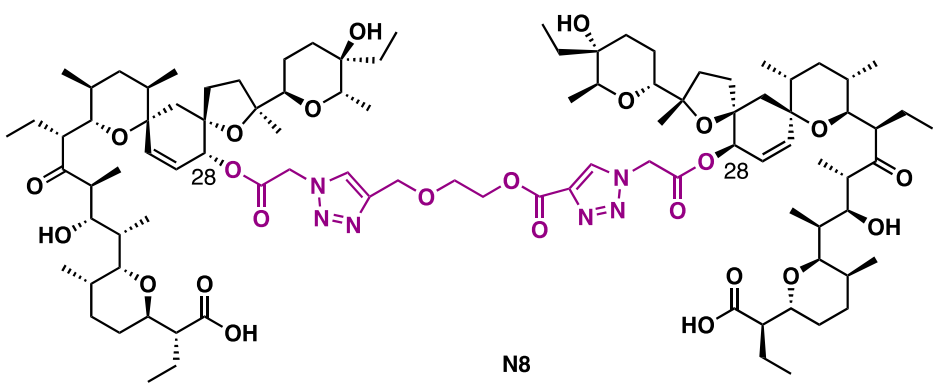

FIGURE 15 | Representative macrocyclic derivatives.

\section{CLICK CHEMISTRY-BASED MODIFICATION OF MACROCYCLIC NATURAL PRODUCTS}

Peptidic macrocyclic histone deacetylases inhibitors (HDACi) contain diverse cap groups that are capable of producing the optimal interactions with amino acid residues that surround the entrance of the HDAC active site, thereby modulating the biological activities of these HDACis. Although they usually could exert nanomolar inhibitory activity against HDACs, their further clinical development has been hindered greatly due to the difficulty in the synthesis of cyclic peptide frameworks for SAR studies. With the aim to solve these drawbacks, Oyelere et al. chose 14-membered macrolide clarithromycin to mimic the peptidic framework of macrocyclic HDACis'. The results indicated that macrolide is a good mimic of the peptide framework. For example, hybrids N1, $\mathrm{N} 2$, and N3, could exert moderate HDAC-6 inhibitory activity 
with $\mathrm{IC}_{50}$ values of 3.76, 2.85, and $6.99 \mu \mathrm{M}$ (Figure 15) (Tapadar et al., 2015), respectively. Hybrid $\mathrm{N} 1\left(\mathrm{IC}_{50}=0.86 \mu \mathrm{M}\right)$ and $\mathrm{N} 2$ $\left(\mathrm{IC}_{50}=0.69 \mu \mathrm{M}\right)$, both bearing a zinc chelating hydroxamate moiety, could exert potent antiproliferative activity against MCF7 cancer cells, while hybrid N2, which contains a para zinc chelating hydroxamate moiety, could exert potent antiinflammatory activity (NF- $\kappa$ B inhibition, $\mathrm{IC}_{50}=47.2 \mathrm{nM}$ ).

Due to the complex structure of rapamycin, CuAAC appears to be the best strategy for the generation of novel rapamycin derivatives. For example, C42 rapamycin-triazole $\mathrm{N} 4\left(\mathrm{IC}_{50}=\right.$ $6.05-25.88 \mu \mathrm{M})$ could exert more potent inhibitory against H1299, MGC-803, H460, and Caski cancer cells than that of rapamycin $\left(\mathrm{IC}_{50}=18.74-35.13 \mu \mathrm{M}\right)$ (Xie et al., 2016). Mechanism studies indicated that N4 could cause the change of cell morphological, and induce apoptosis of the tested Caski cells. Moreover, it could inhibit the mTOR signaling by downregulating mTOR phosphorylation and its downstream key proteins, P70S6K1 and S6. Thus, N4 may have the potential to serve as a new mTOR inhibitor. C28 rapamycin-triazole $\mathrm{N5}\left(\mathrm{IC}_{50}=12.8-14.8 \mu \mathrm{M}\right)$ could also exert more potent inhibitory against A549, 769-P, ECA-109, and Caski cancer cells than rapamycin $\left(\mathrm{IC}_{50}=\right.$ 12.3-24.5 $\mu \mathrm{M}$ ) (Huang Q. et al., 2018). Mechanistic studies indicated that N5 could inhibit the mTOR signaling by downregulating mTOR phosphorylation and its downstream key proteins such as P70S6K1 and 4EBP1.

Spiramycin is a natural antibiotic that is produced by Streptomyces ambofaciens. Spiramycin-triazole$N$-acetylsaccharide N6 could exert potent antibacterial activity against a panel of bacterial strains (B. subtilis, M. luteus, S. epidermidis, and $S$. pneumoniae) with MIC values in the range of $1-4 \mu \mathrm{g} / \mathrm{ml}$ (Klich et al., 2016). Salinomycin-triazole hybrid N7 could exert low micromolar inhibitory against Hela $\left(\mathrm{IC}_{50}=\right.$ $0.29 \mu \mathrm{M})$ and $\mathrm{Caco} 2\left(\mathrm{IC}_{50}=0.44 \mu \mathrm{M}\right)$ cancer cells (Shi et al., 2016), and the dimer N8 could exert submicromolar inhibitory activity against MCF-7 cancer cells $\left(\mathrm{IC}_{50}=0.60 \mu \mathrm{M}\right)$ (Huang et al., 2017). Notably, both of them were more potent than that of parental salinomycin $\left(\mathrm{IC}_{50}=0.32-12.99 \mu \mathrm{M}\right)$.

\section{CONCLUSION REMARKS AND FUTURE PERSPECTIVES}

As natural products are usually complex molecules with little modification space and some of them even contain labile functionalities, the structural modification of natural products with the aim to optimize their drawbacks or the construction of natural product-like drug screening libraries are the most fascinating challenges in organic synthesis. Therefore, the development of synthetic toolboxes that facilitates efficient access to the molecular diversity and unique functions of natural products is highly desirable. One such, perhaps the most successful toolbox is click chemistry, which enables the ready synthesis of a diverse set of natural product derivatives, especially the 1,2,3-triazole derivatives of terpenoids, alkaloids, steroids etc., in a highly efficient manner. Beyond the optimization of the original biological activity and the improvement of kinetics and drug-like properties, many of these derivatives have been endowed with new functions, and thereby could serve as an inexhaustible source for discoveries in drug development. In addition, click chemistry, especially the CuAAC reaction, have also been widely used in the synthesis of homodimers or heterodimers of natural products even in the presence of labile functionalities, mainly due to their high orthogonality reaction properties as compared to other chemistries such as the synthesis of amides and esters. Nevertheless, to fully utilize the power of click chemistry in natural product-based drug discovery, there remain several issues and new directions for future research in the area.

1) One of the most important merits of click chemistry is modular synthesis, which can quickly generate diverse libraries of large numbers of new compounds. However, as we can see from Figure 1, there are usually only a limited number of click chemistry derivatives that have been synthesized and screened for their functions. Thus, it would be impossible to probe the desired chemical space to generate ideal hit compounds. The reason is probably that most of the click chemistry building blocks are commercially unavailable and must be prepared. Fortunately, a 2019 paper reported a perfect solution for the synthesis of various azides by using fluorosulfuryl azide as an efficient diazo transfer reagent (Meng et al., 2019). In the future, the rational design and synthesis of modular natural product building blocks with functionalities that can react with other click chemistry building blocks in large numbers would be a useful strategy to probe the large chemical space.

2) As we can see from Figure 1, about $68 \%$ of click chemistry natural product derivatives have only been selected for anticancer activity, and thus their other functions are missing. In the future, it is important to be aware of the selection of the multiple functions of the natural product click chemistry derivatives against different phenotypes or targets.

3) As most of the natural product-triazole derivatives were screened by phenotypic screening (91\%, Figure 1), therefore, their exact molecular targets are ambiguous. In the future, the rational design of target-based selection systems for natural product click chemistry libraries will be an important research area.

4) Beyond CuAAC click chemistry, which generates 1,2,3triazole derivatives, some other emerging click chemistries like SuFEX chemistry have already shown their power in the generation of valuable hit molecules, and thus also could be used in natural product modification in the future.

5) Notably, another powerful hit screening technology DNAencoded library (DEL), and especially the natural product DNA-encoded library ( $n \mathrm{DEL})$, have already shown their power in the screening of some challenge protein targets (Ma et al., 2019; Xie et al., 2020). So, if we can connect natural products with DNA-encoded libraries and diversify them by click chemistry, we could quickly generate a huge natural product derivative library with unprecedented skeleton diversity. In addition, as DEL selection is affinitybased screening, the exert molecular target of the identified hit 
compounds are clearly after they have been deconvoluted from the screened DEL library.

6) Because most of the natural product click chemistry derivatives were only tested in in vitro assays, their metabolic, pharmacodynamic, and toxicity profiles should be carefully studied in the future. For example, a recent paper reported that 1H-1,2,3-triazole containing anticancer chemotherapeutic might potentially lead to cardiotoxicity by the impairment of mitochondria (Stephenson et al., 2020).

\section{AUTHOR CONTRIBUTIONS}

HX, SZ, and BL conceived the research. HX, SZ, and BL designed the structure of the paper. XZ, SZ, and XW drafted the manuscript. HX, SZ, and BL provided critical revision of this

\section{REFERENCES}

An, R., Hou, Z., Li, J.-T., Yu, H.-N., Mou, Y.-H., and Guo, C. (2018). Design, Synthesis and Biological Evaluation of Novel 4-substituted Coumarin Derivatives as Antitumor Agents. Molecules 23, 2281-2312. doi:10.3390/ molecules23092281

Anand, A., Kulkarni, M. V., Joshi, S. D., and Dixit, S. R. (2016). One Pot Click Chemistry: A Three Component Reaction for the Synthesis of 2mercaptobenzimidazole Linked Coumarinyl Triazoles as Anti-tubercular Agents. Bioorg. Med. Chem. Lett. 26, 4709-4713. doi:10.1016/ j.bmcl.2016.08.045

Aneja, B., Queen, A., Khan, P., Shamsi, F., Hussain, A., Hasan, P., et al. (2020). Design, Synthesis \& Biological Evaluation of Ferulic Acid-Based Small Molecule Inhibitors against Tumor-Associated Carbonic Anhydrase IX. Bioorg. Med. Chem. 28, 115424. doi:10.1016/j.bmc.2020.115424

Anh, D. T. T., Giang, L. N. T., Hien, N. T., Cuc, D. T., Thanh, N. H., Ha, N. T. T., et al. (2017). Synthesis and Cytotoxic Evaluation of Betulin-Triazole-AZT Hybrids. Nat. Product. Commun. 12, 1934578X1701201. doi:10.1177/ $1934578 \times 1701201010$

Artyushin, O. I., Moiseeva, A. A., Zarubaev, V. V., Slita, A. V., Galochkina, A. V., Muryleva, A. A., et al. (2019). Synthesis of Camphecene and Cytisine Conjugates Using Click Chemistry Methodology and Study of Their Antiviral Activity. Chem. Biodivers 16, e1900340. doi:10.1002/cbdv.201900340

Bahia, S. B. B. B., Reis, W. J., Jardim, G. A. M., Souto, F. T., De Simone, C. A., Gatto, C. C., et al. (2016). Molecular Hybridization as a Powerful Tool towards Multitarget Quinoidal Systems: Synthesis, Trypanocidal and Antitumor Activities of Naphthoquinone-Based 5-Iodo-1,4-Disubstituted-, 1,4- and 1,5Disubstituted-1,2,3-Triazoles. Med. Chem. Commun. 7, 1555-1563. doi:10.1039/c6md00216a

Bajracharya, G. B. (2015). Diversity, Pharmacology and Synthesis of Bergenin and its Derivatives: Potential Materials for Therapeutic Usages. Fitoterapia 101, 133-152. doi:10.1016/j.fitote.2015.01.001

Bangalore, P. K., Vagolu, S. K., Bollikanda, R. K., Veeragoni, D. K., Choudante, P. C., Misra, S., et al. (2020). Usnic Acid Enaminone-Coupled 1,2,3-Triazoles as Antibacterial and Antitubercular Agents. J. Nat. Prod. 83, 26-35. doi:10.1021/ acs.jnatprod.9b00475

Barrow, A. S., Smedley, C. J., Zheng, Q., Li, S., Dong, J., and Moses, J. E. (2019). The Growing Applications of SuFEx Click Chemistry. Chem. Soc. Rev. 48, 4731-4758. doi:10.1039/C8CS00960K

Batra, N., Rajendran, V., Agarwal, D., Wadi, I., Ghosh, P. C., Gupta, R. D., et al. (2018). Synthesis and Antimalarial Evaluation of $[1,2,3]$-Triazole-Tethered Sulfonamide-Berberine Hybrids. ChemistrySelect 3, 9790-9793. doi:10.1002/ slct. 201801905

Binh, L. H., Van, N. T. T., Kien, V. T., My, N. T. T., Van Chinh, L., Nga, N. T., et al. (2016). Synthesis and In Vitro Cytotoxic Evaluation of New Triazole article. HX, SZ, and BL supervised the findings of the work and approved the manuscript for submission. All authors agreed with the final version of this manuscript.

\section{FUNDING}

Part of this work is supported by the National Natural Science Foundation of China, China (No. 21977070 and U19A2011).

\section{SUPPLEMENTARY MATERIAL}

The Supplementary Material for this article can be found online at: https://www.frontiersin.org/articles/10.3389/fchem.2021.774977/ full\#supplementary-material

Derivatives Based on Artemisinin via Click Chemistry. Med. Chem. Res. 25, 738-750. doi:10.1007/s00044-016-1524-z

Bistrović, A., Stipaničev, N., Opačak-Bernardi, T., Jukić, M., Martinez, S., GlavašObrovac, L., et al. (2017). Synthesis of 4-Aryl-1,2,3-Triazolyl Appended Natural Coumarin-Related Compounds with Antiproliferative and Radical Scavenging Activities and Intracellular ROS Production Modification. New J. Chem. 41, 7531-7543. doi:10.1039/C7NJ01469D

Boratyński, P. J., Gałęzowska, J., Turkowiak, K., Anisiewicz, A., Kowalczyk, R., and Wietrzyk, J. (2018). Triazole Biheterocycles fromCinchonaAlkaloids: Coordination and Antiproliferative Properties. ChemistrySelect 3, 9368-9373. doi:10.1002/slct.201801810

Boshra, A. N., Abdu-Allah, H. H. M., Mohammed, A. F., and Hayallah, A. M. (2020). Click Chemistry Synthesis, Biological Evaluation and Docking Study of Some Novel 2'-Hydroxychalcone-Triazole Hybrids as Potent Antiinflammatory Agents. Bioorg. Chem. 95, 103505. doi:10.1016/ j.bioorg.2019.103505

Cassamale, T. B., Costa, E. C., Carvalho, D. B., Cassemiro, N. S., Tomazela, C. C., Marques, M. C. S., et al. (2016). Synthesis and Antitrypanosomastid Activity of 1,4-Diaryl-1,2,3-Triazole Analogues of Neolignans Veraguensin, Grandisin and Machilin G. J. Braz. Chem. Soc. 27, 1217-1228. doi:10.5935/01035053.20160017

Chakraborty, B., Dutta, D., Mukherjee, S., Das, S., Maiti, N. C., Das, P., et al. (2015). Synthesis and Biological Evaluation of a Novel Betulinic Acid Derivative as an Inducer of Apoptosis in Human colon Carcinoma Cells (HT-29). Eur. J. Med. Chem. 102, 93-105. doi:10.1016/j.ejmech.2015.07.035

Chinthala, Y., Thakur, S., Tirunagari, S., Chinde, S., Domatti, A. K., Arigari, N. K., et al. (2015). Synthesis, Docking and ADMET Studies of Novel Chalcone Triazoles for Anti-cancer and Anti-diabetic Activity. Eur. J. Med. Chem. 93, 564-573. doi:10.1016/j.ejmech.2015.02.027

Chinthala, Y., K, M., Sharma, P., Kvn, S. S., Jonnala, K., Arigari, N. K., et al. (2016). Synthesis and Cytotoxicity Evaluation of Novel Andrographolide-1,2,3Triazole Derivatives. J. Heterocyclic Chem. 53, 1902-1910. doi:10.1002/ jhet.2505

Chipoline, I. C., Alves, E., Branco, P., Costa-Lotufo, L. V., Ferreira, V. F., and Silva, F. C. D. (2018). Synthesis and Cytotoxic Evaluation of 1H-1,2,3-Triazol-1Ylmethyl-2,3-Dihydronaphtho[1,2-B]furan-4,5-Diones. Acad. Bras. Ciênc. 90, 1027-1033. doi:10.1590/0001-3765201820170698

Chouaïb, K., Delemasure, S., Dutartre, P., and Jannet, H. B. (2016). Microwaveassisted Synthesis, Anti-inflammatory and Anti-proliferative Activities of New Maslinic Acid Derivatives Bearing 1,5- and 1,4-disubstituted Triazoles. J. Enzyme Inhib. Med. Chem. 31, 130-147. doi:10.1080/14756366.2016.1193733

Costa, D. C. S., de Almeida, G. S., Rabelo, V. W.-H., Cabral, L. M., Sathler, P. C., Alvarez Abreu, P., et al. (2018). Synthesis and Evaluation of the Cytotoxic Activity of Furanaphthoquinones Tethered to $1 \mathrm{H}-1,2,3-$ Triazoles in Caco-2, Calu-3, MDA-Mb231 Cells. Eur. J. Med. Chem. 156, 524-533. doi:10.1016/ j.ejmech.2018.07.018 
Crane, E. A., and Gademann, K. (2016). Capturing Biological Activity in Natural Product Fragments by Chemical Synthesis. Angew. Chem. Int. Ed. 55, 3882-3902. doi:10.1002/anie.201505863

da Cruz, E. H. G., Silvers, M. A., Jardim, G. A. M., Resende, J. M., Cavalcanti, B. C., Bomfim, I. S., et al. (2016). Synthesis and Antitumor Activity of SeleniumContaining Quinone-Based Triazoles Possessing Two Redox Centres, and Their Mechanistic Insights. Eur. J. Med. Chem. 122, 1-16. doi:10.1016/ j.ejmech.2016.06.019

Santos, J. d. O., Pereira, G. R., Brandão, G. C., Borgati, T. F., Arantes, L. M., Paula, R. C. d., et al. (2015). Synthesis, in vitroAntimalarial Activity Andin silicoStudies of Hybrid Kauranoid 1,2,3-Triazoles Derived from Naturally Occurring Diterpenes. J. Braz. Chem. Soc. 27, 551-565. doi:10.5935/0103-5053.20150287

Dharavath, R., Nagaraju, N., Reddy, M. R., Ashok, D., Sarasija, M., Vijjulatha, M., et al. (2020). Microwave-assisted Synthesis, Biological Evaluation and Molecular Docking Studies of New Coumarin-Based 1,2,3-triazoles. RSC Adv. 10, 11615-11623. doi:10.1039/d0ra01052a

Ding, C., Zhang, Y., Chen, H., Wild, C., Wang, T., White, M. A., et al. (2013). Overcoming Synthetic Challenges of Oridonin A-Ring Structural Diversification: Regio- and Stereoselective Installation of Azides and 1,2,3-triazoles at the C-1, C2, or C-3 Position. Org. Lett. 15, 3718-3721. doi:10.1021/ol4015865

Ding, Y., Guo, H., Ge, W., Chen, X., Li, S., Wang, M., et al. (2018). Copper(I) Oxide Nanoparticles Catalyzed Click Chemistry Based Synthesis of Melampomagnolide B-Triazole Conjugates and Their Anti-cancer Activities. Eur. J. Med. Chem. 156, 216-229. doi:10.1016/j.ejmech.2018.06.058

Dong, J., Krasnova, L., Finn, M. G., and Sharpless, K. B. (2014). Sulfur(VI) Fluoride Exchange (SuFEx): Another Good Reaction for Click Chemistry. Angew. Chem. Int. Ed. 53, 9430-9448. doi:10.1002/anie.201309399

Duan, Y.-C., Ma, Y.-C., Zhang, E., Shi, X.-J., Wang, M.-M., Ye, X.-W., et al. (2013). Design and Synthesis of Novel 1,2,3-Triazole-Dithiocarbamate Hybrids as Potential Anticancer Agents. Eur. J. Med. Chem. 62, 11-19. doi:10.1016/ j.ejmech.2012.12.046

Faidallah, H. M., Panda, S. S., Serrano, J. C., Girgis, A. S., Khan, K. A., Alamry, K. A., et al. (2016). Synthesis, Antimalarial Properties and 2D-QSAR Studies of Novel Triazole-Quinine Conjugates. Bioorg. Med. Chem. 24, 3527-3539. doi:10.1016/j.bmc.2016.05.060

Farley, C. M., Dibwe, D. F., Ueda, J.-y., Hall, E. A., Awale, S., and Magolan, J. (2016). Evaluation of Synthetic Coumarins for Antiausterity Cytotoxicity against Pancreatic Cancers. Bioorg. Med. Chem. Lett. 26, 1471-1474. doi:10.1016/j.bmcl.2016.01.054

Foley, D. J., Zinken, S., Corkery, D., Laraia, L., Pahl, A., Wu, Y. W., et al. (2020). Phenotyping Reveals Targets of a Pseudo-Natural-Product Autophagy Inhibitor. Angew. Chem. Int. Ed. 59, 12470-12476. doi:10.1002/anie.202000364

Fu, D.-J., Zhang, S.-Y., Liu, Y.-C., Yue, X.-X., Liu, J.-J., Song, J., et al. (2016). Design, Synthesis and Antiproliferative Activity Studies of 1,2,3-Triazole-Chalcones. Med. Chem. Commun. 7, 1664-1671. doi:10.1039/C6MD00169F

Fu, D.-J., Li, P., Wu, B.-W., Cui, X.-X., Zhao, C.-B., and Zhang, S.-Y. (2019). Molecular Diversity of Trimethoxyphenyl-1,2,3-Triazole Hybrids as Novel Colchicine Site Tubulin Polymerization Inhibitors. Eur. J. Med. Chem. 165, 309-322. doi:10.1016/j.ejmech.2019.01.033

Gao, B., Li, S., Wu, P., Moses, J. E., and Sharpless, K. B. (2018). SuFEx Chemistry of Thionyl Tetrafluoride (SOF4 ) with Organolithium Nucleophiles: Synthesis of Sulfonimidoyl Fluorides, Sulfoximines, Sulfonimidamides, and Sulfonimidates. Angew. Chem. Int. Ed. 57, 1939-1943. doi:10.1002/anie.201712145

Gholampour, M., Ranjbar, S., Edraki, N., Mohabbati, M., Firuzi, O., and Khoshneviszadeh, M. (2019). Click Chemistry-Assisted Synthesis of Novel Aminonaphthoquinone-1,2,3-Triazole Hybrids and Investigation of Their Cytotoxicity and Cancer Cell Cycle Alterations. Bioorg. Chem. 88, 102967. doi:10.1016/j.bioorg.2019.102967

Guo, H.-Y., Jin, C., Zhang, H.-M., Jin, C.-M., Shen, Q.-K., and Quan, Z.-S. (2019). Synthesis and Biological Evaluation of (+)-Usnic Acid Derivatives as Potential Anti-toxoplasma Gondii Agents. J. Agric. Food Chem. 67, 9630-9642. doi:10.1021/acs.jafc.9b02173

Guo, H.-Y., Chen, Z.-A., Shen, Q.-K., and Quan, Z.-S. (2021). Application of Triazoles in the Structural Modification of Natural Products. J. Enzyme Inhib. Med. Chem. 36, 1115-1144. doi:10.1080/14756366.2021.1890066

Gupta, N., Qayum, A., Raina, A., Shankar, R., Gairola, S., Singh, S., et al. (2018). Synthesis and Biological Evaluation of Novel Bavachinin Analogs as Anticancer Agents. Eur. J. Med. Chem. 145, 511-523. doi:10.1016/j.ejmech.2018.01.006
Gurrapu, N., Praveen Kumar, E., Kolluri, P. K., Putta, S., Sivan, S. K., and Subhashini, N. J. P. (2020). Synthesis, Biological Evaluation and Molecular Docking Studies of Novel 1,2,3-triazole Tethered Chalcone Hybrids as Potential Anticancer Agents. J. Mol. Struct. 1217, 128356 . doi:10.1016/ j.molstruc.2020.128356

Hao, S.-Y., Feng, S.-L., Wang, X.-R., Wang, Z., Chen, S.-W., and Hui, L. (2019). Novel Conjugates of Podophyllotoxin and Coumarin: Synthesis, Cytotoxicities, Cell Cycle Arrest, Binding CT DNA and Inhibition of Topo II $\beta$. Bioorg. Med. Chem. Lett. 29, 2129-2135. doi:10.1016/j.bmcl.2019.06.063

Hou, W., Luo, Z., Zhang, G., Cao, D., Li, D., Ruan, H., et al. (2017a). Click Chemistry-Based Synthesis and Anticancer Activity Evaluation of Novel C-14 1,2,3-triazole Dehydroabietic Acid Hybrids. Eur. J. Med. Chem. 138, 1042-1052. doi:10.1016/j.ejmech.2017.07.049

Hou, W., Zhang, G., Luo, Z., Li, D., Ruan, H., Ruan, B. H., et al. (2017b). Identification of a Diverse Synthetic Abietane Diterpenoid Library and Insight into the Structure-Activity Relationships for Antibacterial Activity. Bioorg. Med. Chem. Lett. 27, 5382-5386. doi:10.1016/j.bmcl.2017.11.014

Hou, W., Fan, Q., Su, L., and Xu, H. (2019a). Synthesis of Oridonin Derivatives via Mizoroki-Heck Reaction and Click Chemistry for Cytotoxic Activity. Acamc 19, 935-947. doi:10.2174/1871520619666190118121439

Hou, W., Liu, B., and Xu, H. (2019b). Triptolide: Medicinal Chemistry, Chemical Biology and Clinical Progress. Eur. J. Med. Chem. 176, 378-392. doi:10.1016/ j.ejmech.2019.05.032

Hou, W., Zhang, G., Luo, Z., Su, L., and Xu, H. (2019c). Click Chemistry-based Synthesis and Cytotoxic Activity Evaluation of 4a-triazole Acetate Podophyllotoxin Derivatives. Chem. Biol. Drug Des. 93, 473-483. doi:10.1111/cbdd.13436

Hou, W., Liu, B., and Xu, H. (2020). Celastrol: Progresses in StructureModifications, Structure-Activity Relationships, Pharmacology and Toxicology. Eur. J. Med. Chem. 189, 112081. doi:10.1016/j.ejmech.2020.112081

Huang, M., Deng, Z., Tian, J., and Liu, T. (2017). Synthesis and Biological Evaluation of Salinomycin Triazole Analogues as Anticancer Agents. Eur. J. Med. Chem. 127, 900-908. doi:10.1016/j.ejmech.2016.10.067

Huang, Q., Xie, L., Chen, X., Yu, H., Lv, Y., Huang, X., et al. (2018a). Synthesis and Anticancer Activity of Novel Rapamycin C-28 Containing Triazole Moiety Compounds. Arch. Pharm. Chem. Life Sci. 351, 1800123. doi:10.1002/ ardp.201800123

Huang, X., Shen, Q.-K., Zhang, H.-J., Li, J.-L., Tian, Y.-S., and Quan, Z.-S. (2018b). Design and Synthesis of Novel Dehydroepiandrosterone Analogues as Potent Antiproliferative Agents. Molecules 23, 2243. doi:10.3390/molecules23092243

Huang, R.-Z., Liang, G.-B., Li, M.-S., Fang, Y.-L., Zhao, S.-F., Zhou, M.-M., et al. (2019). Synthesis and Discovery of Asiatic Acid Based 1,2,3-triazole Derivatives as Antitumor Agents Blocking NF- $\mathrm{BB}$ Activation and Cell Migration. Med. Chem. Commun. 10, 584-597. doi:10.1039/c8md00620b

Huigens III, R. W., III, Morrison, K. C., Hicklin, R. W., Flood Jr, T. A., Jr, Richter, M. F., and Hergenrother, P. J. (2013). A Ring-Distortion Strategy to Construct Stereochemically Complex and Structurally Diverse Compounds from Natural Products. Nat. Chem. 5, 195-202. doi:10.1038/nchem.1549

Hunter, P. (2008). Harnessing Nature's Wisdom. EMBO Rep. 9, 838-840. doi:10.1038/embor.2008.160

Hussaini, S. M. A., Yedla, P., Babu, K. S., Shaik, T. B., Chityal, G. K., and Kamal, A. (2016). Synthesis and Biological Evaluation of 1,2,3-triazole Tethered Pyrazoline and Chalcone Derivatives. Chem. Biol. Drug Des. 88, 97-109. doi:10.1111/cbdd. 12738

Iraji, A., Firuzi, O., Khoshneviszadeh, M., Tavakkoli, M., Mahdavi, M., Nadri, H., et al. (2017). Multifunctional Iminochromene-2H-Carboxamide Derivatives Containing Different Aminomethylene Triazole with BACE1 Inhibitory, Neuroprotective and Metal Chelating Properties Targeting Alzheimer's Disease. Eur. J. Med. Chem. 141, 690-702. doi:10.1016/j.ejmech.2017.09.057

Jalaja, R., Leela, S. G., Valmiki, P. K., Salfeena, C. T. F., Ashitha, K. T., Krishna Rao, V. R. D., et al. (2018). Discovery of Natural Product Derived Labdane Appended Triazoles as Potent Pancreatic Lipase Inhibitors. ACS Med. Chem. Lett. 9, 662-666. doi:10.1021/acsmedchemlett.8b00109

Jana, S., Iram, S., Thomas, J., Liekens, S., and Dehaen, W. (2017). Synthesis and Anticancer Activity of Novel Aza-Artemisinin Derivatives. Bioorg. Med. Chem. 25, 3671-3676. doi:10.1016/j.bmc.2017.04.041

Janganati, V., Ponder, J., Balasubramaniam, M., Bhat-Nakshatri, P., Bar, E. E., Nakshatri, H., et al. (2018). MMB Triazole Analogs Are Potent NF-кB 
Inhibitors and Anti-cancer Agents against Both Hematological and Solid Tumor Cells. Eur. J. Med. Chem. 157, 562-581. doi:10.1016/ j.ejmech.2018.08.010

Jiménez, C. (2018). Marine Natural Products in Medicinal Chemistry. ACS Med. Chem. Lett. 9, 959-961. doi:10.1021/acsmedchemlett.8b00368

Jin, X., Yan, L., Li, H.-j., Wang, R.-L., Hu, Z.-L., Jiang, Y.-Y., et al. (2014). Novel Triazolyl Berberine Derivatives Prepared via CuAAC Click Chemistry: Synthesis, Anticancer Activity and Structure-Activity Relationships. Acamc 15, 89-98. doi:10.2174/1871520614666141203142012

Jurášek, M., Černohorská, M., Řehulka, J., Spiwok, V., Sulimenko, T., Dráberová, E., et al. (2018). Estradiol Dimer Inhibits Tubulin Polymerization and Microtubule Dynamics. J. Steroid Biochem. Mol. Biol. 183, 68-79. doi:10.1016/j.jsbmb.2018.05.008

Kacprzak, K., Skiera, I., Piasecka, M., and Paryzek, Z. (2016). Alkaloids and Isoprenoids Modification by Copper(I)-Catalyzed Huisgen 1,3-Dipolar Cycloaddition (Click Chemistry): Toward New Functions and Molecular Architectures. Chem. Rev. 116, 5689-5743. doi:10.1021/acs.chemrev.5b00302

Kant, R., Kumar, D., Agarwal, D., Gupta, R. D., Tilak, R., Awasthi, S. K., et al. (2016). Synthesis of Newer 1,2,3-triazole Linked Chalcone and Flavone Hybrid Compounds and Evaluation of Their Antimicrobial and Cytotoxic Activities. Eur. J. Med. Chem. 113, 34-49. doi:10.1016/j.ejmech.2016.02.041

Kapkoti, D. S., Singh, S., Luqman, S., and Bhakuni, R. S. (2018). Synthesis of Novel 1,2,3-triazole Based Artemisinin Derivatives and Their Antiproliferative Activity. New J. Chem. 42, 5978-5995. doi:10.1039/C7NJ04271J

Ke, Y., Liang, J.-J., Hou, R.-J., Li, M.-M., Zhao, L.-F., Wang, W., et al. (2018a). Synthesis and Biological Evaluation of Novel Jiyuan Oridonin A-1,2,3-TriazoleAzole Derivatives as Antiproliferative Agents. Eur. J. Med. Chem. 157, 1249-1263. doi:10.1016/j.ejmech.2018.08.056

Ke, Y., Wang, W., Zhao, L.-F., Liang, J.-J., Liu, Y., Zhang, X., et al. (2018b). Design, Synthesis and Biological Mechanisms Research on 1,2,3-triazole Derivatives of Jiyuan Oridonin A. Bioorg. Med. Chem. 26, 4761-4773. doi:10.1016/ j.bmc.2017.11.005

Khan, I., Guru, S. K., Rath, S. K., Chinthakindi, P. K., Singh, B., Koul, S., et al. (2016). A Novel Triazole Derivative of Betulinic Acid Induces Extrinsic and Intrinsic Apoptosis in Human Leukemia HL-60 Cells. Eur. J. Med. Chem. 108, 104-116. doi:10.1016/j.ejmech.2015.11.018

Kitamura, S., Zheng, Q., Woehl, J. L., Solania, A., Chen, E., Dillon, N., et al. (2020). Sulfur(VI) Fluoride Exchange (SuFEx)-Enabled High-Throughput Medicinal Chemistry. J. Am. Chem. Soc. 142, 10899-10904. doi:10.1021/jacs.9b13652

Klich, K., Pyta, K., Kubicka, M. M., Ruszkowski, P., Celewicz, L., Gajecka, M., et al. (2016). Synthesis, Antibacterial, and Anticancer Evaluation of Novel Spiramycin-like Conjugates Containing C(5) Triazole Arm. J. Med. Chem. 59, 7963-7973. doi:10.1021/acs.jmedchem.6b00764

Kolb, H. C., Finn, M. G., and Sharpless, K. B. (2001). Click Chemistry: Diverse Chemical Function from a Few Good Reactions. Angew. Chem. Int. Ed. 40, 2004-2021. doi:10.1002/1521-3773(20010601)40:11<2004:aid-anie2004>3.0.co;2-5

Kraljević, T. G., Harej, A., Sedić, M., Pavelić, S. K., Stepanić, V., Drenjančević, D., et al. (2016). Synthesis, In Vitro Anticancer and Antibacterial Activities and In Silico Studies of New 4-substituted 1,2,3-Triazole-Coumarin Hybrids. Eur. J. Med. Chem. 124, 794-808. doi:10.1016/j.ejmech.2016.08.062

Kumar, S., Saini, A., Gut, J., Rosenthal, P. J., Raj, R., and Kumar, V. (2017). 4Aminoquinoline-chalcone/- N -acetylpyrazoline Conjugates: Synthesis and Antiplasmodial Evaluation. Eur. J. Med. Chem. 138, 993-1001. doi:10.1016/ j.ejmech.2017.07.041

Kumar, S., Sharma, B., Mehra, V., and Kumar, V. (2021). Recent Accomplishments on the Synthetic/biological Facets of Pharmacologically Active 1H-1,2,3Triazoles. Eur. J. Med. Chem. 212, 113069. doi:10.1016/j.ejmech.2020.113069

Kumari, P., Dubey, S., Venkatachalapathy, S., Narayana, C., Gupta, A., and Sagar, R. (2019). Synthesis of New Triazole Linked Carbohybrids with ROS-Mediated Toxicity in Breast Cancer. New J. Chem. 43, 18590-18600. doi:10.1039/ c9nj03288f

Lal, K., Yadav, P., Kumar, A., Kumar, A., and Paul, A. K. (2018). Design, Synthesis, Characterization, Antimicrobial Evaluation and Molecular Modeling Studies of Some Dehydroacetic Acid-Chalcone-1,2,3-Triazole Hybrids. Bioorg. Chem. 77, 236-244. doi:10.1016/j.bioorg.2018.01.016

Li, J. W.-H., and Vederas, J. C. (2011). Drug Discovery and Natural Products: End of Era or an Endless Frontier? Biomed. Khim 57, 148-160. doi:10.18097/ pbmc20115702148
Li, S., Wu, P., Moses, J. E., and Sharpless, K. B. (2017a). Multidimensional SuFEx Click Chemistry: Sequential Sulfur(VI) Fluoride Exchange Connections of Diverse Modules Launched from an SOF4 Hub. Angew. Chem. Int. Ed. 56, 2903-2908. doi:10.1002/anie.201611048

Li, X., Wu, Y., Wang, Y., You, Q., and Zhang, X. (2017b). 'Click Chemistry' Synthesis of Novel Natural Product-like Caged Xanthones Bearing a 1,2,3Triazole Moiety with Improved Druglike Properties as Orally Active Antitumor Agents. Molecules 22, 1834-1913. doi:10.3390/molecules22111834

Li, H.-n., Wang, H., Wang, Z.-p., Yan, H.-n., Zhang, M., Liu, Y., et al. (2018). Synthesis, Antitumor Activity Evaluation and Mechanistic Study of Novel Hederacolchiside A1 Derivatives Bearing an Aryl Triazole Moiety. Bioorg. Med. Chem. 26, 4025-4033. doi:10.1016/j.bmc.2018.06.026

Li, F.-Y., Huang, L., Li, Q., Wang, X., Ma, X.-L., Jiang, C.-N., et al. (2019). Synthesis and Antiproliferative Evaluation of Novel Hybrids of Dehydroabietic Acid Bearing 1,2,3-triazole Moiety. Molecules 24, 4191-4211. doi:10.3390/ molecules 24224191

Li, S., Liyang, X.-y., ZhangjianKamara, T.-j. M. O., Kamara, M. O., Liang, J.-w., Zhu, J., et al. (2020a). Design, Synthesis and Biological Evaluation of Homoerythrina Alkaloid Derivatives Bearing a Triazole Moiety as PARP-1 Inhibitors and as Potential Antitumor Drugs. Bioorg. Chem. 94, 103385. doi:10.1016/j.bioorg.2019.103385

Li, S., Li, X.-y., Zhang, T. J., Zhu, J., Xue, W.-h., Qian, X.-h., et al. (2020b). Design, Synthesis and Biological Evaluation of erythrina Derivatives Bearing a 1,2,3triazole Moiety as PARP-1 Inhibitors. Bioorg. Chem. 96, 103575. doi:10.1016/ j.bioorg.2020.103575

Liang, T., Sun, X., Li, W., Hou, G., and Gao, F. (2021). 1,2,3-Triazole-Containing Compounds as Anti-lung Cancer Agents: Current Developments, Mechanisms of Action, and Structure-Activity Relationship. Front. Pharmacol. 12, 1-20. doi:10.3389/fphar.2021.661173

Lipeeva, A. V., Pokrovsky, M. A., Baev, D. S., Shakirov, M. M., Bagryanskaya, I. Y., Tolstikova, T. G., et al. (2015). Synthesis of 1H-1,2,3-Triazole Linked Aryl(arylamidomethyl) - Dihydrofurocoumarin Hybrids and Analysis of Their Cytotoxicity. Eur. J. Med. Chem. 100, 119-128. doi:10.1016/ j.ejmech.2015.05.016

Lipeeva, A. V., Zakharov, D. O., Burova, L. G., Frolova, T. S., Baev, D. S., Shirokikh, I. V., et al. (2019). Design, Synthesis and Antibacterial Activity of Coumarin1,2,3-Triazole Hybrids Obtained from Natural Furocoumarin Peucedanin. Molecules 24, 2126. doi:10.3390/molecules24112126

Lipeeva, A. V., Dolgikh, M. P., Tolstikova, T. G., and Shults, E. E. (2020). A Study of Plant Coumarins. 18. Conjugates of Coumarins with Lupane Triterpenoids and 1,2,3-Triazoles: Synthesis and Anti-Inflammatory Activity. Russ. J. Bioorg. Chem. 46, 125-132. doi:10.1134/S1068162020010161

Liu, C.-J., Liu, Y.-P., Yu, S.-L., Dai, X.-J., Zhang, T., and Tao, J.-C. (2016). Syntheses, Cytotoxic Activity Evaluation and HQSAR Study of 1,2,3Triazole-Linked Isosteviol Derivatives as Potential Anticancer Agents. Bioorg. Med. Chem. Lett. 26, 5455-5461. doi:10.1016/j.bmcl.2016.10.028

Liu, Z., Li, J., Li, S., Li, G., Sharpless, K. B., and Wu, P. (2018). SuFEx Click Chemistry Enabled Late-Stage Drug Functionalization. J. Am. Chem. Soc. 140, 2919-2925. doi:10.1021/jacs.7b12788

Liu, F., Wang, H., Li, S., Bare, G. A. L., Chen, X., Wang, C., et al. (2019). Biocompatible SuFEx Click Chemistry: Thionyl Tetrafluoride (SOF 4 )-Derived Connective Hubs for Bioconjugation to DNA and Proteins. Angew. Chem. Int. Ed. 58, 8029-8033. doi:10.1002/anie.201902489

Luan, T., Cao, L.-H., Deng, H., Shen, Q.-K., Tian, Y.-S., and Quan, Z.-S. (2019). Design and Synthesis of C-19 Isosteviol Derivatives as Potent and Highly Selective Antiproliferative Agents. Molecules 24, 121-124. doi:10.3390/ molecules 24010121

Luan, T., Quan, Z., Fang, Y., and Yang, H. (2020). Design, Synthesis and Antiproliferative Activity of Chrysin Derivatives Bearing Triazole Moieties. Chin. J. Org. Chem. 40, 440-446. doi:10.6023/cjoc201907012

Ma, P., Xu, H., Li, J., Lu, F., Ma, F., Wang, S., et al. (2019). FunctionalityIndependent DNA Encoding of Complex Natural Products. Angew. Chem. Int. Ed. 58, 9254-9261. doi:10.1002/anie.201901485

Maggioni, D., Biffi, L., Nicolini, G., and Garavello, W. (2015). Flavonoids in Oral Cancer Prevention and Therapy. Eur. J. Cancer Prev. 24, 517-528. doi:10.1097/ CEJ.0000000000000109

Masood-ur-RahmanMohammad, Y., Fazili, K. M., Bhat, K. A., and Ara, T. (2017). Synthesis and Biological Evaluation of Novel 3- O -tethered Triazoles of 
Diosgenin as Potent Antiproliferative Agents. Steroids 118, 1-8. doi:10.1016/ j.steroids.2016.11.003

Meng, G., Guo, T., Ma, T., Zhang, J., Shen, Y., Sharpless, K. B., et al. (2019). Modular Click Chemistry Libraries for Functional Screens Using a Diazotizing Reagent. Nature 574, 86-89. doi:10.1038/s41586-019-1589-1

Mernyák, E., Kovács, I., Minorics, R., Sere, P., Czégány, D., Sinka, I., et al. (2015). Synthesis of Trans-16-triazolyl-13a-methyl-17-estradiol Diastereomers and the Effects of Structural Modifications on Their In Vitro Antiproliferative Activities. J. Steroid Biochem. Mol. Biol. 150, 123-134. doi:10.1016/ j.jsbmb.2015.04.001

Mistry, B., Patel, R. V., and Keum, Y.-S. (2017). Access to the Substituted Benzyl1,2,3-Triazolyl Hesperetin Derivatives Expressing Antioxidant and Anticancer Effects. Arabian J. Chem. 10, 157-166. doi:10.1016/ j.arabjc.2015.10.004

Montanari, S., Scalvini, L., Bartolini, M., Belluti, F., Gobbi, S., Andrisano, V., et al. (2016). Fatty Acid Amide Hydrolase (FAAH), Acetylcholinesterase (AChE), and Butyrylcholinesterase (BuChE): Networked Targets for the Development of Carbamates as Potential Anti-alzheimer's Disease Agents. J. Med. Chem. 59, 6387-6406. doi:10.1021/acs.jmedchem.6b00609

Moradi, A., Faraji, L., Nadri, H., Hasanpour, Z., Moghadam, F. H., Pakseresht, B., et al. (2018). Synthesis, Docking Study, and Biological Evaluation of Novel Umbellipherone/hymecromone Derivatives as Acetylcholinesterase/ butyrylcholinesterase Inhibitors. Med. Chem. Res. 27, 1741-1747. doi:10.1007/s00044-018-2187-8

Newman, D. J., and Cragg, G. M. (2020). Natural Products as Sources of New Drugs over the Nearly Four Decades from 01/1981 to 09/2019. J. Nat. Prod. 83, 770-803. doi:10.1021/acs.jnatprod.9b01285

Ottoni, F. M., Gomes, E. R., Pádua, R. M., Oliveira, M. C., Silva, I. T., and Alves, R. J. (2020). Synthesis and Cytotoxicity Evaluation of Glycosidic Derivatives of Lawsone against Breast Cancer Cell Lines. Bioorg. Med. Chem. Lett. 30, 126817. doi:10.1016/j.bmcl.2019.126817

Park, J.-Y., Shin, S., Park, K. C., Jeong, E., and Park, J. H. (2016). Synthesis and In Vitro Assay of New Triazole Linked Decursinol Derivatives Showing Inhibitory Activity against Cholinesterase for Alzheimer's Disease Therapeutics. J. Korean Chem. Soc. 60, 125-130. doi:10.5012/jkcs.2016.60.2.125

Pavan Kumar, C., Devi, A., Ashok Yadav, P., Rao Vadaparthi, R., Shankaraiah, G., Sowjanya, P., et al. (2016). "Click" Reaction Mediated Synthesis of Costunolide and Dehydrocostuslactone Derivatives and Evaluation of Their Cytotoxic Activity. J. Asian Nat. Prod. Res. 18, 1063-1078. doi:10.1080/ 10286020.2016.1193012

Pavan Kumar, P., Siva, B., Venkateswara Rao, B., Dileep Kumar, G., Lakshma Nayak, V., Nishant Jain, S., et al. (2019). Synthesis and Biological Evaluation of Bergenin-1,2,3-Triazole Hybrids as Novel Class of Anti-mitotic Agents. Bioorg. Chem. 91, 103161. doi:10.1016/j.bioorg.2019.103161

Pertino, M., Theoduloz, C., Butassi, E., Zacchino, S., and Schmeda-Hirschmann, G. (2015). Synthesis, Antiproliferative and Antifungal Activities of 1,2,3-TriazoleSubstituted Carnosic Acid and Carnosol Derivatives. Molecules 20, 8666-8686. doi:10.3390/molecules20058666

Podolski-Renić, A., Bősze, S., Dinić, J., Kocsis, L., Hudecz, F., Csámpai, A., et al. (2017). Ferrocene-cinchona Hybrids with Triazolyl-Chalcone Linkers Act as Pro-oxidants and Sensitize Human Cancer Cell Lines to Paclitaxel. Metallomics 9, 1132-1141. doi:10.1039/c7mt00183e

Poornima, B., Siva, B., Shankaraiah, G., Venkanna, A., Nayak, V. L., Ramakrishna, S., et al. (2015). Novel Sesquiterpenes from Schisandra Grandiflora: Isolation, Cytotoxic Activity and Synthesis of Their Triazole Derivatives Using "click" Reaction. Eur. J. Med. Chem. 92, 449-458. doi:10.1016/j.ejmech.2014.12.040

Poornima, B., Siva, B., Venkanna, A., Shankaraiah, G., Jain, N., Yadav, D. K., et al. (2017). Novel Gomisin B Analogues as Potential Cytotoxic Agents: Design, Synthesis, Biological Evaluation and Docking Studies. Eur. J. Med. Chem. 139, 441-453. doi:10.1016/j.ejmech.2017.07.076

Prasad, C. V., Nayak, V. L., Ramakrishna, S., and Mallavadhani, U. V. (2018). Novel Menadione Hybrids: Synthesis, Anticancer Activity, and Cell-Based Studies. Chem. Biol. Drug Des. 91, 220-233. doi:10.1111/cbdd.13073

Pyta, K., Blecha, M., Janas, A., Klich, K., Pecyna, P., Gajecka, M., et al. (2016). Synthesis, Structure and Antimicrobial Evaluation of a New Gossypol Triazole Conjugates Functionalized with Aliphatic Chains and Benzyloxy Groups. Bioorg. Med. Chem. Lett. 26, 4322-4326. doi:10.1016/j.bmcl.2016.07.033
Qi, Y., Ding, Z., Yao, Y., Ma, D., Ren, F., Yang, H., et al. (2018). Novel Triazole Analogs of Apigenin 7 methyl Ether Exhibit Potent Antitumor Activity against Ovarian Carcinoma Cells via the Induction of Mitochondrial Mediated Apoptosis. Exp. Ther. Med. 17, 1670-1676. doi:10.3892/etm.2018.7138

Raj, P. J., and Bahulayan, D. (2017). "MCR-Click" Synthesis of Coumarin-Tagged Macrocycles with Large Stokes Shift Values and Cytotoxicity against Human Breast Cancer Cell Line MCF-7. Tetrahedron Lett. 58, 2122-2126. doi:10.1016/ j.tetlet.2017.04.052

Rani, A., Singh, G., Singh, A., Maqbool, U., Kaur, G., and Singh, J. (2020). CuAACensembled 1,2,3-Triazole-Linked Isosteres as Pharmacophores in Drug Discovery: Review. RSC Adv. 10, 5610-5635. doi:10.1039/C9RA09510A

Rao, Y. J., Sowjanya, T., Thirupathi, G., Murthy, N. Y. S., and Kotapalli, S. S. (2018). Synthesis and Biological Evaluation of Novel Flavone/triazole/benzimidazole Hybrids and Flavone/isoxazole-Annulated Heterocycles as Antiproliferative and Antimycobacterial Agents. Mol. Divers. 22, 803-814. doi:10.1007/s11030018-9833-4

Rastegari, A., Nadri, H., Mahdavi, M., Moradi, A., Mirfazli, S. S., Edraki, N., et al. (2019). Design, Synthesis and Anti-alzheimer's Activity of Novel 1,2,3Triazole-Chromenone Carboxamide Derivatives. Bioorg. Chem. 83, 391-401. doi:10.1016/j.bioorg.2018.10.065

Reddy, V. G., Bonam, S. R., Reddy, T. S., Akunuri, R., Naidu, V. G. M., Nayak, V. L., et al. (2018). $4 \beta$-amidotriazole Linked Podophyllotoxin Congeners: DNA Topoisomerase-IIa Inhibition and Potential Anticancer Agents for Prostate Cancer. Eur. J. Med. Chem. 144, 595-611. doi:10.1016/j.ejmech.2017.12.050

Rodríguez-Hernández, D., Barbosa, L. C. A., Demuner, A. J., Nain-Perez, A., Ferreira, S. R., Fujiwara, R. T., et al. (2017). Leishmanicidal and Cytotoxic Activity of Hederagenin-Bistriazolyl Derivatives. Eur. J. Med. Chem. 140, 624-635. doi:10.1016/j.ejmech.2017.09.045

Rodrigues, T., Reker, D., Schneider, P., and Schneider, G. (2016). Counting on Natural Products for Drug Design. Nat. Chem. 8, 531-541. doi:10.1038/ nchem. 2479

Rodríguez-Hernández, D., Barbosa, L. C. A., Demuner, A. J., de Almeida, R. M., Fujiwara, R. T., and Ferreira, S. R. (2016a). Highly Potent Anti-leishmanial Derivatives of Hederagenin, a Triperpenoid from Sapindus saponaria L. Eur. J. Med. Chem. 124, 153-159. doi:10.1016/j.ejmech.2016.08.030

Rodríguez-Hernández, D., Demuner, A. J., Barbosa, L. C. A., Heller, L., and Csuk, R. (2016b). Novel Hederagenin-Triazolyl Derivatives as Potential Anti-cancer Agents. Eur. J. Med. Chem. 115, 257-267. doi:10.1016/j.ejmech.2016.03.018

Ruddarraju, R. R., Murugulla, A. C., Kotla, R., Chandra Babu Tirumalasetty, M., Wudayagiri, R., Donthabakthuni, S., et al. (2016). Design, Synthesis, Anticancer, Antimicrobial Activities and Molecular Docking Studies of Theophylline Containing Acetylenes and Theophylline Containing 1,2,3triazoles with Variant Nucleoside Derivatives. Eur. J. Med. Chem. 123, 379-396. doi:10.1016/j.ejmech.2016.07.024

Ruddarraju, R. R., Murugulla, A. C., Kotla, R., Tirumalasetty, M. C. B., Wudayagiri, R., Donthabakthuni, S., et al. (2017). Design, Synthesis, Anticancer Activity and Docking Studies of Theophylline Containing 1,2,3-triazoles with Variant Amide Derivatives. Med. Chem. Commun. 8, 176-183. doi:10.1039/ c6md00479b

Saeedi, M., Safavi, M., Karimpour-Razkenari, E., Mahdavi, M., Edraki, N., Moghadam, F. H., et al. (2017). Synthesis of Novel Chromenones Linked to 1,2,3-triazole Ring System: Investigation of Biological Activities against Alzheimer's Disease. Bioorg. Chem. 70, 86-93. doi:10.1016/j.bioorg.2016.11.011

Sahu, A., Agrawal, R. K., and Pandey, R. (2019). Synthesis and Systemic Toxicity Assessment of Quinine-Triazole Scaffold with Antiprotozoal Potency. Bioorg. Chem. 88, 102939. doi:10.1016/j.bioorg.2019.102939

Savanur, H. M., Naik, K. N., Ganapathi, S. M., Kim, K. M., and Kalkhambkar, R. G. (2018). Click Chemistry Inspired Design, Synthesis and Molecular Docking Studies of Coumarin, Quinolinone Linked 1,2,3-Triazoles as Promising Anti-Microbial Agents. ChemistrySelect 3, 5296-5303. doi:10.1002/slct.201800319

Serafini, M., Pirali, T., and Tron, G. C. (2020). "Click 1,2,3-triazoles in Drug Discovery and Development: From the Flask to the Clinic," in Advances in Heterocyclic Chemistry (Novara, Italy: Elsevier), 101-148. doi:10.1016/ bs.aihch.2020.10.001

Shan, Y. S., Zhang, J., Liu, Z., Wang, M., and Dong, Y. (2011). Developments of Combretastatin A-4 Derivatives as Anticancer Agents. Curr. Med. Chem. 18, 523-538. doi:10.2174/092986711794480221 
Sharma, B., Gu, L., Pillay, R. P., Cele, N., Awolade, P., Singh, P., et al. (2020). Design, Synthesis, and Anti-proliferative Evaluation of 1H-1,2,3-Triazole Grafted Tetrahydro- $\beta$-Carboline-Chalcone/ferrocenylchalcone Conjugates in Estrogen Responsive and Triple Negative Breast Cancer Cells. New J. Chem. 44, 11137-11147. doi:10.1039/D0NJ00879F

Shen, Q.-K., Liu, C.-F., Zhang, H.-J., Tian, Y.-S., and Quan, Z.-S. (2017). Design and Synthesis of New Triazoles Linked to Xanthotoxin for Potent and Highly Selective Anti-gastric Cancer Agents. Bioorg. Med. Chem. Lett. 27, 4871-4875. doi:10.1016/j.bmcl.2017.09.040

Shen, Q.-K., Deng, H., Wang, S.-B., Tian, Y.-S., and Quan, Z.-S. (2019). Synthesis, and Evaluation of In Vitro and In Vivo Anticancer Activity of 14-substituted Oridonin Analogs: A Novel and Potent Cell Cycle Arrest and Apoptosis Inducer through the P53-MDM2 Pathway. Eur. J. Med. Chem. 173, 15-31. doi:10.1016/j.ejmech.2019.04.005

Shi, W., Tang, N., and Yan, W.-D. (2015). Synthesis and Cytotoxicity of Triterpenoids Derived from Betulin and Betulinic Acid via Click Chemistry. J. Asian Nat. Prod. Res. 17, 159-169. doi:10.1080/10286020.2014.979164

Shi, Q., Li, Y., Bo, S., Li, X., Zhao, P., Liu, Q., et al. (2016). Discovery of a 19F MRI Sensitive Salinomycin Derivative with High Cytotoxicity towards Cancer Cells. Chem. Commun. 52, 5136-5139. doi:10.1039/C6CC01508E

Silalai, P., Sirion, U., Piyachaturawat, P., Chairoungdua, A., Suksen, K., and Saeeng, R. (2020). Design, Synthesis and Evaluations of New 10-Triazolyl-1methoxygenipin Analogues for Their Cytotoxicity to Cancer Cells. ChemistrySelect 5, 9540-9546. doi:10.1002/slct.202001908

Singh, H., Kumar, M., Nepali, K., Gupta, M. K., Saxena, A. K., Sharma, S., et al. (2016). Triazole Tethered C 5 -Curcuminoid-Coumarin Based Molecular Hybrids as Novel Antitubulin Agents: Design, Synthesis, Biological Investigation and Docking Studies. Eur. J. Med. Chem. 116, 102-115. doi:10.1016/j.ejmech.2016.03.050

Singh, H., Singh, J. V., Gupta, M. K., Saxena, A. K., Sharma, S., Nepali, K., et al. (2017). Triazole Tethered Isatin-Coumarin Based Molecular Hybrids as Novel Antitubulin Agents: Design, Synthesis, Biological Investigation and Docking Studies. Bioorg. Med. Chem. Lett. 27, 3974-3979. doi:10.1016/ j.bmcl.2017.07.069

Sinha, S., Kumaran, A. P., Mishra, D., and Paira, P. (2016). Synthesis and Cytotoxicity Study of Novel 3-(triazolyl)coumarins Based Fluorescent Scaffolds. Bioorg. Med. Chem. Lett. 26, 5557-5561. doi:10.1016/ j.bmcl.2016.09.078

Smedley, C. J., Zheng, Q., Gao, B., Li, S., Molino, A., Duivenvoorden, H. M., et al. (2019). Bifluoride Ion Mediated SuFEx Trifluoromethylation of Sulfonyl Fluorides and Iminosulfur Oxydifluorides. Angew. Chem. Int. Ed. 58, 4552-4556. doi:10.1002/anie.201813761

Smedley, C. J., Li, G., Barrow, A. S., Gialelis, T. L., Giel, M. C., Ottonello, A., et al. (2020). Diversity Oriented Clicking (DOC): Divergent Synthesis of SuFExable Pharmacophores from 2-Substituted-Alkynyl-1-Sulfonyl Fluoride (SASF) Hubs. Angew. Chem. Int. Ed. 59, 12460-12469. doi:10.1002/ anie.202003219

Souza, T. B., Caldas, I. S., Paula, F. R., Rodrigues, C. C., Carvalho, D. T., and Dias, D. F. (2020). Synthesis, Activity, and Molecular Modeling Studies of 1,2,3triazole Derivatives from Natural Phenylpropanoids as New Trypanocidal Agents. Chem. Biol. Drug Des. 95, 124-129. doi:10.1111/cbdd.13628

Stephenson, Z. A., Harvey, R. F., Pryde, K. R., Mistry, S., Hardy, R. E., Serreli, R., et al. (2020). Identification of a Novel Toxicophore in Anti-cancer Chemotherapeutics that Targets Mitochondrial Respiratory Complex I. Elife 9, 1-31. doi:10.7554/eLife.55845

Sunitha, V., Kumar, A. K., Jalapathi, P., and Lincoln, C. A. (2020). Synthesis and Antimicrobial Activity of Bis-1,2,3-Triazole Based Chalcones. Russ. J. Gen. Chem. 90, 154-159. doi:10.1134/S1070363220010247

Taia, A., Essaber, M., Oubella, A., Aatif, A., Bodiguel, J., Jamart-Grégoire, B., et al. (2020). Synthesis, Characterization, and Biological Evaluation of New Heterocyclic Systems 1, 2, 3-Triazole-Isoxazoline from Eugenol by the Mixed Condensation Reactions. Synth. Commun. 50, 2052-2065. doi:10.1080/00397911.2020.1762224

Tang, K.-W., Yang, S.-C., and Tseng, C.-H. (2019). Design, Synthesis, and Antibacterial Evaluation of Triazolyl-Pterostilbene Derivatives. Int. J. Mol. Sci. 20, 4564. doi:10.3390/ijms20184564

Tapadar, S., Fathi, S., Raji, I., Omesiete, W., Kornacki, J. R., Mwakwari, S. C., et al. (2015). A Structure-Activity Relationship of Non-peptide Macrocyclic
Histone Deacetylase Inhibitors and Their Anti-proliferative and Antiinflammatory Activities. Bioorg. Med. Chem. 23, 7543-7564. doi:10.1016/ j.bmc.2015.10.045

Teixeira, R. R., Gazolla, P. A. R., da Silva, A. M., Borsodi, M. P. G., Bergmann, B. R., Ferreira, R. S., et al. (2018). Synthesis and Leishmanicidal Activity of Eugenol Derivatives Bearing 1,2,3-triazole Functionalities. Eur. J. Med. Chem. 146, 274-286. doi:10.1016/j.ejmech.2018.01.046

Thomopoulou, P., Sachs, J., Teusch, N., Mariappan, A., Gopalakrishnan, J., and Schmalz, H.-G. (2016). New Colchicine-Derived Triazoles and Their Influence on Cytotoxicity and Microtubule Morphology. ACS Med. Chem. Lett. 7, 188-191. doi:10.1021/acsmedchemlett.5b00418

Tian, Y., Liang, Z., Xu, H., Mou, Y., and Guo, C. (2016). Design, Synthesis and Cytotoxicity of Novel Dihydroartemisinin-Coumarin Hybrids via Click Chemistry. Molecules 21, 758-815. doi:10.3390/molecules 21060758

Tien, D. D., Giang, L. N. T., Anh, D. T. T., Dung, N. T., Ha, T. N., Ha, N. T. T., et al. (2016). Synthesis and Cytotoxic Evaluation of Artemisinin-Triazole Hybrids. Nat. Product. Commun. 11, 1934578X1601101. doi:10.1177/ 1934578x1601101204

Wang, M., Li, H., Xu, F., Gao, X., Li, J., Xu, S., et al. (2018a). Diterpenoid lead Stevioside and its Hydrolysis Products Steviol and Isosteviol: Biological Activity and Structural Modification. Eur. J. Med. Chem. 156, 885-906. doi:10.1016/ j.ejmech.2018.07.052

Wang, W., Wang, W., Yao, G., Ren, Q., Wang, D., Wang, Z., et al. (2018b). Novel Sarsasapogenin-Triazolyl Hybrids as Potential Anti-alzheimer's Agents: Design, Synthesis and Biological Evaluation. Eur. J. Med. Chem. 151, 351-362. doi:10.1016/j.ejmech.2018.03.082

Wei, G., Luan, W., Wang, S., Cui, S., Li, F., Liu, Y., et al. (2015). A Library of 1,2,3Triazole-Substituted Oleanolic Acid Derivatives as Anticancer Agents: Design, Synthesis, and Biological Evaluation. Org. Biomol. Chem. 13, 1507-1514. doi:10.1039/C4OB01605J

Wilson, B. A. P., Thornburg, C. C., Henrich, C. J., Grkovic, T., and O'Keefe, B. R. (2020). Creating and Screening Natural Product Libraries. Nat. Prod. Rep. 37, 893-918. doi:10.1039/c9np00068b

Wu, J., Dai, J., Zhang, Y., Wang, J., Huang, L., Ding, H., et al. (2019). Synthesis of Novel Xanthone Analogues and Their Growth Inhibitory Activity against Human Lung Cancer A549 Cells. Drug Des. Devel. Ther. 13, 4239-4246. doi:10.2147/DDDT.S217827

Xie, L., Huang, J., Chen, X., Yu, H., Li, K., Yang, D., et al. (2016). Synthesis of Rapamycin Derivatives Containing the Triazole Moiety Used as Potential mTOR-Targeted Anticancer Agents. Arch. Pharm. Chem. Life Sci. 349, 428-441. doi:10.1002/ardp.201500457

Xie, J., Wang, S., Ma, P., Ma, F., Li, J., Wang, W., et al. (2020). Selection of Small Molecules that Bind to and Activate the Insulin Receptor from a DNAEncoded Library of Natural Products. iScience 23, 101197. doi:10.1016/ j.isci.2020.101197

Xu, H., and Liu, B. (2019). Triptolide-targeted Delivery Methods. Eur. J. Med. Chem. 164, 342-351. doi:10.1016/j.ejmech.2018.12.058

Xu, H., Tang, H., Feng, H., and Li, Y. (2014a). Design, Synthesis and Anticancer Activity Evaluation of Novel C14 Heterocycle Substituted Epi-Triptolide. Eur. J. Med. Chem. 73, 46-55. doi:10.1016/j.ejmech.2013.11.044

Xu, H., Tang, H., Yang, Z., Feng, H., and Li, Y. (2014b). Synthesis and Biological Evaluation of 20-hydroxytriptonide and its Analogues. Tetrahedron 70, 3107-3115. doi:10.1016/j.tet.2014.03.070

Xu, X., Wu, Y., Liu, W., Sheng, C., Yao, J., Dong, G., et al. (2016). Discovery of 7Methyl-10-Hydroxyhomocamptothecins with 1,2,3-Triazole Moiety as Potent Topoisomerase I Inhibitors. Chem. Biol. Drug Des. 88, 398-403. doi:10.1111/ cbdd.12767

Xu, H., Liu, L., Fan, X., Zhang, G., Li, Y., and Jiang, B. (2017). Identification of a Diverse Synthetic Abietane Diterpenoid Library for Anticancer Activity. Bioorg. Med. Chem. Lett. 27, 505-510. doi:10.1016/j.bmcl.2016.12.032

Xu, H., Ma, F., Wang, N., Hou, W., Xiong, H., Lu, F., et al. (2019a). DNA-Encoded Libraries: Aryl Fluorosulfonates as Versatile Electrophiles Enabling Facile OnDNA Suzuki, Sonogashira, and Buchwald Reactions. Adv. Sci. 6, 1901551. doi:10.1002/advs.201901551

$\mathrm{Xu}$, Z., Zhao, S.-J., and Liu, Y. (2019b). 1,2,3-Triazole-containing Hybrids as Potential Anticancer Agents: Current Developments, Action Mechanisms and Structure-Activity Relationships. Eur. J. Med. Chem. 183, 111700. doi:10.1016/ j.ejmech.2019.111700 
Yadav, P., Lal, K., Kumar, A., Guru, S. K., Jaglan, S., and Bhushan, S. (2017). Green Synthesis and Anticancer Potential of Chalcone Linked-1,2,3-Triazoles. Eur. J. Med. Chem. 126, 944-953. doi:10.1016/j.ejmech.2016.11.030

Yadav, N., Agarwal, D., Kumar, S., Dixit, A. K., Gupta, R. D., and Awasthi, S. K. (2018). In Vitro antiplasmodial Efficacy of Synthetic Coumarin-Triazole Analogs. Eur. J. Med. Chem. 145, 735-745. doi:10.1016/j.ejmech.2018.01.017

Yang, Y., Yan, J., Yan, F., Yin, Y., and Zhuang, F. (2015). Synthesis and Antitumour Activity Evaluation of Bergenin Derivatives. J. Chem. Res. 39, 590-593. doi:10.3184/174751915X14419910149674

Yu, B., Qi, P.-P., Shi, X.-J., Huang, R., Guo, H., Zheng, Y.-C., et al. (2016). Efficient Synthesis of New Antiproliferative Steroidal Hybrids Using the Molecular Hybridization Approach. Eur. J. Med. Chem. 117, 241-255. doi:10.1016/ j.ejmech.2016.04.024

Yu, H., Hou, Z., Tian, Y., Mou, Y., and Guo, C. (2018). Design, Synthesis, Cytotoxicity and Mechanism of Novel Dihydroartemisinin-Coumarin Hybrids as Potential Anti-cancer Agents. Eur. J. Med. Chem. 151, 434-449. doi:10.1016/j.ejmech.2018.04.005

Zaki, M., Allouchi, H., El Bouakher, A., Duverger, E., El Hakmaoui, A., Daniellou, R., et al. (2016). Synthesis and Anticancer Evaluation of Novel 9a-Substituted13-(1,2,3-Triazolo)-Parthenolides. Tetrahedron Lett. 57, 2591-2594. doi:10.1016/j.tetlet.2016.04.115

Zhang, T.-j., Li, S.-y., Yuan, W.-y., Wu, Q.-X., Wang, L., Yang, S., et al. (2017). Discovery and Biological Evaluation of Some (1H-1,2,3-Triazol-4-Yl) methoxybenzaldehyde Derivatives Containing an Anthraquinone Moiety as Potent Xanthine Oxidase Inhibitors. Bioorg. Med. Chem. Lett. 27, 729-732. doi:10.1016/j.bmcl.2017.01.049

Zhang, H.-J., Zhang, G.-R., Piao, H.-R., and Quan, Z.-S. (2018a). Synthesis and Characterisation of Celastrol Derivatives as Potential Anticancer Agents. J. Enzyme Inhib. Med. Chem. 33, 190-198. doi:10.1080/ 14756366.2017.1404590

Zhang, H.-b., Shen, Q.-K., Wang, H., Jin, C., Jin, C.-M., and Quan, Z.-S. (2018b). Synthesis and Evaluation of Novel Arctigenin Derivatives as Potential Antitoxoplasma Gondii Agents. Eur. J. Med. Chem. 158, 414-427. doi:10.1016/ j.ejmech.2018.08.087

Zhang, C., Li, N., and Niu, F. (2019a). Baicalein Triazole Prevents Respiratory Tract Infection by RSV through Suppression of Oxidative Damage. Microb. Pathogenesis 131, 227-233. doi:10.1016/j.micpath.2019.03.026

Zhang, S., Xiong, H., Lu, F., Ma, F., Gu, Y., Ma, P., et al. (2019b). Synthesis of N-Acyl Sulfamates from Fluorosulfonates and Potassium Trimethylsilyloxyl Imidates. J. Org. Chem. 84, 15380-15388. doi:10.1021/acs.joc.9b02394
Zhang, X., Xiao, Z., and Xu, H. (2019c). A Review of the Total Syntheses of Triptolide. Beilstein J. Org. Chem. 15, 1984-1995. doi:10.3762/bjoc.15.194

Zhang, Y., Chen, W., Tan, T., Gu, Y., Zhang, S., Li, J., et al. (2021). Palladiumcatalyzed One-Pot Phosphorylation of Phenols Mediated by Sulfuryl Fluoride. Chem. Commun. 57, 4588-4591. doi:10.1039/D1CC00769F

Zhao, L., Mao, L., Hong, G., Yang, X., and Liu, T. (2015). Design, Synthesis and Anticancer Activity of Matrine-1H-1,2,3-Triazole-Chalcone Conjugates. Bioorg. Med. Chem. Lett. 25, 2540-2544. doi:10.1016/j.bmcl.2015.04.051

Zheng, Q., Xu, H., Wang, H., Du, W.-G. H., Wang, N., Xiong, H., et al. (2021) Sulfur [18F]Fluoride Exchange Click Chemistry Enabled Ultrafast Late-Stage Radiosynthesis. J. Am. Chem. Soc. 143, 3753-3763. doi:10.1021/jacs.0c09306

Zi, C.-T., Liu, Z.-H., Li, G.-T., Li, Y., Zhou, J., Ding, Z.-T., et al. (2015). Design, Synthesis, and Cytotoxicity of Perbutyrylated Glycosides of $4 \beta$ Triazolopodophyllotoxin Derivatives. Molecules 20, 3255-3280. doi:10.3390/ molecules20023255

Zi, C.-T., Yang, L., Gao, W., Li, Y., Zhou, J., Ding, Z.-T., et al. (2017). Click Glycosylation for the Synthesis of 1,2,3-Triazole-Linked Picropodophyllotoxin Glycoconjugates and Their Anticancer Activity. Chemistry Select 2, 5038-5044. doi:10.1002/slct.201700347

Zi, C.-T., Yang, L., Xu, F.-Q., Dong, F.-W., Yang, D., Li, Y., et al. (2018). Synthesis and Anticancer Activity of Dimeric Podophyllotoxin Derivatives. Dddt 12, 3393-3406. doi:10.2147/DDDT.S167382

Conflict of Interest: The authors declare that the research was conducted in the absence of any commercial or financial relationships that could be construed as a potential conflict of interest.

Publisher's Note: All claims expressed in this article are solely those of the authors and do not necessarily represent those of their affiliated organizations, or those of the publisher, the editors and the reviewers. Any product that may be evaluated in this article, or claim that may be made by its manufacturer, is not guaranteed or endorsed by the publisher.

Copyright (c) 2021 Zhang, Zhang, Zhao, Wang, Liu and Xu. This is an open-access article distributed under the terms of the Creative Commons Attribution License (CC $B Y)$. The use, distribution or reproduction in other forums is permitted, provided the original author(s) and the copyright owner(s) are credited and that the original publication in this journal is cited, in accordance with accepted academic practice. No use, distribution or reproduction is permitted which does not comply with these terms. 